\title{
THE VALUE OF A STATISTICAL LIFE: A CRITICAL REVIEW OF MARKET ESTIMATES THROUGHOUT THE WORLD
}

\author{
W. Kip Viscusi \\ Joseph E. Aldy \\ Working Paper 9487 \\ http://www.nber.org/papers/w9487
NATIONAL BUREAU OF ECONOMIC RESEARCH 1050 Massachusetts Avenue
Cambridge, MA 02138
February 2003

\begin{abstract}
Viscusi's research is supported by the Sheldon Seevak Research Fund, the Harvard Olin Center for Law, Business, and Economics, and the Environmental Protection Agency. Aldy's research is supported by the Environmental Protection Agency STAR Fellowship program The authors thank James Hammitt, Randall Lutter, and Robert Smith for helpful comments on an earlier draft of this paper. The views expressed herein are those of the authors and not necessarily those of the National Bureau of Economic Research.
\end{abstract}

(C2003 by W. Kip Viscusi and Joseph E. Aldy. All rights reserved. Short sections of text not to exceed two paragraphs, may be quoted without explicit permission provided that full credit including notice, is given to the source. 
The Value of a Statistical Life: A Critical Review of Market Estimates throughout the World W. Kip Viscusi and Joseph E. Aldy

NBER Working Paper No. 9487

February 2003

JEL No. I10, J17, J28

\section{$\underline{\text { ABSTRACT }}$}

A substantial literature over the past thirty years has evaluated tradeoffs between money and fatality risks. These values in turn serve as estimates of the value of a statistical life. This article reviews more than 60 studies of mortality risk premiums from ten countries and approximately 40 studies that present estimates of injury risk premiums. This critical review examines a variety of econometric issues, the role of unionization in risk premiums, and the effects of age on the value of a statistical life. Our meta-analysis indicates an income elasticity of the value of a statistical life from about 0.5 to 0.6 . The paper also presents a detailed discussion of policy applications of these value of a statistical life estimates and related issues, including risk-risk analysis.

W. Kip Viscusi

Harvard Law School

Hauser Hall, 302

Cambridge, MA 02138

and NBER

kip@law.harvard.edu
Joseph E. Aldy

Department of Economics

Harvard University

Littauer Center, 2nd Floor

Cambridge, MA 02138

aldy@fas.harvard.edu 


\section{Introduction}

Individuals make decisions everyday that reflect how they value health and mortality risks, such as driving an automobile, smoking a cigarette, and eating a mediumrare hamburger. Many of these choices involve market decisions, such as the purchase of a hazardous product or working on a risky job. Because increases in health risks are undesirable, there must be some other aspect of the activity that makes it attractive. Using evidence on market choices that involve implicit tradeoffs between risk and money, economists have developed estimates of the value of a statistical life (VSL). This article provides a comprehensive review and evaluation of the dozens of such studies throughout the world that have been based on market decisions. ${ }^{1}$

These VSL estimates in turn provide governments with a reference point for assessing the benefits of risk reduction efforts. The long history of government risk policies ranges from the draining of swamps near ancient Rome to suppress malaria to the limits on air pollution in developed countries over the past 30 years (McNeill 1976, OECD 2001). All such policy choices ultimately involve a balancing of additional risk reduction and incremental costs.

The proper value of the risk reduction benefits for government policy is society's willingness to pay for the benefits. In the case of mortality risk reduction, the benefit is the value of the reduced probability of death that is experienced by the affected population, not the value of the lives that have been saved ex post. The economic literature has focused on willingness-to-pay (willingness-to-accept) measures of mortality risk since Schelling's (1968) discussion of the economics of life saving. 
Most of this literature has concentrated on valuing mortality risk by estimating compensating differentials for on-the-job risk exposure in labor markets. While the early studies assessed such compensating differentials in the United States, much of the more recent work has attempted to estimate risk-money tradeoffs for other developed and some developing countries. In addition, economists have also investigated price-risk (pricesafety) tradeoffs in product markets, such as for automobiles and fire alarms.

Use of the economic research on the value of mortality and injury risks in government policy evaluation has been a key benefit component of policy evaluations for a wide range of health, safety, and environmental policies. The policy use of risk valuations, however, has raised new questions about the appropriateness of these applications. How should policymakers reconcile the broad range of VSL estimates in the literature? Should the value of a statistical life vary by income? Should the VSL vary by the age distribution of the affected population? What other factors may influence the transfer of mortality risk valuation estimates from journal articles to policy evaluation in different contexts?

We begin our assessment of this literature with an overview of the hedonic wage methodology in Section 1. This approach motivates the discussion of the data and econometric issues associated with estimating a VSL. Although there continue to be controversies regarding how best to isolate statistically the risk-money tradeoffs, the methodologies used in the various studies typically follow a common strategy of estimating the locus of market equilibria regarding money-risk tradeoffs rather than isolating either market supply curves or market demand curves. 
Section 2 examines the extensive literature based on estimates using U.S. labor market data, which typically show a VSL in the range of $\$ 4$ million to $\$ 9$ million. These values are similar to those generated by U.S. product market and housing market studies, which are reviewed in Section 3. A parallel literature reviewed in Section 4 examines the implicit value of the risk of nonfatal injuries. These nonfatal risks are of interest in their own right and as a control for hazards other than mortality risks that could influence the VSL estimates.

Researchers subsequently have extended such analyses to other countries. Section 5 indicates that notwithstanding the quite different labor market conditions throughout the world, the general order of magnitude of these foreign VSL estimates tends to be similar to that in the United States. International estimates tend to be a bit lower than in the United States, as one would expect given the positive income elasticity with respect to the value of risks to one's life.

A potentially fundamental concern with respect to use of VSL estimates in different contexts is how these values vary with income. While the income elasticity should be positive on theoretical grounds, extrapolating these values across different contexts requires an empirical estimate of this elasticity. Our meta-analyses of VSL estimates throughout the world in Section 6 imply point estimates of the income elasticity in the range of 0.50 to 0.60 . The meta-analysis also provides a characterization of the uncertainty around the measures of central tendency for the value of a statistical life, i.e., 95 percent confidence intervals for the predicted VSLs. Heterogeneity in VSL estimates based on union status (Section 7) and age (Section 8) indicate that the VSL not only varies by income but also across these important labor market dimensions. The existence 
of such heterogeneity provides a cautionary note for policy. While policymakers have relied on VSL estimates to an increasing degree in their benefit assessments, as Section 9 indicates, matching these values to the pertinent population at risk is often problematic, particularly for people at the extreme ends of the age distribution.

\section{Estimating the value of a statistical life from labor markets}

\subsection{The hedonic wage methodology}

More than two centuries ago, Adam Smith (1776) noted in The Wealth of Nations that: "The wages of labour vary with the ease or hardship, the cleanliness or dirtiness, the honourableness or dishonourableness of the employment" (p. 112). Finding empirical evidence of such compensating differentials, however, has been problematic. Because of the positive income elasticity of the demand for safety, the most attractive jobs in society tend to be the highest paid. To disentangle the wage-risk tradeoff from the other factors that affect wages, economists have relied on statistical models that control both for differences in worker productivity as well as different quality components of the job. The primary approach has been hedonic wage and hedonic price models that examine the equilibrium risk choices and either the wage levels or price levels associated with these

choices. ${ }^{2}$ Market outcomes reflect the joint influence of labor demand and labor supply, but hedonic models do not examine the underlying economic structure that gives rise to these outcomes. For concreteness, we focus on the hedonic wage case.

The firm's demand for labor decreases with the total cost of employing a worker. The cost of a worker may include the worker's wage; training; benefits such as health insurance, vacation, child care; and the costs of providing a safe working environment. 
Because worker costs increase with the level of safety, for any given level of profits the firm must pay workers less as the safety level rises. Figure 1 depicts two firms with wage-risk offer curves (isoprofit curves) with wage as an increasing function of risk, $\mathrm{OC}_{1}$ for firm 1 and $\mathrm{OC}_{2}$ for firm 2. For any given level of risk, workers prefer the wage-risk combination from the market offer curve with the highest wage level. The outer envelope of these offer curves is the market opportunities locus $w(p)$.

[Figure 1]

The worker's supply of labor is in part a function of the worker's preferences over wages and risk. The labor supply is best characterized subject to several mild restrictions on preferences. Consider a von Neumann-Morgenstern expected utility model with statedependent utility functions. ${ }^{3}$ Let $\mathrm{U}(\mathrm{w})$ represent the utility of a healthy worker at wage w and let $\mathrm{V}(\mathrm{w})$ represent the utility of an injured worker at wage w. Typically, workers' compensation after an injury is a function of the worker's wage. We assume that the relationship between workers' compensation and the wage is subsumed into the functional form of $\mathrm{V}(\mathrm{w})$. Further, assume that workers prefer to be healthy than injured $[\mathrm{U}(\mathrm{w})>\mathrm{V}(\mathrm{w})]$ and that the marginal utility of income is positive $\left[\mathrm{U}^{\prime}(\mathrm{w})>0, \mathrm{~V}^{\prime}(\mathrm{w})>0\right]{ }^{4}$

Workers choose from potential wage-risk combinations along some market opportunities locus $\mathrm{w}(\mathrm{p})$ to maximize expected utility. In Figure 1, the tangency between the constant expected utility locus $\mathrm{EU}_{1}$ and firm 1's offer curve $\mathrm{OC}_{1}$ represents worker 1's optimal job risk choice. Likewise, worker 2 maximizes expected utility at the tangency between $\mathrm{EU}_{2}$ and $\mathrm{OC}_{2}$. All wage-risk combinations associated with a given worker's constant expected utility locus must satisfy

$$
Z=(1-p) U(w)+p V(w) .
$$


The wage-risk tradeoff along this curve is given by

$$
\frac{d w}{d p}=-\frac{Z_{p}}{Z_{w}}=\frac{U(w)-V(w)}{(1-p) U^{\prime}(w)+p V^{\prime}(w)}>0,
$$

so that the required wage rate is increasing in the risk level. The wage-risk tradeoff consequently equals the difference in the utility levels in the two states divided by the expected marginal utility of income.

Actual labor market decisions by workers can be depicted by the wage-risk combinations at the tangencies of the offer curves and expected utility loci at points $\left(\mathrm{p}_{1}\right.$, $\left.\mathrm{w}_{1}\right)$ and $\left(\mathrm{p}_{2}, \mathrm{w}_{2}\right)$. All that is observable using market data are these points of tangency. Expanding beyond our two worker example, observations of a large set of workers can show the locus of these workers' wage-risk tradeoffs, depicted by the curve w(p) in Figure 1. Hedonic wage analyses trace out points on this $w(p)$ curve that workers find acceptable.

The observed labor market decisions $\left(\mathrm{p}_{\mathrm{i}}, \mathrm{w}_{\mathrm{i}}\right)$ reflect the joint influence of supply and demand on the market equilibrium. The estimated tradeoff between wage and risk, $\partial \mathrm{w} / \partial \mathrm{p}$, is a local measure of the wage-risk tradeoff for marginal changes in risk. This estimated slope corresponds to both the worker's marginal willingness to accept risk and the worker's marginal willingness to pay for more safety and the firm's marginal cost of more safety as well as the firm's marginal cost reduction from an incremental increase in risk. For the worker and firm associated with a given labor market decision $\left(\mathrm{p}_{\mathrm{i}}, \mathrm{w}_{\mathrm{i}}\right)$, $\partial \mathrm{w}_{\mathrm{i}} / \partial \mathrm{p}_{\mathrm{i}}$ reflects both the marginal supply price and the marginal demand price of risk. Econometric models that estimate a linear $w(p)$ curve are estimating an average tradeoff rate across different levels of risk. 
The estimated wage-risk tradeoff curve w(p) does not imply how a particular worker must be compensated for non-marginal changes in risk. Consider workers 1 and 2 in Figure 1. Worker 2 has revealed a willingness to accept risk $\mathrm{p}_{2}$ at wage $\mathrm{w}_{2}\left(\mathrm{p}_{2}\right)$ along $\mathrm{EU}_{2}$. A change in the risk exposure to worker 1 from $\mathrm{p}_{1}$ to $\mathrm{p}_{2}$ would require a higher wage compensation to keep worker $\mathrm{w}_{1}$ on the expected utility locus $\left(\mathrm{EU}_{1}\right)$, implying that $\mathrm{w}_{1}\left(\mathrm{p}_{2}\right)>\mathrm{w}_{2}\left(\mathrm{p}_{2}\right)$ (or alternatively, that $\left.\partial \mathrm{w}_{1} / \partial \mathrm{p}_{2}>\partial \mathrm{w}_{2} / \partial \mathrm{p}_{2}\right)$. With large changes in risk, a worker's wage-risk tradeoff will not be the same because the relevant tradeoff must be made along the worker's expected utility locus, not the estimated market wage-risk tradeoff.

\subsection{Econometrics and data issues in hedonic labor market analysis}

Most researchers estimate the wage-risk relationship in labor markets by specifying a wage equation along the lines of the following:

$$
w_{i}=\alpha+H_{i}^{\prime} \beta_{1}+X_{i}^{\prime} \beta_{2}+\gamma_{1} p_{i}+\gamma_{2} q_{i}+\gamma_{3} q_{i} W C_{i}+p_{i} H_{i}^{\prime} \beta_{3}+\varepsilon_{i}
$$

where $\mathrm{w}_{\mathrm{i}}$ is the worker i's wage rate, $\alpha$ is a constant term, $\mathrm{H}$ is a vector of personal characteristic variables for worker $\mathrm{i}, \mathrm{X}$ is a vector of job characteristic variables for worker $i, p_{i}$ is the fatality risk associated with worker i's job, $q_{i}$ is the nonfatal injury risk associated with worker i's job, $\mathrm{WC}_{\mathrm{i}}$ is the workers' compensation benefits payable for a job injury suffered by worker $i$, and $\varepsilon_{i}$ is the random error reflecting unmeasured factors influencing worker i's wage rate. The terms $\alpha, \beta_{1}, \beta_{2}, \beta_{3}, \gamma_{1}, \gamma_{2}$, and $\gamma_{3}$ represent parameters estimated through regression analysis.

The personal characteristic variables represented by $\mathrm{H}_{\mathrm{i}}$ often include a variety of human capital measures, such as education and job experience, as well as other individual 
measures, such as age and union status. The job characteristic variables represented by X often include indicators for blue-collar jobs, white-collar jobs, management positions, the worker's industry, and measures of physical exertion associated with the job. These two sets of variables reflect both workers' preferences over jobs as well as firms' offer curves for labor. Some studies interact personal characteristics $H_{i}$ with the fatality risk $p_{i}$ to capture how the returns to risk may vary with these characteristics, such as age and union status.

1.2.1 Risk data. An ideal measure of on-the-job fatality and injury risk would reflect both the worker's perception of such risk and the firm's perception of the risk. Because the market opportunity locus reflects both workers' preferences over income and risk and firms' preferences over costs and safety, information on both sets of beliefs would be necessary to appropriately characterize the risk premium. However, very few studies have compiled workers' subjective preferences regarding risks (Viscusi 1979, Viscusi and O’Connor 1984, Gerking et al. 1988, and Liu and Hammitt 1999) and there is no available research on firms' risk perceptions. If individuals' and firms' subjective risk perceptions closely reflect objective measures of fatality risk, then such objective risk data could be used instead as a proxy for unobserved subjective risk data. ${ }^{5}$ The standard approach in the literature is to use industry-specific or occupation-specific risk measures reflecting an average of at least several years of observations for fatalities, which tend to be relatively rare events. ${ }^{6}$

Measures of job-related fatality and injury risk have included self-reported risks based on worker surveys and objective risk measures derived from actuarial tables, 
workers' compensation records, and surveys and censuses of death certificates. The choice of the measure of fatality risk can significantly influence the magnitude of the risk premium estimated through regression analysis. The nature of the risk measures also raise questions about possible errors in estimation and the need to correct the econometric specification to address them.

Several early papers on compensating differentials used the University of Michigan Survey of Working Conditions and Quality of Employment Survey data that include several qualitative measures of on-the-job risk. These measures utilize direct surveys of workers and their perceptions of their work environment. For example, Hamermesh (1978), Viscusi $(1979,1980)$, and Fairris (1989) estimated the hedonic wage equation with a dichotomous measure of injury risk based on a worker's perception of whether his or her job is "dangerous." 7 The survey asked workers if their job exposed them to physical dangers or unhealthy conditions. These studies estimated statistically significant coefficients on this "risk" variable in some of the specifications. Duncan and Holmlund (1983) undertook a similar analysis of compensating differentials with a "danger" variable in a study of male workers in Sweden.

Several papers on the U.S. labor market from the 1970s and early 1980s used actuarial data (Thaler and Rosen 1975, Brown 1980, Leigh 1981, Arnould and Nichols 1983). These studies all employed a job-related risk measure based on data collected by the Society of Actuaries for 1967 . The Society of Actuaries data set provides fatality risk data for 37 occupations. Across these 37 occupations, the annual risk averaged approximately 1 in 1,000. This fatality risk exceeds averages from other data sets by nearly an order of magnitude. To the extent that these data reflect workers in extremely 
high risk jobs, the estimated wage-risk tradeoffs will suffer from a selection bias. As a result, one would expect these estimates to be lower than found in more broadly representative samples, which has in fact proven to be the case.

Another difficulty is that the Society of Actuaries data do not distinguish fatalities caused by the job but rather reflect the overall fatality rates of people within a particular job category. For example, one of the highest risk occupations based on these actuarial ratings is actors, who typically face few risks other than unfavorable reviews.

Several studies of U.S. and Canadian labor markets have used workers' compensation records to construct risk measures (Butler 1983, Dillingham 1985, Leigh 1991, Martinello and Meng 1992, Meng 1991, Cousineau et al. 1992, Lanoie et al. 1995). Only three studies have used workers' compensation data to evaluate compensating differentials in U.S. labor markets, which may reflect the decentralized nature and differences in information collection associated with state (not Federal) management of U.S. workers' compensation programs. ${ }^{8}$ In contrast, researchers in Canada can obtain workers' compensation-based risk data from Labour Canada (the labor ministry for the Federal government) and the Quebec government.

For analyses of the United States, the majority of the mortality risk studies have used data collected by the U.S. Department of Labor Bureau of Labor Statistics (BLS). About 80 percent of the U.S. nonfatal injury risk studies summarized below used BLS injury risk data. The BLS has compiled industry-specific fatality and injury risk data since the late 1960s. Through the early 1990s, BLS collected its data via a survey of industries, and reported the data at a fairly aggregated level, such as at the 2-digit and 3digit Standard Industrial Classification (SIC) code level. The aggregation and sampling 
strategy have elicited some concerns about measurement error in the construction of the mortality risk variable (see Moore and Viscusi 1988a).

Concerns about the BLS fatality risk data led the National Institute of Occupational Safety and Health (NIOSH) to collect information on fatal occupational injuries through its National Traumatic Occupational Fatalities surveillance system (NTOF) since 1980. NIOSH compiles these data from death certificates managed by U.S. vital statistics reporting units (NIOSH 2000). These data are reported at the 1-digit SIC code level by state. Because NIOSH compiles data from a census of death certificates, it circumvents some of the concerns about sampling in the pre-1990s BLS approach. Some have raised concerns, however, about the accuracy of reported cause of death in death certificates (Dorman and Hagstrom 1998).

Comparing the BLS and NIOSH fatality risk data over time provides some interesting contrasts. The original NIOSH data set for the fatality census averaged over $1980-1985$ has a mean fatality risk nearly 50 percent higher than a roughly comparable BLS data set averaged over $1972-1982 .{ }^{9}$ Moreover, the BLS data had greater variation (a standard deviation 95 percent greater than its mean) than the NTOF data, although the NIOSH data also had substantial variation (standard deviation 23 percent greater than its mean) (Moore and Viscusi 1988a).

Since 1992, the BLS has collected fatal occupational injury data through the Census of Fatal Occupational Injuries (CFOI). The BLS compiles information about workplace fatality including worker characteristics and occupation, circumstances of the event, and possible equipment involved. The BLS draws on multiple sources such as death certificates, workers' compensation records, and other Federal and state agency 
reports. The BLS reports these fatality data by industry at the 4-digit SIC level. In contrast to the earlier comparisons of BLS and NIOSH data, more recent years' data on fatality risk collected through the CFOI now show that the BLS measure includes approximately 1,000 more fatalities per year than the NIOSH measure (NIOSH 2000). Table 1 illustrates the recent national rates of job-related fatalities at the one-digit industry level for the four-year period in which both NIOSH and CFOI data are publicly available. In every instance the BLS measure shows a higher risk mortality rate, which in some cases, such as wholesale trade, is quite substantial.

[Table 1]

The risk variables used in several of the non-U.S. studies were based on jobrelated accident and mortality data collected by foreign governments. For example, the data sets used in Shanmugam $(1996 / 7,1997,2000,2001)$ were from the Office of the Chief Inspector of Factories in Madras. Several of the United Kingdom studies employ data provided by the Office of Population Censuses and Surveys (Marin and Psacharopoulos 1982, Sandy and Elliott 1996, Arabsheibani and Marin 2000) while others used unpublished data from the U.K. Health and Safety Executive (Siebert and Wei 1994). In their study of the South Korean labor market, Kim and Fishback (1999) obtained their accident data from the Ministry of Labor. Few of these studies indicate whether the mortality risk data were derived from samples or censuses of job-related deaths.

While the large number of studies of labor markets around the world evaluated the compensating differential for an on-the-job death and/or on-the-job injury, very few attempted to account for the risk of occupational disease. Lott and Manning (2000) used 
an alternative data set to estimate the risk premium for jobs with higher cancer risk associated with occupational exposure to various chemicals (see Section 2).

1.2.2 Wages and related data. Labor market studies of the value of risks to life and health match these risk measures to data sets on characteristics of wages, workers, and employment. Some researchers survey workers directly to collect this information, such as Gegax et al. (1991) for the United States, Lanoie et al. (1995) for Canada, Shanmugam (1996/7) for India, and Liu and Hammitt (1999) for Taiwan, among others. For the United States, researchers have also used the University of Michigan's Survey of Working Conditions (SWC), the Quality of Employment Survey (QES), the Bureau of Labor Statistics' Current Population Survey (CPS), the Panel Study of Income Dynamics (PSID), and decennial census data. Similar types of surveys undertaken in other countries have also provided the data necessary to undertake hedonic labor market analysis, such as the General Household Survey in the United Kingdom (e.g., Siebert and Wei 1994 and Arabsheibani and Marin 2000).

The dependent variable in virtually all labor market analyses has been a measure of the hourly wage. With some data sets, researchers have had to construct the wage measure from weekly or annual labor earnings data. For some data sets, a worker's aftertax wage rate is provided, which can put wage and workers' compensation benefits in comparable terms. While many studies have included pre-tax wages as the dependent variable, this would not likely bias the results significantly so long as workers' income levels and tax rates do not differ substantially. If the regression model includes workers' compensation benefits, then both the wage and these benefits should be expressed in 
comparable terms (both in after-tax or both in pre-tax terms) to ensure proper evaluation of the benefits' impacts on wages. ${ }^{10}$

Typically, researchers match a given year's survey data on wages and worker and employment characteristics with risk data for that year, or preferably, the average over a recent set of years. Some researchers have restricted their samples to subsets of the surveyed working population. For example, it is common to limit the analysis to fulltime workers, and many have focused only on male, blue-collar workers. Restricting the sample in this manner partially addresses the measurement problem with industry-level risk values common to most risk datasets by including only those workers for whom the risk data are most pertinent.

1.2.3 Wage vs. $\log$ (wage). Most researchers have estimated the wage equation using linear and semi-logarithmic specifications. Choosing a preferred functional form from these two specifications cannot be determined on theoretic grounds (see Rosen 1974). To identify the specification with greatest explanatory power, Moore and Viscusi (1988a) employed a flexible functional form given by the Box-Cox transformation. The Box-Cox transformation modifies the dependent variable such that the estimated regression model takes the form:

$$
\frac{w_{i}^{\lambda}-1}{\lambda}=\alpha+H_{i}^{\prime} \beta_{1}+X_{i}^{\prime} \beta_{2}+\gamma_{1} p_{i}+\gamma_{2} q_{i}+\gamma_{3} q_{i} W C_{i}+p_{i} H_{i}^{\prime} \beta_{3}+\varepsilon_{i}
$$

This approach presumes that a $\lambda$ exists such that this model is normally distributed, homoskedastic, and linear in the regressors. Note that the case where $\lambda \rightarrow 0$ represents the semi-logarithmic functional form and the case where $\lambda \rightarrow 1$ represents the linear functional form. The flexible form under the Box-Cox transformation can test the 
appropriateness of these two restrictions on the form of the model. Using maximum likelihood methods, Moore and Viscusi's estimate for $\lambda$ equaled approximately 0.3 for their data. While this value is more consistent with a semi-logarithmic form than a linear form, the authors reject both specifications based on a likelihood ratio test. The estimated value of a statistical life based on the Box-Cox transformed regression model, however, differed only slightly from the $\log$ (wage) specification. Shanmugam (1996/7) replicated this flexible form evaluation with his evaluation of compensating differentials in India. His maximum likelihood estimate for $\lambda$ equaled approximately 0.2 . While Shanmugam rejected the semi-logarithmic and linear models, he found that the semi-logarithmic functional form also generated results closer to those found with the unrestricted flexible form. ${ }^{11}$

1.2.4 Errors in variables problem with risk measures. Every compensating differential study employs a less than perfect measure of any particular worker's job-related fatality risk. The majority of these studies have used fatality risk measures from the BLS averaged across the entire industry. Such an approach, however, suffers from measurement error. As noted above, some researchers have found that the pre-1992 BLS data sets (and NIOSH data sets to a lesser extent) suffer from incomplete reporting. The industry averages constructed by the BLS do not exactly reflect realized industry averages. Further, applying industry averages to individuals may result in errors associated with matching workers to industries due to response error in worker surveys. Mellow and Sider (1983) evaluated several surveys that asked workers and their employers to identify the workers' industry and occupation (among other questions). In 
their assessment of the January 1977 Current Population Survey, 84 percent of workers and their employers agreed on industry affiliation at the three-digit SIC code level while only 58 percent agreed on the three-digit occupational status. Merging a worker characteristics data set with a risk measure data set based on industry affiliation (or occupation status) can result in a mismatch of worker characteristics and industry risk. Mellow and Sider's statistical analysis of the 16 percent "mismatched" workers by industry affiliation showed that the errors in matching reduced the compensating differential for injury risk by about 50 percent in their samples.

Even with a perfect industry measure of fatality risk and appropriate matching of workers and their industry, measurement error still exists since some workers bear risk that differs from their industry's average. For example, different occupations within an industry may pose different levels of risk. This measurement error can be characterized as:

$$
p_{i}=p_{i}^{*}+\eta_{i},
$$

where $\mathrm{p}_{\mathrm{i}}$ reflects the observed industry average fatality risk, $\mathrm{p}_{\mathrm{i}}^{*}$ reflects the unobserved (to the econometrician) fatality risk associated with worker i's job, and $\eta_{\mathrm{i}}$ reflects the deviation of that job's risk from the industry average. Random measurement error will result in a downward bias on coefficient estimates, and the least squares estimate of the coefficient on fatality risk in this example would be inconsistent:

$$
\hat{\gamma}_{1, O L S} \stackrel{p}{\longrightarrow}\left(\frac{\sigma_{p}^{2}}{\sigma_{p}^{2}+\sigma_{\eta}^{2}}\right) \gamma_{1}
$$

where the signal-noise ratio determines the extent of the downward bias towards zero. 
In addition to the downward effect on the risk coefficient, applying industry-level risk data to individual observations may also induce some correlation in the residuals among individuals within industries. Robust (White) standard errors would not appropriately correct for this correlation and result in inappropriately small standard errors. Hersch (1998) and Viscusi and Hersch (2001) employ robust standard errors correcting for within-group (within-industry) correlation.

1.2.5 Omitted variables bias and endogeneity. Failing to capture all of the determinants of a worker's wage in a hedonic wage equation may result in biased results if the unobserved variables are correlated with observed variables. Dangerous jobs are often unpleasant in other respects. Omission of non-pecuniary characteristics of a job may bias the estimated risk premium if an omitted variable is correlated with risk. For example, one may find a correlation between injury risk and physical exertion required for a job or risk and environmental factors such as noise, heat, or odor. While some studies have attempted to control for these unobservables by including industry or occupation dummy variables (see below), a model may still suffer from omitted variables bias.

Several studies have explored how omitting injury risk affects the estimation of mortality risk. Viscusi (1981) found that omitting injury risk resulted in a positive bias in the mortality risk measure for union affiliated workers. Cousineau et al. (1992) also found that omitting injury risk may cause a positive bias in the estimation of the coefficient on mortality risk. The high correlation (collinearity) between injury and mortality risks, however, can make joint estimation difficult. Some studies have attempted to estimate regression equations with both types of risk and have found non- 
significant coefficients on at least one of the measures, including Smith (1976), Leigh (1981), Dillingham and Smith (1984), and Kniesner and Leeth (1991).

While including injury risk in a regression model could address concern about one omitted variable, other possible influences on wages that could be correlated with mortality risk may not be easily measured. Several papers have investigated this bias. Garen (1988) notes that "individuals may systematically differ in unobserved characteristics which affect their productivity and earnings in dangerous jobs and so these unobservables will affect their choice of job risk" (p. 9). One example Garen offers is "coolheadedness," which may make a worker more productive under the stresses of a dangerous job but may not be relevant in a safe job. In this case, an econometrician would prefer to include both the mortality risk variable and the interaction or the mortality risk variable with a variable measuring coolheadedness as regressors in the hedonic labor market model. Failing to include this interaction term results in biased least squares estimation. Garen attempts to address this concern with an instrumental variables technique, although subsequent researchers such as Hwang et al. (1992) have noted the difficulty in identifying appropriate instruments for his procedure. Employing this instrumental variables technique, Garen found a mortality risk premium about double what the standard least squares model produced.

The significant increase in the risk premium associated with a method to account for unobserved productivity is consistent with the theoretical and simulation findings in Hwang et al. (1992). They estimate that for plausible parameter estimates, models that fail to account for heterogeneity in unobserved productivity may bias estimates of the risk premium by about 50 percent and could result in incorrectly (negative) signing of the risk 
variable. With the exception of some non-union samples in several studies (e.g., Dorsey 1983 and Dickens 1984), the empirical literature presents very little evidence of this wrong signing. Siebert and Wei (1994) have also found that accounting for the endogeneity of risk can increase the risk premium compared to a standard least squares approach. Recent theoretical research, however, has also illustrated the potential for over-estimating the risk premium by failing to control for unobservables (Shogren and Stamland 2002). They note that workers with the ability to avoid injury select into risky jobs while those less able to avoid injury ("clumsy" workers) select into less-risky jobs. They argue that risk premiums could be overestimated by a factor of four with plausible parameter estimates in their simulations. Whether there will be such biases hinges on the monitorability of individual's safety-related productivity. If these differences are monitorable, as in Viscusi and Hersch (2001), there will be a separating compensating differential equilibrium for workers of different riskiness.

Viscusi and Hersch (2001) note that differences in workers' preferences over risk can affect the shape of their indifference curves and workers' safety behavior and, by affecting firms' cost to supply safety, can influence firms' offer curves. They evaluated the wage-risk (injury) tradeoff of workers with a data set that includes measures of risk preferences (e.g., smoking status) and measures of workers' prior accident history. While smokers work, on average, in industries with higher injury risk than non-smokers, smokers also are more likely to have a work-related injury controlling for industry risk. Smokers also are more prone to have had a recent non-work-related accident. As a result, Viscusi and Hersch find that nonsmokers receive a greater risk premium in their wages 
than do smokers because the safety effect flattens smokers' offer curves enough to offset smokers' preferences for greater wages at higher risk levels.

To address potential omitted variable bias arising from differences in worker characteristics, employing a panel data set could allow one to difference out or dummy out individual-specific unobservables, so long as these are constant throughout the time period covered by the panel. Unfortunately, very few data sets exist that follow a set of workers over a period of several years. Brown (1980) used the National Longitudinal Study Young Men's sample over 1966 - 1973 (excluding 1972) with the Society of Actuaries mortality risk data. While he reported results that were not consistent with the theory of compensating differentials for a variety of nonpecuniary aspects of employment, he did estimate a positive and statistically significant coefficient on the mortality risk variable. Brown noted that his estimate of the risk premium was nearly three times the size of the estimate in Thaler and Rosen (1975), which first used the Society of Actuaries mortality risk data.

\subsubsection{Compensating differentials for risk or inter-industry wage differentials. Several}

recent papers have claimed that estimates of risk premiums in this kind of wage regression analysis actually reflect industry wage premiums because the fatality risk variables typically reflect industry-level risk (Leigh 1995, Dorman and Hagstrom 1998). Both Leigh and Dorman and Hagstrom evaluate the proposition that risk premiums simply reflect industry premiums by comparing compensating differential models without dummy variables for industry affiliation of each worker with models that include such dummy variables. 
Their claim that industry premiums mask as risk premiums in these wage regressions suffers from several deficiencies. First, a large number of studies have included industry dummy variables in their statistical analyses and found significant compensating differentials for risk. For example, the first wage-risk tradeoff study by Smith (1974) employed six industry dummies and yielded a statistically significant compensating differential for risk. Viscusi (1978a) included 25 industry dummy variables in his analysis based on the Survey of Working Conditions danger variable ( 0 , 1 variable reflecting a worker's subjective perception of on-the-job risk), although he excluded the dummy variables from the analysis based on the industry-level BLS risk data. ${ }^{12}$ In both sets of analyses, danger and the BLS risk measure were statistically significant and generated very similar estimates of the risk premium. Freeman and Medoff (1981) found a statistically significant risk premium in their analyses that included 20 industry dummy variables and the BLS injury rate measure. In their evaluation of the U.K. labor market with an occupational mortality risk variable, Marin and Psacharopoulos (1982) found a statistically significant risk coefficient while their SIC code dummies were insignificant. Dickens (1984) estimated regression models with the BLS fatality risk measure and 20 industry dummy variables (1- and 2-digit SIC code industries). For the union sample, he found a positive and statistically significant coefficient on risk. Leigh and Folsum (1984) included 2-digit SIC code industry dummy variables in their wage regressions, and they found statistically significant coefficients on mortality risk in all eight mortality risk models reported. Dillingham (1985) estimated regression models with industry dummy variables (at the 1-digit SIC code level) and without. In both cases, he found statistically significant and positive coefficients on his 
measure of mortality risk. Moreover, the coefficients were virtually identical (0.0023 vs. 0.0022), although the standard error was higher for the model with industry dummy variables (perhaps related to risk-industry dummy variable collinearity). Cousineau et al. (1992) included 29 industry variables in their evaluation of the Canadian labor market that estimated statistically significant coefficients on both injury and mortality risks. Lott and Manning (2000) included 13 industry dummy variables in their evaluation of longterm cancer risks in U.S. labor markets, and found a statistically significant risk premium based on industry-level measures of carcinogen exposure.

Second, inserting industry dummy variables into the regression equation induces multicollinearity with the risk variable. Previous researchers such as Viscusi (1979) have noted this as well. Hamermesh and Wolfe (1990) employed dummy variables for five major industries in their analysis of injury risk on wages. They note that a finer breakdown by industry could be used. A complete set of dummy variables at the 3-digit SIC code level, however, would completely eliminate all variation in the injury risk variable, which is measured at the 3-digit SIC code level (p. S183). While multicollinearity does not affect the consistency of the parameter estimates, it will increase standard errors.

This induced multicollinearity is also evident in the Dorman and Hagstrom results for the models using NIOSH fatality risk data. ${ }^{13}$ Dorman and Hagstrom interact the NIOSH fatality risk measure by a dummy variable for union status (and for non-union status in the second set of regressions). Contrary to their hypothesis, including industry dummy variables does not reduce the coefficient in the union-risk interaction models. Inducing multicollinearity does depress the t-statistics slightly, although not enough to 
render the coefficients statistically insignificant. The models with the non-union-risk interaction reflect the induced multicollinearity, as the t-statistics fall below levels typically associated with statistical significance moving from the standard model to the industry dummy model. While the coefficients in these industry dummy-augmented models fall from their levels in the standard models, they are not statistically different from the standard models' coefficients. Based on the NIOSH fatality risk data, the Dorman and Hagstrom results appear to illustrate that including collinear regressors (industry variables) can increase standard errors but not significantly affect the magnitudes of the parameter estimates.

\section{The value of a statistical life based on U.S. labor market studies}

The value of a statistical life should not be considered a universal constant or some "right number" that researchers aim to infer from market evidence. Rather, the VSL reflects the wage-risk tradeoffs that reflect the preferences of workers in a given sample. Moreover, transferring the estimates of a value of a statistical life to non-labor market contexts, as is the case in benefit-cost analyses of environmental health policies for example, should recognize that different populations have different preferences over risks and different values on life-saving. If people face continuous safety choices in a variety of contexts, however, the same individual should exhibit the same risk-money tradeoff across different contexts, provided the character of the risks is the same.

Researchers have undertaken more than 30 studies of compensating differentials for risk in the U.S. labor market. Some studies have evaluated the wage-risk tradeoff for the entire labor force, while others have focused on subsamples such as specific occupations 
(e.g., police officers in Low and McPheters 1983), specific states (e.g., South Carolina in Butler 1983), blue-collar workers only (e.g., Dorman and Hagstrom 1998 and Fairris 1989), males only (e.g., Berger and Gabriel 1991), and union members only (e.g., Dillingham and Smith 1984). These hedonic labor market studies also vary in terms of their choice of mortality risk variable, which can significantly influence the estimation of a value of a statistical life (for comparison of NIOSH and BLS data, refer to Moore and Viscusi 1988a and Dorman and Hagstrom 1998).

Table 2 summarizes the estimated VSLs for the U.S. labor market from the literature over the past three decades. ${ }^{14}$ Because some studies provided multiple estimates, in these instances we provide illustrative results based on the principal specification in the analysis. Table 2 provides a sense of the magnitude and range of U.S. labor market VSLs and illustrates the influence of factors such as income and the magnitude of risk exposure as well as specification issues such as including nonfatal injury risk and worker's compensation. ${ }^{15}$

[Table 2]

Viscusi (1993) reported that most surveyed studies fall within a $\$ 3.8$ - $\$ 9.0$ million range, when converted into year 2000 dollars. ${ }^{16,17}$ While we include more papers from the United States as well as findings from other countries, the general conclusion remains unchanged. Half of the studies of the U.S. labor market reveal a value of a statistical life range from $\$ 5$ million to $\$ 12$ million. Estimates below the $\$ 5$ million value tend to come from studies that used the Society of Actuaries data, which tends to reflect workers who have self-selected themselves into jobs that are an order of magnitude riskier than the average. Many of the studies yielding estimates beyond $\$ 12$ 
million used structural methods that did not estimate the wage-risk tradeoff directly or were derived from studies in which the authors reported unstable estimates of the value of a statistical life. Our median estimated VSL from Table 2 is about $\$ 7$ million, which is in line with the estimates from the studies that we regard as most reliable. In terms of methodology, we are more confident in the results presented in Viscusi (1978a, 1979), which include the most extensive set of non-pecuniary characteristics variables to explain workers' wages, and the results presented in Moore and Viscusi (1988a), which include the NIOSH mortality risk data in lieu of the pre-1992 BLS mortality risk data.

A salient research issue of policy importance is the effect of income levels on the wage-risk tradeoff. For example, Hamermesh (1999) notes that as wage inequality has increased over the last several decades, so have on-the-job mortality risks diverged. He notes that workplace safety is highly income-elastic. This result is related to the findings in Viscusi (1978b) that the value of a statistical life is increasing in worker wealth. Similarly, Viscusi and Evans (1990) have estimated the income elasticity of the value of statistical job injury risks to be 0.6 to 1.0 . The effect of income on the wage-risk tradeoff is evident in a historical evaluation of employment risks as well. Kim and Fishback (1993) estimated compensating differentials for mortality risk in the railroad industry over the period 1893 - 1909 and found implicit values of statistical life on the order of $\$ 150,000$ in today's dollars. ${ }^{18}$ Our meta-analysis below examines the role of income differences in generating the variation in VSL estimates.

While most hedonic labor market studies focus on the risk of accidental death or accidental injury, several papers have attempted to explore the effect of occupational disease. Lott and Manning (2000) evaluated the effect of carcinogen exposure on 
workers' wages within the context of changing employer liability laws. In lieu of the standard mortality risk measures, the authors employ the Hickey and Kearney carcinogen index, which represents worker carcinogen exposure at the 2-digit SIC code level. ${ }^{19}$ They find that workers' wages reflect a risk premium for carcinogen exposure. Lott and Manning convert their results into a value of a statistical life assuming that the index is a proportional representation of the actual probability of getting occupational-related cancer, that $10-20$ percent of all cancer deaths result from occupational exposures, and that the probability of a worker getting cancer ranges from 0.04 to 0.08 percent per year. We have modified their reported VSL range to account for a latency period. ${ }^{20}$ Based on these assumptions, the authors estimate that the value of a statistical life based on occupational cancer would range from $\$ 1.5-\$ 3.0$ million. Assuming that occupational cancers, however, comprise a smaller fraction of all cancer deaths would increase the implicit VSL. ${ }^{21}$

Several early papers in the literature did not find statistically significant compensating differentials for on-the-job mortality risk. For example, Leigh (1981) estimated a risk premium for injuries but not for fatalities. Dorsey (1983) likewise did not find a mortality-based risk premium. The Leigh study coupled the Society of Actuaries mortality data with BLS injury data. The combination of greater measurement error in the data and the high correlation between injury risks and mortality risks probably led to the insignificance of the mortality risk variable. The Dorsey study uses industry-level averages, instead of worker-specific values, as its unit of observation. This averaging across industry for wages and related explanatory variables may have reduced 
the variation necessary to discern the effects of job-specific influences on wage, such as job risk.

More recent papers by Leigh (1995) and Dorman and Hagstrom (1998) also do not find compensating differentials in many model specifications. As discussed above, we do not find their inter-industry wage differential discussion compelling. Nevertheless, Table 2 includes their results based on the NIOSH data with industry dummy variables. ${ }^{22}$

Some of these analyses of U.S. labor markets investigated the potential heterogeneity in the risk preferences of workers in the labor force in which there is worker sorting by level of risk. The empirical issue is whether the wage-risk tradeoff takes a linear or concave shape. A linear form would imply that an incremental increase of risk in the labor market requires a proportional increase in the wage differential. A concave form, however, would imply a less than proportional increase in the wage differential, perhaps reflecting sorting by workers based on their risk preferences.

To evaluate the shape of this tradeoff, one can modify the wage equation regression model to include both mortality risk and the square of mortality risk. If the latter term is not significant, then the wage-risk tradeoff is linear for the range of risks and wages covered by the study's sample. If the squared term is significant and negative, then the wage-risk tradeoff takes a concave form. Viscusi (1981), Olson (1981), Dorsey and Walzer (1983), and Leigh and Folsum (1984) all found evidence that the risk-wage tradeoff curve is concave. ${ }^{23}$ All four studies include regression models with a quadratic representation of mortality risk.

Figure 2 illustrates how the value of a statistical life varies with mortality risk for a sample of six regression models from these four papers. Viscusi (1981; linear) and 
Leigh and Folsum (L\&F 1984; linear) represent regression models where the dependent variable is the hourly wage while the other four lines represent regression models with the logarithm of the wage as the dependent variable. All six models include measures of nonfatal injury risks (probability of a lost-workday accident and, in some cases, duration of lost-workday accident). The slopes of the risk-VSL lines in this figure are similar within the wage-specification type where the wage-based models appear to have a steeper tradeoff than do the logarithm of wage-based models (with the exception of the Dorsey and Walzer model, although this may reflect the fact that the sample in their study faced mortality risks 2 to 3 times smaller on average than the samples in the other studies). Based on these models, populations of individuals who select into jobs with very minor risks (e.g., on the order of 1 in 100,000) have implicit values of statistical life ranging from $\$ 12$ to $\$ 22$ million. Increasing the risk ten-fold, to levels that are close to the mean mortality risks in these studies, modestly reduces the VSL into the range of $\$ 10$ to $\$ 18$ million. Figure 2 illustrates that very high risks result in small values of statistical lives, although caution should be exercised when considering extrapolations beyond the samples' ranges.

[Figure 2]

\section{Evidence of the value of a statistical life from U.S. housing and product markets}

Housing and product market decisions also reflect individual tradeoffs between mortality risk and money. The main methodological difference is that economists typically estimate a hedonic price equation rather than a hedonic wage equation. The 
underlying theory is essentially the same, as comparison of Rosen (1974) with the wage equation analysis above will indicate.

Table 3 presents the results from ten studies that evaluated the price-risk tradeoffs for seatbelt use, cigarette smoking, home fire detectors, automobile safety, bicycle helmets, and housing price responses to hazardous waste site risks. ${ }^{24}$ The studies in general find an implicit value of a statistical life on the same order of magnitude as the labor market studies, although they tend to be a little lower.

\section{[Table 3]}

The lower estimates may reflect several characteristics of these studies that distinguish them from the labor market studies. First, some product decisions do not provide a continuum of price-risk opportunities (unlike the labor market that does offer a fairly continuous array of wage-risk employment options) but rather a discrete safety decision. For example, Dardis' (1980) evaluation of smoke detectors represents such a discrete choice. In such a case, the consumer's decision to purchase a smoke detector reveals only the lower bound on the willingness to pay for the reduced risk. Similarly, the study by Jenkins, Owens, and Wiggins (2001) examines the purchase of bicycle helmets. It is interesting, however, that their results show VSLs increasing over the first half of the life cycle.

Second, the types of products considered in some studies may induce selection based on risk preferences. For example, the low estimated VSL for cigarette smokers found by Ippolito and Ippolito (1984) presumably reflects the non-random character of the smoking population. Their research focuses on cigarette smokers, and they estimate a VSL lower than from most product market studies. The lower VSL is consistent with the 
findings in Hersch and Viscusi (1990) and Viscusi and Hersch (2001) who find that individuals who engage in risky behaviors, such as cigarette smoking and driving without seatbelts, have lower implicit values for injury than do those who do not engage in such behavior.

Third, several studies are based on inferred, instead of observed, price-risk tradeoffs. Consider the seat belt and child seat studies by Blomquist (1979) and Carlin and Sandy (1991). In these studies, drivers' or occupants' safety is traded off with the time to secure a seat belt or a child seat. The authors assume a given time cost - for example, Blomquist assumes that it takes 8 seconds to secure a seat belt. Then this time is monetized at the individual's wage rate. Unlike labor market studies where the monetary value of the attribute in question (job wage) is observed, these studies do not observe the actual time drivers take to buckle their seat belts. Moreover, they do not account for other aspects of seat belt use, such as the costs of discomfort of wearing a seatbelt, which would increase the implicit valuation of a statistical life derived by this methodology.

The studies focused on automobile purchases and home purchases do not suffer from the need to infer the monetary component of the price-risk tradeoff. For example, Atkinson and Halvorsen (1990) and Dreyfus and Viscusi (1995) evaluate the risk-price tradeoff for automobiles. They construct hedonic price models very similar to the hedonic wage models used in labor market analyses. Both studies include car purchase price (annual average for a given model) as the dependent variable and an array of automobile attributes as explanatory variables, such as vehicle size, power, reliability, fuel economy, and safety (fatal accident rate). Just as in the labor market hedonic studies, 
the coefficient on the safety variable in these automobile price hedonic studies reveals the price-risk tradeoff. Automobile purchases should be less likely to suffer the selection bias of the cigarette smoking study or the discreteness in decision of the fire alarm study.

Gayer, Hamilton, and Viscusi (2000) evaluate the tradeoff between housing prices and cancer risk associated with hazardous waste sites. The authors develop a housing hedonic price model, similar in form to the labor market hedonic studies. The dependent variable is the price of a house sold over a five-year period in the greater Grand Rapids, MI area, and explanatory variables include house characteristics such as number of bedrooms and bathrooms, neighborhood characteristics, property tax rates, measures of proximity to a Superfund hazardous waste site, and calculated cancer risk associated with exposure from the nearest hazardous site. The VSL interpretation from this study is analogous to that of Lott and Manning (2000). The hedonic price model generates the value of avoiding a statistical cancer case, which may not necessarily reflect the value of a statistical life to the extent that some cancers are treatable. If housing decisions are made based on the expectation that cancers associated with hazardous waste site exposure are terminal, then this price-risk tradeoff can be considered comparable to a VSL. ${ }^{25}$

\section{The value of a statistical life based on non-U.S. labor market studies}

While about 25 wage-risk studies of the U.S. labor market were published in the 1970s and 1980s, only three studies on non-U.S. labor markets appeared in the literature during this period. We have identified another 19 labor market hedonic studies in both developed and developing countries outside of the U.S. context published since 1990. The studies presented in Table 4 include evaluations of wage-risk tradeoffs in labor 
markets in Australia, Austria, Canada, Japan, and the United Kingdom. More recent work in developing countries has focused on Asia, including analyses of labor markets in Hong Kong, India, South Korea, and Taiwan.

[Table 4]

Marin and Psacharopoulos (1982) undertook the first hedonic labor market analysis of job risks outside of the United States in their study of the U.K. labor market. Based on wage and risk data from the 1970s, they found a value of a statistical life of about \$3.5 million. Arabsheibani and Marin (2000) sought to replicate the earlier Marin and Psacharopoulos analysis for the United Kingdom. By employing a similar methodology and more recent wage and risk data from the same sources as in the original study, the authors evaluated the stability of VSL estimates over time. They found, consistent with other studies of the U.K. labor market during the 1980s, a higher value of a statistical life than did Marin and Psacharopoulos. While the evaluation of the whole U.K. labor force yielded a relatively large VSL of about \$18 million, regression analyses of subsamples resulted in VSLs ranging up to $\$ 68$ million (in this case, for non-manual workers). While this result qualitatively conforms to the U.S. findings of lower VSLs for workers in higher risk jobs (see Figure 2), the magnitude of the U.K. compensating differentials seems implausibly large.

The results from several of the studies of the United Kingdom reveal compensating differentials on the order of 10 percent of total worker wage income. One regression result (with a VSL of \$63 million) from Sandy and Elliott (1996) implies a compensating differential for mortality risk comprising nearly 20 percent of worker wages. These risk premia are substantially larger than the compensating differentials 
evident in other developed countries' labor markets, even those countries with higher per capita incomes. Moreover, risk levels cannot account for the high wage share of compensating differentials as the mortality risk is lower than in many U.S. studies. The large U.K. compensating differentials may reflect correlation between the risk measure and other unobservables that yield substantial returns to the worker.

After the United States, no country has been the focus of more hedonic labor market analyses of wage-risk tradeoffs than Canada. The Canadian studies appear to produce compensating differentials more in line with the U.S. experience than with the evidence from the U.K. labor market. With the exception of the Lanoie, Pedro, and LaTour (1995), most Canadian labor market VSLs fall within the range of $\$ 3-\$ 6$ million. The Lanoie et al. findings of a VSL on the order of $\$ 18$ million $-\$ 20$ million may reflect their data collection methodology. They surveyed about 200 workers in the Montreal area and solicited workers' perceptions of risk with a risk information ladder similar to that in Gegax et al. (1991), which suffered from using a truncated job risk scale that omitted most job risks in the U.S. economy. Analyses by Lanoie et al. with industry risk measures provided by the Quebec Compensation Board did not yield statistically significant risk coefficients, while the perceived risk measures generated these large VSLs. This result contrasts with the findings of Cousineau, Lacroix, and Girard (1992) who found a statistically significant compensating differential for risk using mortality risk data from the same source on a sample of more than 30,000 Quebec workers.

With the exception of some U.K. studies, the compensating differentials estimated in developed country analyses tend to find risk premiums ranging between $1-2$ percent of labor income. These results are broadly consistent with the findings in the Duncan and 
Holmlund (1983) that used Swedish workers' perceptions of danger in lieu of measured industry mortality risks. The authors estimated a statistically significant and positive compensating wage differential for dangerous jobs on the order of about 2 percent of wages. Swedish workers' perceptions of danger yield comparable compensating differentials to measured industry mortality risk in both U.S. and European studies (see Viscusi 1979 for an example from the U.S. labor market).

Researchers have also evaluated the VSL in several of the newly industrialized countries of Asia, including Hong Kong, South Korea, and Taiwan. Note that these countries have on-the-job mortality risks three to five times greater than the average in Australia, the United States, and the United Kingdom. Further, the average worker earnings are two to four times lower than labor earnings in developed countries.

Kim and Fishback (1999) examined the South Korean labor market over the 1984 - 1990 period. Unlike many of the studies in developed countries, which employ workerlevel data, their unit of observation is at the industry level. Kim and Fishback estimate a VSL of approximately $\$ 0.5$ million. They note that the estimated VSL is about 94 times the average annual earnings of workers. Siebert and Wei (1998) estimate a VSL for the Hong Kong workforce that is larger than the Korean estimate by about a factor of three. The ratio of VSL to average annual earnings for Hong Kong is about 150. These estimates are of the same order of magnitude as the ratio of VSL to annual earnings evident in the U.S. labor market.

Liu, Hammitt, and Liu (1997) and Liu and Hammitt (1999) estimated the wagerisk tradeoff in Taiwan. The Liu, Hammitt, and Liu study focuses on all non-agricultural workers while Liu and Hammitt base their analysis on in-person surveys of petrochemical 
workers. In the former case, the authors use 3-digit industry level risk data, while the latter paper uses workers' risk perceptions derived from a survey instrument similar to that in Gegax et al. (1991). Workers' risk perceptions in the petrochemical industry yield a mortality risk rate about 35 percent greater than the rate published by the Taiwan Labor Insurance Agency, the data source for the Liu, Hammitt, and Liu study. ${ }^{26}$ While petrochemical workers face higher average mortality risk (perceived and measured) than the average for all non-agricultural workers in Taiwan, the higher wages and income associated with petrochemical workers in 1995 relative to the broader workforce in the early to mid 1980s probably explains why Liu and Hammitt estimated a VSL about twice what Liu, Hammitt, and Liu found.

Estimates for the Indian labor market yield a value of a statistical life greater than the VSLs in other developing countries despite the fact that per capita income in India is an order of magnitude smaller than in these countries. Shanmugam (1996/1997, 1997, $2000,2001)$ assessed the wage-risk tradeoff in a variety of studies using survey data of manufacturing workers in Madras, India in 1990. The VSL estimates from these studies range by nearly a factor of four, even though they reflect the same wage and risk data, illustrating how a variety of econometric specifications can produce in some cases a range of results.

\section{The implicit value of a statistical injury: U.S. and international estimates}

Complementing the research on the returns to bearing fatal risks in the workplace, a significant number of studies have evaluated the risk premium associated with bearing nonfatal job risks. The hedonic labor market studies of nonfatal risk employ the same 
econometric approach as used for mortality risk. As discussed above, some studies that attempt to estimate jointly the effects of fatal and nonfatal risks on workers' wages do not find significant effects of risk on wages for at least one of the risk measures. Fatal risk is highly correlated with nonfatal risk, so joint estimation may result in large standard errors due to collinearity. Omitting one of these variables when estimating the other could result in an upwardly biased estimate of the return to that type of risk.

Table 5 summarizes 31 studies from the U.S. labor market (Table 5a) and 7 studies of labor markets outside of the United States (Table 5b) that have found statistically significant influences of nonfatal job risk on wages. These studies employ three different measures of nonfatal job risks: the overall injury rate, the rate of injuries severe enough to result in a lost workday, and the rate of total lost workdays. Studies using different measures of nonfatal job risks will generate different risk premiums because the return to the frequency of injuries (the injury rate) will usually differ from the return to the severity of injuries (lost workdays rate). In two studies with specialized data, Butler (1983) constructed an injury rate from South Carolina workers' compensation claims, restricting his risk measure to only the more serious work accidents and French and Kendall (1992) and French (1990) constructed an injury rate for railroad workers based on data collected by the Federal Railroad Administration. As an alternative to these objective measures of risk, Viscusi and O'Connor (1984) and Hersch and Viscusi (1990) used workers' own assessments of risk with risk scales based on the BLS injury rate and the BLS lost workday accident rate, respectively. These authors estimated comparable wage-risk tradeoffs based on subjective risk perception as the other studies based on objectively measured industry-level risk. 


\section{[Table 5]}

These value of statistical injury studies yield a wide range of estimates, reflecting both the differences in the risk measures used as well as whether mortality risk is included in the results. While several studies have very high values of injury, such as McLean, Wendling, and Neergaard (1978), Leigh and Folsum (1984), and Biddle and Zarkin (1988), most studies have estimates in the range of $\$ 20,000-\$ 70,000$ per injury.

The value of statistical injury appears to vary with workers' preferences over risk, consistent with some of the findings based on the mortality risk literature. As a proxy for risk attitudes, several studies have used information about workers' behavior outside of the workplace, such as smoking status and seatbelt use, to identify the effect of risk preferences on wage-risk tradeoffs. Hersch and Viscusi (1990), Hersch and Pickton (1995), and Viscusi and Hersch (2001) all found that smokers have lower injury risk premiums than do non-smokers. Hersch and Viscusi as well as Hersch and Pickton also found that individuals who do not wear seatbelts have lower injury risk premiums than do individuals who regularly wear seatbelts.

The study by Hersch (1998) is of particular interest because it used genderspecific risk measures. Many previous studies had focused on male samples only because estimates using industry-based measures often failed to yield significant risk premiums for women. Researchers hypothesized that women did not work in risky jobs that would pose health and safety risks. The estimates by Hersch indicate that the nonfatal injury risk for women is over two-thirds the size of that for men and that the wage-injury risk tradeoff rates are similar for men and women. 
The evidence outside of the United States, while based on a smaller set of studies, also indicates significant injury risk premiums. For example, the Cousineau et al. (1992) result falls within the U.S. range of about $\$ 20,000-\$ 70,000$. However, several other Canadian labor market studies provide some estimates that are lower, such as Martinello and Meng (1992) and Meng and Smith (1999). The value of statistical injury estimates for India are much smaller, likely reflecting the effect of per capita income on wage-risk tradeoffs. The low values of statistical injury are somewhat surprising given that these same studies generated fairly large values of statistical life.

\section{The effects of income on the value of a statistical life}

The review of the VSLs above shows that developing countries tend to have lower values of statistical life than do developed countries. A variety of factors could account for such an outcome, such as cultural influences on risk preferences and variations in labor market institutions. The dominant cause, however, is most likely that developing countries are poorer, and safety is a normal good, as shown in Viscusi (1978a). The value of a statistical life should increase with per capita income. To assess the relationship between the value of a statistical life and income, we first review several meta-analyses of the wage-risk literature. Second, we provide our estimates of the income elasticity of the value of a statistical life based on the meta-analysis approaches employed in four previous studies with a data set we constructed from our review of the papers presented in Tables 2 and 4. Third, we report income elasticities for a number of specifications in our preferred meta-analytic approach. 
Since wage-risk studies employ a measure of income (usually a function of hourly or weekly labor earnings) as the dependent variable, an individual study cannot estimate the effect of income on the premium for bearing mortality risk. The injury risk study of Viscusi and Evans (1990) used experimental data coupled with market evidence to estimate income elasticities of injury risk valuations from 0.6 to 1.0. A meta-analysis of existing VSL studies can facilitate the calculation of the income elasticity for the value of a statistical life. The type of meta-analysis used in the VSL literature attempts to evaluate the VSL (the constructed dependent variable) as a function of a number of studies' characteristics (such as mean income of the sample population, mean mortality risk, and econometric specification).

The published meta-analyses on the value of a statistical life literature vary in terms of their sample construction, explanatory variables, and regression technique. Liu, Hammitt, and Liu (1997) sampled 17 wage-risk studies surveyed in Viscusi (1993) and regressed VSL on income and mean risk. The Liu et al. sample comprised primarily U.S. wage-risk studies. They reported a statistically insignificant income elasticity of 0.53. Miller (2000) developed an international sample including more than 60 wage-risk, product-risk, and contingent valuation studies. Miller employed a relatively small set of explanatory variables, including income. For five models, Miller estimated statistically significant income elasticities ranging from 0.85 to 0.96 . Bowland and Beghin (2001) conducted a meta-analysis with a set of 33 wage-risk and contingent valuation studies surveyed in Viscusi (1993) and Desvousges et al. (1995). They matched the data on these studies with a variety of country-specific data on demographics, human capital, etc. Bowland and Beghin employed robust regression with Huber weights to address concerns 
about the non-normality in the residuals of their data. Bowland and Beghin reported statistically significant income elasticities of 1.7 and 2.3. In contrast to the previous three papers, Mrozek and Taylor (2002) constructed a sample of about 200 observations reflecting multiple VSL estimates from 33 wage-risk studies (eight of which evaluated non-U.S. labor markets). They employed the most extensive set of control variables, including those characterizing a study's sample, risk measure, specification, and earnings. For two models, Mrozek and Taylor impute statistically significant estimates of 0.46 and 0.49 for the income elasticity for the value of a statistical life.

To further explore the relationship between income and WTP, we have conducted a meta-analysis based on the U.S. and international VSLs reported in this paper. Our sample includes the VSLs for 49 studies presented in Tables 2 and $4 .{ }^{27}$ Each study yields one observation. Refer to the appendix for a description of the explanatory variables and their summary statistics.

We replicated the results from the four previous meta-analysis studies with our wage-risk study sample (see Table 6). For the Liu et al. (1997) model, we replicated their econometric specification exactly. Miller (2000) reported a number of specifications. Only model 3 of Miller's meta-analysis employed per capita incomes converted to US dollars on a purchasing power parity (PPP) basis. Because we constructed all VSLs and annual incomes based on a PPP basis, we replicated his model 3. Note that dummy variables for contingent valuation surveys and wage-risk studies are unnecessary since our data set comprises only wage-risk studies. Bowland and Beghin (2001) reported results for linear, log-linear, and trans-log specifications. While they presented very limited information about most of their control variables, we have attempted to replicate 
their set of controls. We do not have information on the average age of the sample used in the VSL studies, and we have omitted this variable from our specification. We have proxied for percent of sample in union-affiliated jobs by accounting for whether the VSL study includes union membership as a control and whether the VSL is union-based. Our studies do not provide average educational attainment, so we have proxied these values with national annual average educational attainment for the over- 25 population from Barro and Lee (1996). We replicated the robust regressions with Huber weights. Our analyses with log-linear and trans-log specifications, however, yielded insignificant coefficients on income. We only present the results from the linear robust regression model with our data. Mrozek and Taylor (2002) reported results from four specification models. We have focused on their model 2 since model 1 yields virtually identical results and models 3 and 4 are U.S.-specific. We have included all the control variables that Mrozek and Taylor report, with the exception of a dummy variable for white collar-based VSLs. Our sample does not include any white collar-based VSLs.

\section{[Table 6]}

Three of the four specifications yield statistically significant coefficients on the relevant income variable. We found a comparable point estimate with much narrower bounds than Liu et al. with their specification, perhaps reflecting our larger sample, as their sample is essentially a subset of our sample. We found a smaller coefficient on the income variable than Miller with his specification, although a very comparable coefficient on the Society of Actuaries risk data dummy variable (equivalent to Miller's variable label "risk beyond workplace" with our data). For comparison with Bowland and Beghin's choice of using "marginal willingness to pay" as their dependent variable 
(apparently equivalent to the VSL expressed in terms of hourly wage instead of annual labor income), we modified our dependent variable accordingly. Imputing the income elasticity with the linear income coefficient in this model requires the sample means of VSL ( $\$ 3,350$ per hour worked, assuming 2000 hours worked per year and $\$ 6.7$ million VSL) and income $(\$ 26,006)$. With 23 explanatory variables and only 41 observations, the Mrozek and Taylor specification yields very few precise coefficient estimates.

While the reported income elasticities from these four studies vary by a factor of

3 , the imputed elasticity point estimates with our data set cover a much smaller range (see Table 7). With these studies' specifications, we found income elasticities from about 0.5 to 0.6 . The 95 percent confidence interval upper bounds fall below 1.0 for two of the three statistically significant income elasticities estimated by the specifications outlined in these four studies. The apparently large variation in income elasticities in this literature apparently reflects authors' choices of studies for inclusion more so than choices over control variables, regression techniques, etc.

\section{[Table 7]}

To augment the replications of previously published meta-analysis specifications, we evaluated a large number of specifications. Based on the existing literature, we focused on two regression techniques, ordinary least squares and robust regression with Huber weights. We have varied the control variables from as few as 3 to as many as 18 , recognizing that coefficient estimates' precision will decline with the length of the righthand side of the regression equations given our sample size. We chose to include explanatory variables of the following types: income and mean risk (common to all specifications), type of risk measure, and specification variables. 
The estimated coefficient on the income variable is rather stable across both regression techniques and for a wide variation in the number of control variables (see Table 8). For the OLS specifications, the income elasticity varies from 0.49 to 0.60 . The 95 percent confidence intervals never range below 0.2 and never exceed 0.95 . For the robust regression specifications, the income elasticity varies from 0.46 to 0.48 . The 95 percent confidence intervals never fall below 0.15 and never exceed $0.78 .^{28}$ The income coefficients in all specifications are statistically significant at the 1 percent level.

[Table 8]

Based on the approximately 50 wage-risk studies from 10 countries, we can conclude from these results that the income elasticity for the value of a statistical life is less than 1.0. Across a number of specifications with our data, our point estimates of the income elasticity range between about 0.5 and 0.6 . Note that in none of our specifications did the income elasticity's 95 percent confidence interval upper bound exceed 1.0.

Current practice by regulatory agencies is effectively in line with these findings. The U.S. EPA (1999) accounted for income growth into the 22nd century in monetizing the long-term mortality risk reduction benefits from stratospheric ozone protection. ${ }^{29}$ In a regulatory context, the U.S. EPA (2000b) also accounted for income growth over a thirtyyear period in monetizing the mortality risk reduction benefits from reduced particulate matter pollution associated with the diesel sulfur standard for heavy-duty trucks. In both these cases, the U.S. EPA employed an income elasticity of 0.4 and conducted sensitivity analyses with a low-end elasticity of 0.1 and a high-end elasticity of 1.0. If our results of 
the income elasticity apply over time, the point estimate chosen by the EPA is reasonable, although more narrow bounds may be appropriate for the sensitivity analysis.

The meta-analysis regressions can also serve to characterize some of the uncertainty in value of a statistical life estimates. We constructed the mean predicted VSL values presented in the last two rows of Table 8 by first using the estimated coefficients from the meta-analysis regressions to predict the natural logarithm of VSL for each study. Then we converted each predicted $\log (\mathrm{VSL})$ to a predicted VSL. We averaged these over all studies that were included in each regression model's sample to produce the average values reported in the table. We constructed the average 95 percent confidence intervals by first estimating the prediction error for each study from the metaanalysis regressions. We then used this prediction error to construct study-specific 95 percent confidence intervals. The values for the lower and upper bounds of these confidence intervals were then averaged over all the studies in the regression sample. The U.S. specific results are based on regression samples that include non-U.S. studies; only the averaging is U.S.-specific. ${ }^{30}$

The mean predicted VSLs from the meta-analysis regression models for the whole sample vary from $\$ 5.0$ to $\$ 6.2$ million, and from $\$ 5.5$ to $\$ 7.6$ million for the U.S. sample. An assessment of median predicted VSLs produced very similar results. For most regression models, the 95 percent confidence interval upper bound is double or more than the 95 percent confidence interval lower bound. Note that the small number of degrees of freedom in specifications 3 and 6 yielded very large bounds around the measure of central tendency. While this analysis can characterize some of the uncertainty around the value of a statistical life, several caveats are in order. First, the description of uncertainty 
presumes that the proper VSL meta-analysis model has been specified. Otherwise, the bounds around the predicted means are not valid. Second, this assessment of uncertainty regards the value of a statistical life constructed from a sample of wage-risk studies of prime-aged workers. Policy applications of these VSLs in benefits transfer should consider appropriate modifications to the VSL point estimate and the distribution around it.

\section{The effects of union affiliation on the value of a statistical life}

Since the U.S. and international evidence from labor markets and other product markets demonstrate a significant wage-risk tradeoff, numerous researchers have explored several factors that may influence the compensating differential for risk. The relationship between union affiliation and the wage-risk tradeoff has received substantial attention in the literature. Most studies of the U.S. labor market find that union affiliation is positively correlated with a greater wage-risk tradeoff while the international evidence is much more mixed.

Workers in union jobs may enjoy an additional premium for bearing risk greater than those in nonunion jobs for several reasons. First, if firms face an upward sloping labor supply curve, then the absence of collective bargaining may result in inefficiently low level of workplace safety. Viscusi (1980) shows that if the marginal worker's valuation of workplace safety differs from the average worker's valuation, then the firm would provide a suboptimal level of safety. If the marginal worker is willing to accept less of a decrease in wage for an incremental improvement in safety than the average worker, then workplace safety would be too low. If the marginal worker tends to be 
younger and less experienced while the average worker tends to be older and wealthier, then the average worker with greater wealth and family obligations may have a greater preference for workplace safety than the marginal worker. In light of this inefficiently low provision of safety, unions may bargain over workplace safety in addition to wages and other benefits on behalf of the inframarginal workers who may place greater value on risk reduction than the marginal worker.

A second, and not entirely unrelated phenomenon, is that workplace safety may be a quasi-public good and suffer the common under-provision associated with such goods due to free-riding (Dillingham and Smith 1984). If a firm provides some level of workplace safety (e.g., a fire extinguishing system), then one worker's consumption of this safety does not preclude another worker from enjoying the same consumption. Since safety is quasi-public, a worker lacks the incentive to truthfully reveal his or her preference for safety, especially since an increase in safety would likely correspond to a decline in the wage (or some other benefit). Collective action can overcome such freeriding. In this case, collective bargaining by a union with a firm could reflect all workers' true preferences for safety, and result in higher aggregate demand for safety by workers than what would be expected in a non-union setting. This higher demand would translate into greater compensating differentials for job-related injury and fatality risk.

Third, if some workers lack adequate information about the safety at their workplace, then they may underestimate the actual risks they face. Workers underestimating their on-the-job risk would demand lower wages than if they held correct perceptions of risk. Unions potentially could provide workers with more accurate information about their on-the-job risks (Viscusi 1979, Olson 1981). Unions can take 
advantage of economies of scale in providing information not available to unorganized non-union workers (Dillingham and Smith 1984). Unions may also negotiate for mechanisms that increase worker exposure to safety information. For example, Olson noted that a 1976 BLS survey showed that 36 percent of all workers covered by a collective bargaining agreement worked in establishments that sponsored joint firmworker safety committees.

To evaluate the extent to which these factors influence compensating differentials for on-the-job risk, researchers have taken two estimation approaches (see Table 9). First, some have split their samples into union and non-union subsamples and estimated the wage regressions separately for each subsample. Second, others have included an interaction term, risk variable $\mathrm{x}$ union dummy variable, in the wage regression model. In our review of papers evaluating union effects, only Olson (1981) assessed the union-risk premium with both the separate sample regression approach and the risk-union interaction approach. Both approaches yield substantial differences in compensating differentials for union and non-union members.

[Table 9]

Regardless of estimation strategy, most assessments of the U.S. labor market found higher risk premiums for union workers than for non-union workers (see Table 9a). Of the ten U.S. labor market value of life studies we reviewed that evaluated the role of unions in risk premiums, nine found union workers enjoyed greater compensating differentials for bearing risk than nonunion workers. In contrast to accepted theory, several of these papers found that non-union workers had insignificant or statistically significant negative compensating differentials for risk. ${ }^{31}$ 
Table $9 \mathrm{~b}$ summarizes the rather mixed effects of unionization on premiums for nonfatal risks in the U.S. labor market. In the studies that controlled for fatal risks, the compensating differential for injury risk for nonunion workers often exceeded the differential for union workers, even in the same studies where the union fatality risk premium was greater (e.g., Olson 1981, Dorsey 1983, Dorsey and Walzer 1984). Olson found that union workers enjoyed a greater positive premium than nonunion workers for injury incidence but a negative premium for injury duration (number of lost workdays), in contrast to nonunion workers' positive premium.

In regressions that did not include a variable for fatality risk in the estimation model, the findings reflected the results for fatality risk discussed above. Hamermesh and Wolfe (1990) found that the extra compensating differential for union workers reflected injury incidence, while injury duration was insignificant, similar to Olson. While Freeman and Medoff (1981) could not discern between the statistically significant injury risk premiums for union and non-union workers, Smith (1983), Biddle and Zarkin (1988), Fairris (1992), and Hersch and Pickton (1995) all found greater compensating differentials for nonfatal risks for union than for nonunion workers.

While the majority of the U.S. research illustrates greater risk premiums for union workers, the research on labor markets in other countries often reveals a more ambiguous union impact on risk premiums. Marin and Psacharopoulos (1982) conducted the first analysis of compensating differentials for risk in the U.K. labor market, and found that union affiliation had an insignificant impact on the risk premium. In an attempt to replicate this initial study, Arabsheibani and Marin (2000) also could not find any evidence supporting a union-risk premium based on membership or union strength. In 
contrast, Siebert and Wei (1994) found higher union risk premiums when accounting for potential endogeneity of risk. Subsequent research by Sandy and Elliott (1996) countered this finding with analysis indicating larger compensating differentials for risk for nonunion members. These four researchers collaborated in a follow-up study, Sandy et al. (2001), which concluded with a qualified claim that nonunion workers enjoy greater risk premiums.

For the Canadian labor market, several analyses have found little support for a positive impact of union affiliation on compensating differentials for risk. In a series of analyses with union x fatality risk interaction terms, Meng $(1989,1991)$, and Martinello and Meng (1992) found no significant effect for accident risk, while Meng and Smith (1990) found a negative statistically significant coefficient that when combined with the fatality risk coefficient would translate into no compensating differential for union members (in contrast to the positive risk premium for non-union members). In contrast, Cousineau et al. (1992) found for a large Quebec sample that union members received larger premiums for both fatality risk and injury incidence, but a smaller premium for injury duration, than nonunion members. Further, Lanoie et al. (1995) found significant positive compensating differentials for perceived risk for the union sub-sample from their survey of Montreal work establishments.

Finally, the few analyses of developing country labor markets have also found mixed effects of union affiliation on a worker's risk premium. In his analysis of the Indian labor market, Shanmugam (1996-7) included a union x fatality risk interaction term, and found that union members alone enjoy a compensating differential for risk. For 
the South Korean labor market, Kim and Fishback (1999) could not statistically discern compensating differentials for risk between union and non-union workers.

\section{The effects of age on the value of a statistical life}

Evaluating wage-risk tradeoffs in labor markets to estimate the value of a statistical life raises the important question of whether life expectancy affects the value of a statistical life. Age affects the duration of life at risk and also may be correlated with other variables that affect one's willingness to bear risk, which are not age effects per se but rather reflect changing preferences over the life cycle. Numerous analyses have shown that the magnitude of the VSL is a decreasing function of age, whereas the value of any particular year of life may increase with age (Rosen 1988). ${ }^{32}$ Wholly apart from life expectancy effects, accounting for the effect of age in the utility function in terms of deteriorating health and quality of life would have generated similar results. ${ }^{33}$

Using this framework, Rosen undertook several simulations based on his previous empirical work (Thaler and Rosen 1975). He estimated that the value of a statistical lifeyear, which is equal to the expected consumer surplus for another year, for the averageaged individual in the sample ranges from about $\$ 31,000$ to $\$ 130,000$, based on discount rates ranging from 0 to 12 percent. Using data on life expectancy by age, Rosen calculated the value of a statistical life for comparable individuals who varied from 36 years to 48 years of age. The 48 -year old's VSL is 10 percent less than the 36 -year old's VSL.

Several researchers have undertaken direct empirical estimates of the effect of age on the return to risk in hedonic labor market analysis. A simple approach to estimating 
the effect requires interacting the mortality risk and age variables in the regression model. While some researchers did not identify significant coefficients to this interaction (Meng and Smith 1990 and Shanmugam 1996/7, 2001), several others found statistically significant and negative estimates broadly consistent with the theory (see Table 10). Research by Thaler and Rosen (1975), Viscusi (1979), Arnould and Nichols (1983), and Moore and Viscusi (1988b) yielded the negative relationship between age and the return to risk. Within the context of a local housing market, Portney (1981) found that the value of a statistical life based on trading off mortality risk associated with local air pollution exposure and housing prices declines significantly with age: an individual under the age of 45 has a VSL 20 times greater than an individual over the age of 65 .

\section{[Table 10]}

Dillingham, Miller, and Levy (1996) employed a modified approach by focusing on the willingness to pay to avoid a fully impaired worklife, where death is the extreme case of impairment. The authors construct a risk variable that reflects injury frequency, severity, and probability of fatality. They assume that a worklife shortened by a fatal injury is equivalent to a worklife shortened by a permanently disabling injury. Their "value of remaining worklife" ranges from $\$ 3.1$ - $\$ 4.7$ million for the whole sample, although it decreases with age. For example, they estimate that a 50-year old values remaining worklife at half the value held by a 30-year old.

Some researchers have proposed a value per discounted expected life-year approach (Moore and Viscusi 1988b). In lieu of a value of a statistical life, one could adjust the VSL measure for the life expectancy of individuals by essentially annuitizing the estimated VSL. Based on actuarial tables, one could estimate the life expectancy for 
the average-aged individual in a study and then develop estimates of the life-year value (either by assuming a discount rate, or as in several studies, estimating a discount rate based on revealed preference procedures - see below). Then this life-year could be applied to other situations where life expectancy would differ from the average in the study in question. This approach provides an "age-adjusted" or "life expectancyadjusted" VSL alternative to the standard VSL. While the life-year approach does address the concern that values of a statistical life should vary with life expectancy, they assume that the marginal value of another year is constant across the age spectrum and across time for a given individual. ${ }^{34}$

Accounting for the effects of age on the value of a statistical life through a lifeyear approach requires the discounting of future consumer surplus (since, on the margin, the compensating differential should equal the present discounted value of a worker's expected consumer surplus). A variety of papers have imputed workers' or consumers' implicit rates of discount (Moore and Viscusi 1988b, 1990a, 1990b, 1990c, Viscusi and Moore 1989, Dreyfus and Viscusi 1995). While the Moore and Viscusi (1988b) and Dreyfus and Viscusi papers estimate implicit discount rates and marginal discounted lifeyears based on reduced form models, the other three papers develop structural models to estimate discount rates. Also note that all of these models are based on data from labor markets, except for the Dreyfus and Viscusi's automobile hedonic study. Rational individuals can implicitly discount their health capital at a different rate than what they face in markets (e.g., real interest rate for a home mortgage) since health status is a nontraded commodity (one cannot "save" good health at age 25 for consumption at age 75 ). 
Despite this possibility, these models estimate discount rates that are broadly consistent with the real rates of interest typical workers and consumers face (see Table 11).

[Table 11]

\section{The application of the value of a statistical life to public policy decisions}

At least in the countries with a high level of development, governments

recommend or require economic analyses of proposed regulations and public policies. ${ }^{35}$ Regulatory agencies in the United States, the United Kingdom, and Canada, have been most prominent in their use of VSL estimates to value the benefits of proposed environmental, health, and safety rules. In some cases, regulatory agencies have modified the VSL to account for distinctive characteristics of the risk and the affected population. In the United States, some environmental laws preclude the promulgation of regulations based on benefit-cost analysis. In these cases, analysts have turned to riskrisk analysis - based in part on an application of the value of a statistical life - to provide some guidance about whether a proposed policy is in fact risk reducing.

9.1 The use of VSLs in government decision-making around the world

9.1.1 United States. Over the past twenty years in the United States, executive orders by Presidents Carter, Reagan, and Clinton have mandated economic impact analyses of all significant Federal regulations (E.O. 12044, E.O. 12291 and E.O. 12866). Beginning with the Reagan Administration, these executive orders vested with the Office of Management and Budget (OMB) the responsibility for overseeing and coordinating the 
review of regulatory impact analyses. OMB has published guidelines for all Federal agencies, such as its report with respect to the use of "best practices" in these analyses (U.S. OMB 1996). The guidance recommends the use of a value of a statistical life to monetize the benefits associated with rules that change the population's mortality risk. While OMB does not recommend a specific VSL or set of VSLs, it does provide a discussion of the issues agencies should consider when choosing a VSL based on the current state of knowledge.

Until the 1980s the dominant policy approach to valuing the benefits of reduced risks of death was based on various human capital measures, such as the present value of lost earnings and medical expenses. These values are lower than the VSL amounts. Typical of this approach was the 1982 analysis by OSHA of its proposed hazard communication regulation. OSHA valued lives saved based on the cost of death, which was the human capital value, because in its view life was too sacred to value. After OMB rejected the regulation, claiming that the costs exceeded the benefits, OSHA appealed the decision to then Vice-President Bush. W. Kip Viscusi was asked to settle the economic dispute between the two agencies. By valuing life properly using a VSL, the estimated benefits exceeded the costs. The regulation was approved the day after his analysis reached the Reagan White House. ${ }^{36}$ Thus, the historical impetus for the adoption of the VSL methodology was that these values boosted assessed benefits by roughly an order of magnitude, improving the attractiveness of agencies' regulatory efforts.

The flexibility provided to U.S. agencies in choosing a VSL appropriate to the population affected by their specific rules has resulted in significant variations in the selected VSL both across agencies and through time (see Table 12 and Adler and Posner 
2000). In addition, some regulatory impact analyses have included a range of benefits reflecting different assumptions about the VSL, often reflecting the age profile of the affected population by using a VSL adjusted by the number of life-years saved (e.g., the FDA rule restricting tobacco sales to children, 61 FR 44396, and the EPA rule regulating the sulfur content of gasoline, 65 FR 6698). The U.S. Environmental Protection Agency (EPA), responsible for more costly Federal rule-makings than any other U.S. agency, has developed economic guidelines for its regulatory impact analyses (U.S. EPA 2000a). The EPA guidelines recommend a VSL of $\$ 6.2$ million (2000US\$), reflecting the arithmetic mean of 26 studies reviewed in Viscusi (1992a).

In contrast, the U.S. Federal Aviation Administration (1998) recommends a value of a statistical life of $\$ 3$ million in its 2002 economic analyses of regulations. ${ }^{37}$ This comparatively low value of life may reflect in part an anchoring effect. The U.S. Department of Transportation was a leader in valuing mortality risk reductions, but began doing so in an era in which the present value of lost earnings was the dominant approach. The agency has slowly increased the value attached to reduced risks of death, but it has continued to lag behind the estimates in the literature. ${ }^{38}$

[Table 12]

9.1.2 United Kingdom. In the United Kingdom, the Cabinet Office has likewise provided guidance for economic analyses for the government's regulatory and policy-making agencies (U.K. Cabinet Office 2000, H.M. Treasury 1997). While the guidance does not specify the value of a statistical life to be used by agencies, it does recommend careful 
consideration of the challenges in applying values estimated in the economic literature to potentially different risk and population contexts of the policy or regulation.

The U.K. Department of the Environment, Transport, and Regions (DETR; formerly Department of Transport) has employed a willingness-to-pay based value of preventing a fatality since 1988 in its regulatory and policy analyses (Chilton et al. 1999). The value of preventing a fatality selected in 1988 , $\$ 1.2$ million ( $£ 500,000$ in 1987 prices), is still used by the Department. This value reflects contingent valuation-based estimates of individuals' willingness-to-pay for risk reduction. The U.K. Health and Safety Executive uses the DETR value of preventing a fatality as a starting point for its regulatory impact analyses. The HSE has employed a value of preventing a fatality double the DETR value for cancer-related fatalities, concluding that individuals' dread of the disease significantly outweighs the affects of latency on willingness-to-pay (Andrews and McCrea 1999). ${ }^{39}$

Whereas U.S. agencies rely on market-based VSL estimates, in the U.K. the emphasis is on contingent valuation estimates. This difference in approach no doubt stems in part from the different character of the empirical evidence in the two countries. There have been dozens of studies of U.S. wage-risk tradeoffs, most of which have been in a reasonable range. There have been far fewer such analyses for the U.K., and the resulting empirical estimates have been much more unstable.

9.1.3 Canada. In Canada, the Privy Council Office published guidelines for benefit-cost analysis in 1995. While these guidelines do not specify one or a set of values of a statistical life, they do note the need for serious consideration of the value of life, 
determinants of the appropriate VSL, and possible approaches to presenting useful information for policymakers and the public. The value of a statistical life is left to the discretion of agencies promulgating regulations, again much like the U.S. and U.K. approaches.

Transport Canada reviewed the economic analyses for 145 transportation-related projects over 1982 - 1993 (Blanchard 1996). The VSL used in these analyses ranged from $\$ 400,000$ to $\$ 3.2$ million. A recent analysis of a Canadian proposed rule on tobacco products information used a range of the value of a statistical life of $\$ 1.7-\$ 5.7$ million, ${ }^{40}$ with higher values for individuals under age 65 (Hara Associates 2000). A comparable range and age-based VSL differential was employed in an evaluation of a Canadian proposal for cleaner vehicles in fuels as well (Lang et al. 1995).

9.1.4 Multinational organizations. The value of a statistical life has also received attention in multinational contexts. The Intergovernmental Panel on Climate Change (IPCC), established by the United Nations Environment Programme and the World Health Organization in 1988 to provide technical support to participants in global climate change negotiations, discussed issues regarding the value of a statistical life in its 1995 and 2001 assessments of the economic and social dimensions of climate change (IPCC 1996, 2001). Moreover, the European Commission (EC) began in 2000 a process to prepare guidance for benefits analysis to improve benefit-cost analysis procedures within the EC. The EC effort has focused a substantial amount of time and resources on the value of a statistical life question (EC 2000). 


\subsection{Issues Pertaining to Benefits Transfers}

The vast majority of the studies reviewed in this paper cover prime-aged workers who have chosen to bear the risk of accidental, immediate death. Many of the studies based their quantitative analyses on samples from the 1970s and 1980s. With the exception of occupational safety policies, most government regulations affect mortality risks with different qualitative characteristics or affect populations with characteristics that differ from those of the samples in these studies. The demographic characteristics of specific groups and the population at large likely differ today (and will differ in the future) from what they were 20 to 30 years ago. The risk-money tradeoffs of those affected by government policy may differ from those values estimated in hedonic market studies.

For example, many environmental regulations address carcinogen exposure. Reduced cancer-related mortality presents several issues that merit consideration when employing a VSL. First, individuals may be willing to pay more to avoid dying of cancer than to avoid an instantaneous accidental death. Revesz (1999) hypothesizes that this "dread" effect of cancer mortality should result in an upward revision to the VSL. This reasoning apparently underlies the higher VSL used by the UK Health and Safety Executive for cancer-related fatalities. The EPA's Science Advisory Board (2000) recommended against any "dread"-related modification to the value of a statistical life on the grounds that the current literature did not support any such change. ${ }^{41}$ In particular, contingent valuation estimates of cancer mortality risks have produced values similar to those observed for accidental deaths. ${ }^{42}$ The market-based evidence for cancer risks discussed above is similar to the results for accident risks. 
Cancer-related mortality also differs significantly from occupational mortality in terms of the timing of the death. The long latency period for cancer (and other chronic health conditions affected by government regulations) should be discounted in the benefits analysis (Revesz 1999, Science Advisory Board 2000). Given the rough similarity of the implicit rates of discount discussed in Section 8 to current market interest rates, a benefit-cost analysis could employ one common discount rate for all categories of benefits and costs.

Several researchers have questioned the discounting of benefits of reducing future risks to life when evaluating public policies. Heinzerling $(1998,1999,2000)$ has criticized the discounting of statistical lives on moral grounds. She claims that a statistical life cannot be discerned from an actual life, which society would not attempt to price. This concern pertains to both current and future risk reductions and is not a discounting argument per se. While Heinzerling expresses significant concerns with the concept of statistical lives and in their discounting, individuals make private risk-income, risk-time, and risk-risk tradeoffs every day, as evidenced by the literature surveyed in this paper, as well as by simple casual observation. ${ }^{43}$ Further, as the studies presented in Table 11 illustrate, individuals value risks in the future less than they value commensurate risks they face today. Both Revesz and Heinzerling raise concerns about discounting statistical lives in future generations (also see Arrow et al. 1996 for a survey of intergenerational discounting).

Failure to discount creates potentially fundamental paradoxes (see Keeler and Cretin 1983). Suppose that the cost structure for reducing risks to life is unchanged over time. Then it is always desirable to defer any life saving policy and invest the money that 
would have been spent on risk reduction. Indeed, continual postponement of a life saving effort is always desirable if future benefits are never discounted but the money spent on these policies continues to grow at the rate of interest.

Similarly, suppose that future life saving benefits are not discounted. If, however, one converts the cost allocations to a terminal value rather than discounting the benefits back to a present value, the effect will be identical in terms of whether the policy passes a benefit-cost test. What the discounting critics generally fail to grasp is that what is being discounted are not lives but rather society's willingness to pay for these future risks to life.

The differences in the age of the population in labor market studies and of the population affected by a regulation should also affect the value of a statistical life. While fewer studies have focused on the effects of age on the return to risk, those that have tend to find that the value of a statistical life declines with age, consistent with the theoretical work. Since these labor hedonic studies include samples where age usually ranges no higher than about 60 years, it may be difficult to extrapolate these results for older populations. This is a significant issue in benefits transfer, since many environment and public health policies (as opposed to worker safety programs) deliver benefits to the elderly. For example, recent air quality regulations promulgated by the U.S. Environmental Protection Agency disproportionately benefit older individuals as illustrated by the average increase in life expectancy of less than 15 years (U.S. EPA 1999, Science Advisory Board 1999a). In response to this, the EPA's Science Advisory Board (SAB) has questioned the appropriateness of EPA's choice of a VSL for this population. The SAB notes that it "question[s] the application of a WTP estimate for 
prime-aged individuals to a population of older individuals and people who are in poor health" (p. 6). The SAB (1999b) has recommended that the EPA revise its VSL in light of this concern.

Several agencies already employ age-adjusted VSLs. As noted above, the economic analysis of a Canadian tobacco regulation employed a smaller VSL for individuals older than 65. The U.S. Food and Drug Administration regularly employs the value of statistical life-years, instead of VSLs, as a way to monetize the health benefits of their proposed rules. The U.S. Environmental Protection Agency has reluctantly conducted benefit-cost analyses with the value of statistical life-years approach. The clear findings in the theory and existing empirical evidence support such age adjustments. Future empirical research should further refine age-specific estimates of the value of a statistical life for use in regulatory analyses.

\subsection{The role of risk-risk analysis}

While the value of a statistical life can be used to monetize the benefits for risk policy evaluation, most laws do not require that agencies undertake such balancing and some laws in the United States actually preclude the consideration of benefit-cost analysis in setting standards. For example, the courts have interpreted the Clean Air Act such that the U.S. Environmental Protection Agency cannot base ambient air quality standards on benefit-cost analysis or an assessment of the costs. ${ }^{44}$ Even if a benefit-cost test cannot be applied, policies that on balance harm individual health presumably should not be adopted. Several forms of risk-risk analysis can account for these various risk effects of policies in an effort to ascertain whether risk regulations on balance are risk 
reducing. While risk-risk analysis cannot determine if a policy improves societal welfare, it can identify the policies that clearly do not improve societal welfare because they result in a net increase in mortality risk.

Four types of risk-risk tradeoffs could influence the net effect of a policy or regulation on a population's risk exposure. First, a policy may reduce risks of one type while increasing risks of another type. For example, the U.S. Food and Drug Administration considered banning saccharin, the artificial sweetener, in response to an animal study finding that it may be a potential human carcinogen. However, banning saccharin would likely increase the risks associated with obesity. In this case, the U.S. Congress allowed the use of saccharin in foods subject to a warning label on products containing the sweetener (Viscusi 1994b).

Second, policies to reduce risks may create incentives for individuals to undertake less individual effort to reduce their exposure to risks (moral hazard). These behavioral responses will offset some of the risk reduction of the policy, and could potentially increase net risks. For example, Peltzman (1975) described how drivers responded to mandated safety devices in automobiles by changing their driving behavior. Drivers in "safer cars" drove more recklessly than before. The empirical evidence showed that while the safety measures reduced fatalities among automobile occupants, these gains have been offset at least in part by increases in pedestrian deaths and nonfatal accidents.

Third, risk-reduction policies may result in regulatory expenditures that directly increase fatalities. For example, policies to remove asbestos from buildings may increase asbestos exposure by workers and use of excavation equipment at Superfund hazardous waste sites may result in construction-related injuries and fatalities (Graham and Wiener 
1995). Viscusi and Zeckhauser (1994) illustrate through an input-output analysis the total direct and indirect injury and fatality risks associated with expenditures by industry. Regulations that require a reallocation of resources to industries with higher risks, for example towards construction to build new wastewater treatment facilities or to install pollution control technologies would result in an offsetting increase in mortality risk.

Fourth, the costs of risk-reduction policies decrease income available to finance other health and safety expenditures. Wildavsky $(1980,1988)$ noted that the costs of risk-reduction policies reduce national income, some of which would otherwise be used to promote health and safety. This argument focuses on the correlation between income and health, evident in both international cross-sectional data and U.S. time-series data (Viscusi 1983, 1994b, Graham et al. 1992, Lutter and Morrall 1994; see Smith et al. 1994 for a critique of the international evidence).$^{45}$ These analyses illustrate that wealthier countries have lower mortality rates associated with greater health and safety investments. Graham et al. (1992) extended the previous analyses on the mortalityincome relationship by focusing on the effect of permanent income. They conclude that: "If government regulation reduces the level (or the rate of growth) of permanent income, it is likely to cause smaller health investments and an eventual decline in health status compared to what would have occurred without the economic burdens of regulation" ( $p$. $336){ }^{46}$

Keeney $(1990,1994,1997)$ formalized Wildavsky's proposition and found that some expensive regulations aimed at reducing mortality risks actually increase mortality risks by reducing national income. Keeney's model yields various estimates for the induced-expenditure associated with an additional fatality that depend on the distribution 
of the burden of the policy costs. Based on the mortality-income relationships estimated by Kitawaga and Hauser (1973) and Frerichs et al. (1984), Keeney estimates that between $\$ 13.6$ million and $\$ 15.2$ million of expenditures would induce a fatality, assuming costs are borne proportional to income. ${ }^{47,48}$ This research inspired a legal opinion of an OSHA regulation in the early 1990s. ${ }^{49}$ U.S. Federal Appeals Court Judge Steven F. Williams wrote that regulations that do not pass a risk-risk analysis would be counterproductive. The U.S. Office of Management and Budget then suggested to OSHA that it consider risk-risk analysis in conducting its regulatory impact analyses.

While the research on the income-mortality relationship influenced several policy discussions in the early 1990s in the United States, the results from these studies point towards a peculiar inconsistency. For the studies with expenditure-induced fatalities on the order of $\$ 5$ million per fatality, the expenditure associated with a loss of one life is on par or perhaps below what individuals are willing to pay to reduce the risk of one fatality in the population based on the labor market hedonic studies (Viscusi 1994b). Moreover, the mortality-income studies also suffer several other potential problems. Some of these do not appropriately account for the simultaneity in the data - higher incomes allow individuals to invest more in health, but poor health often draws down an individual's income (Chapman and Hariharan 1994). ${ }^{50}$ Some of these studies also may suffer from omitted variable bias resulting in misidentifying the relationship between income and health.

As an alternative to deriving the income-mortality relationship from aggregate data, Viscusi (1994a) illustrates how to generate an estimate for the expenditure-induced 
fatality rate based on the value of a statistical life and the marginal propensity to spend on health. Viscusi shows that

marginal expenditure per statistical life lost $=\frac{\text { value of a statistical life }}{\text { marginal propensity to spend on health }}$.

This approach requires an estimate of the value of a statistical life and an estimate of the marginal propensity to spend on health. The literature surveyed in previous sections provides estimates for the numerator. For the marginal propensity to spend on health, Viscusi estimated this based on an analysis of 24 OECD countries over the $1960-1989$ period and a time-series analysis for the United States over the same period (Viscusi 1992b, 1994a, 1994b). Over an array of specifications for both data sets, the marginal propensity to spend on health ranged from 0.08 to 0.12 . This implies that for every dollar increase in national income, an additional 8 to 12 cents are spent on health care. Assuming a marginal propensity to spend on health of 0.1 and a VSL of about $\$ 6$ million, the marginal expenditure per statistical life lost would be about $\$ 60$ million. ${ }^{51}$

Lutter, Morrall, and Viscusi (1999) extended Viscusi's (1994a) model to account for the effect of income to influence risky behaviors (such as smoking, drinking, and poor diet) as well as the consumption of health care. Their statistical analyses illustrate that higher incomes promote better health habits, including reduced excessive drinking and cigarette smoking and increased exercise. Including the effects of income on risky health behavior reduces the estimated marginal expenditure per statistical life lost from the Viscusi (1994a) by more than a factor of 3 to $\$ 17$ million. Lutter et al. note that policies that increase national income would reduce one fatality for every $\$ 17$ million increase. The authors also note that since many regulations have costs per life saved of $\$ 100$ million or more, the expenditures may be wasteful and counterproductive. ${ }^{52}$ 
If a regulation directly reduces mortality risk with regulatory-induced expenditures yielding a high cost per life saved ratio, then the indirect increase in mortality risk may exceed the direct decrease in risk resulting in an aggregate increase in societal mortality risk. The existing literature varies in terms of a preferred value for the amount of induced expenditures associated with an additional mortality. However, some regulations would clearly not pass a risk-risk analysis with any plausible value for an induced-expenditure mortality. For example, the 1986 OSHA regulation limiting asbestos occupational exposure cost about $\$ 250$ million per normalized life saved, and the 1987 OSHA regulation limiting formaldehyde occupational exposure cost about $\$ 290$ billion per normalized life saved (Viscusi, Hakes, and Carlin 1997).

While the risk-risk literature has focused on mortality risks, many environment and safety regulations provide other kinds of benefits, such as reduced morbidity and injury as well as non-human health related effects such as improved visibility and ecosystem health (Lutter and Morrall 1994, Portney and Stavins 1994). A regulation that primarily delivers non-mortality benefits could fail a risk-risk analysis but still pass a benefit-cost analysis. One approach could be to convert the morbidity effects into mortality risk equivalents. Alternatively one could focus on policies whose primary intent is to reduce mortality risks. Recognizing this criticism, Hahn, Lutter, and Viscusi (2000) conducted risk-risk analysis on a number of major environment, health, and safety regulations over the 1986 - 1998 period whose primary benefits were reduced mortality risk (see Table 13). ${ }^{53}$ Their analysis focuses on 24 regulations promulgated by the U.S. Environmental Protection Agency (EPA), U.S. Department of Housing and Urban Development (HUD), U.S. Department of Labor (OSHA), and U.S. Consumer Products 
Safety Commission (CPSC). Thirteen of 24 regulations designed primarily to reduce mortality risks actually increased mortality risks based on the Lutter et al. work finding that $\$ 15$ million of expenditures induces a fatality. Ten of these thirteen rules failing a risk-risk analysis had at least ten times more expenditure-induced fatalities than lives saved. ${ }^{54}$

[Table 13]

\section{Conclusion}

For nearly thirty years, economists have attempted to infer individuals' preferences over mortality and morbidity risk and income in labor and product markets. The substantial literature that has developed over that time has confirmed Adam Smith's intuition about compensating differentials for occupational hazards in a significant and growing number of countries. In addition to evaluating various international labor markets, the literature has expanded to address a variety of econometric issues, morbidity risk premiums, and factors influencing mortality risk premiums such as union affiliation and age.

While the tradeoff estimates may vary significantly across studies, the value of a statistical life for prime-aged workers has a median value of about $\$ 7$ million in the United States. Our meta-analysis characterizes some of the uncertainty in estimates of the value of a statistical life, and finds that 95 percent confidence interval upper bounds can exceed the lower bounds by a factor of two or more. Other developed countries appear to have comparable VSLs, although some studies of the United Kingdom have found much larger risk premiums. Consistent with the fact that safety is a normal good, 
developing countries labor markets also have significant, but smaller, values of statistical life. Overall, our point estimates of the income elasticity of the value of a statistical life range from 0.5 to 0.6 . Union members in U.S. labor markets appear to enjoy greater risk premiums than non-members, while the evidence in other developed countries is rather mixed. The theoretical and empirical literature indicates that the value of a statistical life decreases with age.

The estimates of the value of a statistical life can continue to serve as a critical input in benefit-cost analyses of proposed regulations and policies. Refining VSLs for the specific characteristics of the affected population at risk remains an important priority for the research community and the government agencies conducting these economic analyses. Improving the application of VSLs in this way can result in more informed government interventions to address market failures related to environmental, health, and safety mortality risks. 


\section{References}

Adler, M.D. and E.A. Posner. (2000). "Implementing Cost-Benefit Analysis When Preferences Are Distorted," Journal of Legal Studies 29, 1105-1148.

Andrews, R.M. and P. McCrea. (1999). "UK Health and Safety Executive Approach to Exposure Limit Setting." In Proceedings of the OECD Workshop on the Integration of Socio-Economic Analysis in Chemical Risk Management Decision Making, London, January 7-9, 1998. Paris: Organization of Economic Cooperation and Development, pp. 193-202.

Arabsheibani, G.R. and A. Marin. (2000). "Stability of Estimates of the Compensation for Danger," Journal of Risk and Uncertainty 20(3), 247-269.

Arnould, R.J. and L.M. Nichols. (1983). "Wage-Risk Premiums and Workers' Compensation: A Refinement of Estimates of Compensating Wage Differential," Journal of Political Economy 91(2), 332-340.

Arrow, K.J., W.R. Cline, K.-G. Maler, M. Munasinghe, J.E. Stiglitz, and R. Squitieri. (1996). "Intertemporal Equity and Discounting." In J.P. Bruce, H. Lee, and E. Haites (eds.), Climate Change 1995: Economic and Social Dimensions. Cambridge, England: Cambridge University Press, pp. 125-144.

Aten, B., R. Summers, and A. Heston. (2001). The Penn World Table Mark 6. Philadelphia, PA: The Center for International Comparisons at the University of Pennsylvania. Internet: http://pwt.econ.upenn.edu.

Atkinson, S.E. and R. Halvorsen. (1990). "The Valuation of Risks to Life: Evidence from the Market for Automobiles," Review of Economics and Statistics 72(1), 133-136.

Barro, R.J. and J.W. Lee. (1996). "International Measures of Schooling Years and Schooling Quality," American Economic Review 86(2), 218-223.

Berger, M.C. and P.E. Gabriel. (1991). "Risk Aversion and the Earnings of U.S. Immigrants and Natives," Applied Economics 23, 311-318.

Biddle, J.E. and G.A. Zarkin. (1988). "Worker Preference and Market Compensation for Job Risk," Review of Economics and Statistics 70(4), 660-667.

Blanchard, G. (1996). Highway Benefit-Cost Analysis: A Review of Evidence. Transport Canada, Economic Analysis, Special Infrastructure Project. Report no. TP12790E. Ottawa, Ontario.

Blomquist, G. (1979). "Value of Life Saving: Implications of Consumption Activity," Journal of Political Economy 87(3), 540-558. 
Bowland, B.J. and J.C. Beghin. (2001). "Robust Estimates of Value of a Statistical Life for Developing Economies," Journal of Policy Modeling 23, 385-396.

Brown, C. (1980). "Equalizing Differences in the Labor Market," Quarterly Journal of Economics 94(1), 113-134.

Bureau of Labor Statistics. (n.d.). Census of Fatal Occupational Injuries. Washington, DC: Department of Labor. Internet: http://www.bls.gov/iif/oshcfoil.htm.

Butler, R.J. (1983). "Wage and Injury Rate Responses to Shifting Levels of Workers' Compensation." In J.D. Worrall (ed.), Safety and the Workforce: Incentives and Disincentives in Workers' Compensation. Ithaca, NY: ILR Press, pp. 61-86.

Carlin, P.S. and R. Sandy. (1991). "Estimating the Implicit Value of a Young Child's Life," Southern Economic Journal 58(1), 186-202.

Chapman, K.S. and G. Hariharan. (1994). "Controlling for Causality in the Link from Income to Mortality," Journal of Risk and Uncertainty 8(1), 85-94.

Chilton, S., J. Covey, L. Hopkins, M. Jones-Lee, G. Loomes, N. Pidgeon, and A. Spencer. (1999). "Annex: New Research Results on the Valuation of Preventing Fatal Road Accident Casualties." In Health Costs Due to Road Traffic-related Air Pollution: Economic Evaluation, Prepared for the WHO Ministerial Conference on Environment and Health, London, June 1999. Bern, Switzerland: Federal Department of Environment, Transport, Energy and Communications, Bureau for Transport Statistics.

Council of Economic Advisers. (2002). Economic Report of the President. Washington, DC: Government Printing Office.

Cousineau, J-M., R. Lacroix, and A-M. Girard. (1992). "Occupational Hazard and Wage Compensating Differentials," Review of Economics and Statistics 74(1), 166-169.

Cutler, D.M. and E. Richardson. (1997). "Measuring the Health of the U.S. Population," Brookings Papers on Economic Activity, Microeconomics vol. 1997, 217-271.

Dardis, R. (1980). "The Value of Life: New Evidence from the Marketplace," American Economic Review 70(5), 1077-1082.

Desvousges, W.H., F.R. Johnson, H.S. Banzhof, R.R. Russell, E.E. Fries, K.J. Dietz, and S.C. Helms. (1995). Assessing the Environmental Externality Costs for Electricity Generation. Research Triangle Park, NC: Triangle Economic Research.

Dickens, W.T. (1984). "Differences Between Risk Premiums in Union and Nonunion Wages and the Case for Occupational Safety Regulation," American Economic Review $74(2), 320-323$. 
Dillingham, A.E. (1985). "The Influence of Risk Variable Definition on Value-of-Life Estimates," Economic Inquiry 23(2), 277-294.

Dillingham, A.E., T. Miller, and D.T. Levy. (1996). “A More General and Unified Measure for Valuing Labour Market Risk,” Applied Economics 28, 537-542.

Dillingham, A.E. and R.S. Smith. (1984). "Union Effects on the Valuation of Fatal Risk." In Dennis, B.O. (ed.), Proceedings of the Industrial Relations Research Association 36th Annual Meeting, San Francisco, CA, December 28 - 30, 1983. Madison, WI: Industrial Relations Research Association, pp. 270-277.

Dorman, P. and P. Hagstrom. (1998). "Wage Compensation for Dangerous Work Revisited," Industrial and Labor Relations Review 52(1), 116-135.

Dorsey, S. (1983). "Employment Hazards and Fringe Benefits: Further Tests for Compensating Differentials." In J.D. Worrall (ed.), Safety and the Workforce: Incentives and Disincentives in Workers' Compensation. Ithaca, NY: ILR Press, pp. 87-102.

Dorsey S. and N. Walzer. (1983). "Workers' Compensation, Job Hazards, and Wages," Industrial and Labor Relations Review 36(4), 642-654.

Dreyfus, M.K. and W.K. Viscusi. (1995). "Rates of Time Preference and Consumer Valuations of Automobile Safety and Fuel Efficiency," Journal of Law and Economics 38(1), 79-105.

Duncan, G.J. and B. Holmlund. (1983). "Was Adam Smith Right After All? Another Test of the Theory of Compensating Wage Differentials," Journal of Labor Economics $1(4), 366-379$.

European Commission. (2000). Workshop on the Value of Reducing the Risk of IllHealth or a Fatal Illness. Proceedings, November 13, 2000, Brussels, Belgium. Internet: http://europa.eu.int/comm/environment/enveco/others/proceedings of the workshop.pdf.

Fairris, D. (1989). "Compensating Wage Differentials in the Union and Nonunion Sectors," Industrial Relations 28(3), 356-372.

Fairris, D. (1992). "Compensating Payments and Hazardous Work in Union and Nonunion Settings," Journal of Labor Research 13(2), 205-221.

Fishback, P.V. and S.E. Kantor. (1992). "Square Deal' or Raw Deal? Market Compensation for Workplace Disamenities, 1884-1903," Journal of Economic History 52(4), 826-848.

Freeman, R.B. and J.L. Medoff. (1981). "The Impact of the Percentage Organized on Union and Nonunion Wages," Review of Economics and Statistics 63(4), 561-572. 
French, M.T. (1990). "Estimating the Full Cost of Workplace Injuries," American Journal of Public Health 80(9), 1118-1119.

French, M.T. and D.L. Kendall. (1992). "The Value of Job Safety for Railroad Workers," Journal of Risk and Uncertainty 5(2), 175-185.

Frerichs, R.R., J.M. Chapman, P. Nourjah, and E.F. Maes. (1984). Cardiovascular Diseases in Los Angeles, 1979 - 1981. Los Angeles: American Heart Association Greater Los Angeles Affiliate, Inc.

Gaba, A. and W.K. Viscusi. (1998). "Differences in Subjective Risk Thresholds: Worker Groups as an Example," Management Science 44(6), 801-811.

Garbacz, C. (1989). "Smoke Detector Effectiveness and the Value of Saving a Life," Economics Letters 31, 281-286.

Garber, A.M. and C.E. Phelps. (1997). "Economic Foundations of Cost-Effectiveness Analysis," Journal of Health Economics 16, 1-31.

Garen, J. (1988). "Compensating Wage Differentials and the Endogeneity of Job Riskiness," Review of Economics and Statistics 70(1), 9-16.

Gayer, T., J.T. Hamilton, and W.K. Viscusi. (2000). "Private Values of Risk Tradeoffs at Superfund Sites: Housing Market Evidence on Learning About Risk," Review of Economics and Statistics 82(3), 439-451.

Gegax, D., S. Gerking, and W. Schulze. (1991). "Perceived Risk and the Marginal Value of Safety," Review of Economics and Statistics 73(4), 589-596.

Gerdtham, U. and M. Johannesson. (2002). "Do Life-Saving Regulations Save Lives?" Journal of Risk and Uncertainty 24(3), 231-249.

Gerking, S., M. de Haan, and W. Schulze. (1988). "The Marginal Value of Job Safety: A Contingent Valuation Study," Journal of Risk and Uncertainty 1(2), 185-199.

Ghosh, D., D. Lees, and W. Seal. (1975). "Optimal Motorway Speed and Some Valuations of Time and Life," Manchester School Economics and Social Studies 43(2), 134-143.

Graham, J.D., B.-H. Chang, and J.S. Evans. (1992). "Poorer is Riskier," Risk Analysis 12(3): 333-337.

Graham, J.D. and J.B. Wiener. (1995). Risks vs. Risks: Tradeoffs in Protecting Health and the Environment. Cambridge, MA: Harvard University Press. 
Griliches, Z. (ed.). (1971). Price Indexes and Quality Change. Cambridge: Harvard University Press.

Hahn, R.W., R.W. Lutter, and W.K. Viscusi. (2000). Do Federal Regulations Reduce Mortality? Washington, DC: AEI-Brookings Joint Center for Regulatory Studies.

Hamermesh, D.S. (1978). "Economic Aspects of Job Satisfaction.” In O. Ashenfelter and W. Oates (eds.), Essays in Labor Market Analysis. New York: John Wiley and Sons, pp. 53-72.

Hamermesh, D.S. (1999). "Changing Inequality in Markets for Workplace Amenities," Quarterly Journal of Economics 114(4), 1085-1123.

Hamermesh, D.S. and J.R. Wolfe. (1990). "Compensating Wage Differentials and the Duration of Wage Loss," Journal of Labor Economics 8(1), S175-S197.

Hammitt, J.K. (2002). "Commentary on: What Determines the Value of Life? A MetaAnalysis," Journal of Policy Analysis and Management 21(2), 271-273.

Hara Associates Inc. (2000). Benefit/Cost Analysis of Proposed Tobacco Products Information Regulations. Prepared for Health Canada and Consulting and Audit Canada. Ottawa, Ontario. June 5, 2000.

Heinzerling, L. (1998). "Regulatory Costs of Mythic Proportions," Yale Law Journal 107, 1981-2070.

Heinzerling, L. (1999). “Discounting Life,” Yale Law Journal 108, 1911-1915.

Heinzerling, L. (2000). "The Rights of Statistical People," Harvard Environmental Law Review 24, 189-207.

Hersch, J. (1998). "Compensating Differentials for Gender-Specific Job Injury Risks," American Economic Review 88(3), 598-627.

Hersch, J. and T. S. Pickton. (1995). "Risk-Taking Activities and Heterogeneity of JobRisk Tradeoffs," Journal of Risk and Uncertainty 11(3), 205-217.

Hersch, J. and W.K. Viscusi. (1990). "Cigarette Smoking, Seatbelt Use, and Differences in Wage-Risk Tradeoffs," Journal of Human Resources 25(2), 202-227.

Herzog Jr., H.W. and A.M. Schlottmann. (1990). "Valuing Risk in the Workplace: Market Price, Willingness to Pay, and the Optimal Provision of Safety," Review of Economics and Statistics 72(3), 463-470.

H.M. Treasury. (1997). "The Green Book": Appraisal and Evaluation in Central Government, Treasury Guidance. London: Her Majesty's Stationary Office 
Hwang, H.-S., W.R. Reed, and C. Hubbard. (1992). "Compensating Wage Differentials and Unobserved Productivity," Journal of Political Economy 100(4), 835-858.

Intergovernmental Panel on Climate Change (IPCC) (1996). Climate Change 1995: Economic and Social Dimensions of Climate Change. Cambridge: Cambridge University Press.

Intergovernmental Panel on Climate Change (IPCC) (2001). Climate Change 2001: Mitigation. Cambridge: Cambridge University Press.

Ippolito, P.M. and R.A. Ippolito. (1984). "Measuring the Value of Life Saving from Consumer Reactions to New Information," Journal of Public Economics 25, 53-81.

Jenkins, R.R., N. Owens, and L.B. Wiggins. (2001). "Valuing Reduced Risks to Children: The Case of Bicycle Safety Helmets," Contemporary Economic Policy 19(4), 397-408.

Jones-Lee, M.W. (1976). The Value of Life: An Economic Analysis. Chicago: University of Chicago Press.

Jones-Lee, M.W., M. Hammerton, and P.R. Phillips. (1985). "The Value of Safety: Results of a National Sample Survey," Economic Journal 95, 49-72.

Keeler, E.B. and S. Cretin. (1983). "Discounting of Life-Saving and Other Nonmonetary Effects," Management Science 29(3), 300-306.

Keeney, R.L. (1990). "Mortality Risks Induced by Economic Expenditures," Risk Analysis 10(1), 147-159.

Keeney, R.L. (1994). "Mortality Risks Induced by the Costs of Regulation," Journal of Risk and Uncertainty 8(1), 95-110.

Keeney, R.L. (1997). "Estimating Fatalities Induced by the Economic Costs of Regulation." Journal of Risk and Uncertainty 14(1), 5-24.

Kim, S-W. and P.V. Fishback. (1993). "Institutional Change, Compensating Differentials, and Accident Risk in American Railroading, 1892-1945," Journal of Economic History 53(4), 796-823.

Kim, S-W. and P.V. Fishback. (1999). "The Impact of Institutional Change on Compensating Wage Differentials for Accident Risk: South Korea, 1984-1990," Journal of Risk and Uncertainty 18(3), 231-248. 
Kitawaga, E.M. and P.M. Hauser. (1973). Differential Mortality in the United States of America: A Study in Socioeconomic Epidemiology. Cambridge, MA: Harvard University Press.

Kniesner, T.J. and J.D. Leeth. (1991). “Compensating Wage Differentials for Fatal Injury Risk in Australia, Japan, and the United States," Journal of Risk and Uncertainty 4(1), 75-90.

Krupnick, A. (2002). "Commentary on: What Determines the Value of Life? A MetaAnalysis," Journal of Policy Analysis and Management 21(2), 275-282.

Lang, C., G. Yarwood, F. Lalonde, and R. Bloxam. (1995). Environmental and Health Benefits of Cleaner Vehicles and Fuels. Prepared for Canadian Council of Ministers of the Environment, Task Force on Cleaner Vehicles and Fuels. October 5, 1995.

Lanoie, P., C. Pedro, and R. Latour. (1995). "The Value of a Statistical Life: A Comparison of Two Approaches," Journal of Risk and Uncertainty 10, 235-257.

Leigh, J.P. (1981). "Compensating Wages for Occupational Injuries and Diseases," Social Science Quarterly 62(4), 772-778.

Leigh, J.P. (1987). "Gender, Firm Size, Industry, and Estimates of the Value of Life," Journal of Health Economics 1, 331-344.

Leigh, J.P. (1991). "No Evidence of Compensating Wages for Occupational Fatalities," Industrial Relations 30(3), 382-395.

Leigh, J.P. (1995). "Compensating Wages, Value of a Statistical Life, and Inter-Industry Differentials," Journal of Environmental Economics and Management 28(1), 83-97.

Leigh, J.P. and R.N. Folsom. (1984). "Estimates of the Value of Accident Avoidance at the Job Depend on the Concavity of the Equalizing Differences Curve," Quarterly Review of Economics and Business 24(1), 56-66.

Liu, J-T., J. Hammitt, and J-L. Liu. (1997). "Estimating Hedonic Wage Function and Value of Life in a Developing Country," Economics Letters 57, 353-358.

Liu, J-T. and J.K. Hammitt. (1999). "Perceived Risk and Value of Workplace Safety in a Developing Country," Journal of Risk Research 2(3), 263-275.

Lott, J.R. and R.L. Manning. (2000). "Have Changing Liability Rules Compensated Workers Twice for Occupational Hazards? Earnings Premiums and Cancer Risks," Journal of Legal Studies 29, 99-130.

Low, S.A. and L.R. McPheters. (1983). "Wage Differentials and the Risk of Death: An Empirical Analysis,” Economic Inquiry 21, 271-280. 
Lutter, R. and J.F. Morrall. (1994). "Health-Health Analysis: A New Way to Evaluate Health and Safety Regulation," Journal of Risk and Uncertainty 8(1), 43-66.

Lutter, R., J.F. Morrall, and W.K. Viscusi. (1999). "The Cost-Per-Life-Saved Cutoff for Safety-Enhancing Regulations," Economic Inquiry 37(4), 599-608.

Magat, Wesley, W. Kip Viscusi, and Joel Huber. (1996). “A Reference Lottery Metric for Valuing Health," Management Science 42(8), 1118-1130.

Marin, A. and H. Psacharopoulos. (1982). "The Reward for Risk in the Labor Market: Evidence from the United Kingdom and a Reconciliation with Other Studies," Journal of Political Economy 90(4), 827-853.

Marsh, Suzanne M. and Larry A. Layne. (2001). Fatal Injuries to Civilian Workers in the United States, 1980 - 1995. DHHS/NIOSH pub. no. 2001-129s. July. Washington, DC: Department of Health and Human Services.

Martinello, F. and R. Meng. (1992). "Workplace Risks and the Value of Hazard Avoidance," Canadian Journal of Economics 25(2), 333-345.

McLean, R.A., W.R. Wendling, and P.R. Neergaard. (1978). "Compensating Wage Differentials for Hazardous Work: An Empirical Analysis," Quarterly Review of Economics and Business 18(3), 97-107.

McNeill, W.H. (1976). Plagues and Peoples. Garden City, NY: Anchor Press.

Mellow, W. and H. Sider. (1983). "Accuracy of Response in Labor Market Surveys:

Evidence and Implications," Journal of Labor Economics 1(4), 331-344.

Meng, R. (1989). "Compensating Differences in the Canadian Labour Market," Canadian Journal of Economics 22(2), 413-424.

Meng, R. (1991). "Compensating Wages for Long-Term Job Hazards in Canadian Industry," Economics Letters 36(3), 331-336.

Meng, R.A. and D.A. Smith. (1990). "The Valuation of Risk of Death in Public Sector Decision-Making," Canadian Public Policy - Analyse de Politiques 16(2), 137-144.

Meng, R. and D.A. Smith. (1999). "The Impact of Workers' Compensation on Wage Premiums for Job Hazards," Applied Economics 31(9), 1101-1108.

Miller, P., C. Mulvey, and K. Norris. (1997). "Compensating Differentials for Risk of Death in Australia," Economic Record 73(223), 363-372. 
Miller, T.R. (1990). "The Plausible Range for the Value of Life - Red Herrings Among the Mackerel," Journal of Forensic Economics 3(3), 17-39.

Miller, T.R. (2000). "Variations between Countries in Values of Statistical Life," Journal of Transport Economics and Policy 34(2), 169-188.

Moore, M.J. and W.K. Viscusi. (1988a). "Doubling the Estimated Value of Life: Results Using New Occupational Fatality Data," Journal of Policy Analysis and Management $7(3), 476-490$.

Moore, M.J. and W.K. Viscusi. (1988b). "The Quantity-Adjusted Value of Life," Economic Inquiry 26, 369-388.

Moore, M.J. and W.K. Viscusi. (1990a). Compensation Mechanisms for Job Risks. Princeton: Princeton University Press.

Moore, M.J. and W.K. Viscusi. (1990b). "Discounting Environmental Health Risks: New Evidence and Policy Implications," Journal of Environmental Economics and Management 18, S51-S62.

Moore, M.J. and W.K. Viscusi. (1990c). "Models for Estimating Discount Rates for Long-Term Health Risks Using Labor Market Data," Journal of Risk and Uncertainty 3, 381-401.

Morrall, J. (1986). "A Review of the Record," Regulation (Nov/Dec), 25-34.

Mrozek, J.R. and L.O. Taylor. (2002). "What Determines the Value of Life? A MetaAnalysis," Journal of Policy Analysis and Management 21(2), 253-270.

National Institute for Occupational Safety and Health (NIOSH). (2000). Worker Health Chartbook, 2000. Report no. 2000-127. U.S. Department of Health and Human

Services. Internet: http://www.cdc.gov/niosh/pdfs/2000-127.pdf.

Organization for Economic Cooperation and Development (OECD). (1995).

Recommendation of the Council of the OECD on Improving the Quality of Government Regulation. Report OCDE/GD(95)95. Paris: OECD.

Organization for Economic Cooperation and Development (OECD). (2001). OECD Environmental Outlook. Paris: OECD.

Olson, C.A. (1981). "An Analysis of Wage Differentials Received by Workers on Dangerous Jobs," Journal of Human Resources 16(2), 167-185.

Peltzman, S. (1975). "The Effects of Automobile Regulation," Journal of Political Economy 83(4), 677-726. 
Privy Council Office, Canada. (1995). Benefit/Cost Analysis Guide for Regulatory Programs. Ottawa, Ontario. Internet:

http://www.pco-bcp.gc.ca/raoics-srdc/ProcGuides/cbgcntents_e.htm.

Portney, P.R. (1981). "Housing Prices, Health Effects, and Valuing Reductions in Risk of Death," Journal of Environmental Economics and Management 8, 72-78.

Portney, P.R. and R.N. Stavins. (1994). "Regulatory Review of Environmental Policy: The Potential Role of Health-Health Analysis," Journal of Risk and Uncertainty 8(1), 111-122.

Ramsberg, J.A.L. and L. Sjoberg. (1997). “The Cost-Effectiveness of Lifesaving Interventions in Sweden," Risk Analysis 17(4), 467-478.

Revesz, Richard L. (1999). "Environmental Regulation, Cost-Benefit Analysis, and the Discounting of Human Lives," Columbia Law Review 99, 941-1017.

Rosen, S. (1974). "Hedonic Prices and Implicit Markets: Product Differentiation in Pure Competition,” Journal of Political Economy 82, 34-55.

Rosen, S. (1986). "The Theory of Equalizing Differences." In O. Ashenfelter and R. Layard (eds.), Handbook of Labor Economics. Amsterdam: North-Holland, pp. 641692.

Rosen, S. (1988). "The Value of Changes in Life Expectancy," Journal of Risk and Uncertainty 1, 285-304.

Sandy, R. and R.F. Elliott. (1996). "Unions and Risk: Their Impact on the Level of Compensation for Fatal Risk," Economica 63(250), 291-309.

Sandy, R., R.F. Elliott, W.S. Siebert, and X. Wei. (2001). "Measurement Error and the Effects of Unions on the Compensating Differentials for Fatal Workplace Risks," Journal of Risk and Uncertainty 23(1), 33-56.

Schelling, T.C. (1968). "The Life You Save May Be Your Own." In S.B. Chase (ed.), Problems in Public Expenditure and Analysis. Washington, DC: Brookings Institution, pp. 127-162.

Science Advisory Board. (1999a). Advisory Letter to Administrator Browner Regarding the Clean Air Act Amendments Section 812 Prospective Study of Costs and Benefits. October 29, 1999. Internet: http://www.epa.gov/sab/coua0002.pdf.

Science Advisory Board. (1999b). Final Advisory Letter to Administrator Browner Regarding the Clean Air Act Amendments Section 812 Prospective Study of Costs and Benefits. November 19, 1999. Internet: http://www.epa.gov/sab/coua0003.pdf. 
Science Advisory Board. (2000). SAB Report on EPA's White Paper "Valuing the Benefits of Fatal Cancer Risk Reduction." Transmitted to the EPA by letter to Administrator Browner. July 27, 2000. Internet: http://www.epa.gov/sab/eeacf013.pdf.

Shanmugam, K.R. (1996/7). "The Value of Life: Estimates from Indian Labour Market," Indian Economic Journal 44(4), 105-114.

Shanmugam, K.R. (1997). "Value of Life and Injury: Estimating Using Flexible Functional Form," Indian Journal of Applied Economics 6(3), 125-136.

Shanmugam, K.R. (2000). "Valuations of Life and Injury Risks," Environmental and Resource Economics 16, 379-389.

Shanmugam, K.R. (2001). "Self Selection Bias in the Estimates of Compensating Differentials for Job Risks in India," Journal of Risk and Uncertainty 22(3), 263-275.

Shepard, D.S. and R.J. Zeckhauser. (1982). "Life-Cycle Consumption and Willingnessto-Pay for Increased Survival." In M.W. Jones-Lee (ed.), The Value of Life and Safety. Amsterdam: North Holland.

Shepard, D.S. and R.J. Zeckhauser. (1984). "Survival Versus Consumption," Management Science 30(4), 423-439.

Shogren, J.S. and T. Stamland. (2002). "Skill and the Value of Life," Journal of Political Economy 110(5), 1168-1173.

Siebert, W.S. and X. Wei. (1994). "Compensating Wage Differentials for Workplace Accidents: Evidence for Union and Nonunion Workers in the UK," Journal of Risk and Uncertainty 9(1), 61-76.

Siebert, W.S. and X. Wei. (1998). "Wage Compensation for Job Risks: The Case of Hong Kong,” Asian Economic Journal 12(2), 171-181.

Smith, A. (1776). The Wealth of Nations. Chicago: University of Chicago Press. 1976 edition.

Smith, R.S. (1974). “The Feasibility of an 'Injury Tax' Approach to Occupational Safety," Law and Contemporary Problems 38(4), 730-744.

Smith, R.S. (1976). The Occupational Safety and Health Act: Its Goals and Its Achievements. Washington, DC: American Enterprise Institute.

Smith, R.S. (1979). "Compensating Wage Differentials and Public Policy: A Review," Industrial and Labor Relations Review 32(3), 339-352. 
Smith, V.K. (1983). "The Role of Site and Job Characteristics in Hedonic Wage Models," Journal of Urban Economics 13, 296-321.

Smith, V.K., D.J. Epp, and K.A. Schwabe. (1994). "Cross-Country Analyses Don't Estimate Health-Health Responses," Journal of Risk and Uncertainty 8(1), 67-84.

Smith, V.K. and C.C.S. Gilbert. (1984). "The Implicit Valuation of Risks to Life: A Comparative Analysis," Economics Letters 16, 393-399.

Smith, V.K. and C.C.S. Gilbert. (1985). "The Valuation of Environmental Risks Using Hedonic Wage Models." In M. David and T. Smeeding (eds.), Horizontal Equity, Uncertainty, and Economic Well-Being. Chicago: University of Chicago Press. pp. 359385.

Summers, R. and A. Heston. (1991). “The Penn World Table (Mark 5): An Expanded Set of International Comparisons, 1950 - 1988," Quarterly Journal of Economics 106, 327-368.

Tengs, T.O., M.E. Adams, J.S. Pliskin, D.G. Safran, J.E. Siegel, M.C. Weinstein, and J.D. Graham. (1995). "Five-Hundred Life-Saving Interventions and Their CostEffectiveness," Risk Analysis 15(3), 369-390.

Thaler, R. and S. Rosen. (1975). "The Value of Saving a Life: Evidence from the Labor Market." In N.E. Terleckyj (ed.), Household Production and Consumption. New York: Columbia University Press, pp. 265-300.

U.K. Cabinet Office. (2000). Good Policy Making: A Guide to Regulatory Impact Assessment. London: Cabinet Office Regulatory Impact Unit. Internet: http://www.cabinet-office.gov.uk/regulation/2000/riaguide/default.htm.

U.S. Environmental Protection Agency. (1999). The Benefits and Costs of the Clean Air Act 1990 to 2010. Report 410-R-99-001. Washington, DC: Office of Air and Radiation, USEPA. Internet: http://www.epa.gov/oar/sect812/copy99.html.

U.S. Environmental Protection Agency. (2000a). Guidelines for Preparing Economic Analyses. Report 240-R-00-003. Washington, DC: Office of the Administrator, USEPA. Internet: http://yosemite1.epa.gov/ee/epa/eed.nsf/pages/guidelines.

U.S. Environmental Protection Agency. (2000b). Regulatory Impact Analysis: HeavyDuty Engine and Vehicle Standards and Highway Diesel Fuel Sulfur Control Requirements. Report 420-R-00-026. Washington, DC: Office of Air and Radiation, USEPA.

U.S. Federal Aviation Administration. (1998). Economic Values for Evaluation of Federal Aviation Administration Investment and Regulatory Program. Report no. FAA- 
APO-98-8. Washington, DC: Department of Transportation. June. Internet: http://www.api.faa.gov/economic/TOC.PDF.

U.S. Office of Management and Budget. (1992). Guidelines and Discount Rates for Benefit-Cost Analysis of Federal Programs. Circular A-94. Washington, DC: The White House. Internet: http://www.whitehouse.gov/omb/circulars/a094/a094.pdf.

U.S. Office of Management and Budget. (1996). Economic Analysis of Federal Regulations Under Executive Order 12866. Washington, DC: The White House. Internet: http://www.whitehouse.gov/omb/inforeg/riaguide.html.

U.S. Office of Management and Budget. (2001). Making Sense of Regulation: 2001 Report to Congress on the Costs and Benefits of Regulations and Unfunded Mandates on State, Local, and Tribal Entities. Washington, DC: The White House. Internet: http://www.whitehouse.gov/omb/inforeg/costbenefitreport.pdf.

Viscusi, W.K. (1978a). "Labor Market Valuations of Life and Limb: Empirical Evidence and Policy Implications," Public Policy 26(3), 359-386.

Viscusi, W.K. (1978b). "Wealth Effects and Earnings Premiums for Job Hazards," Review of Economics and Statistics 60(3), 408-416.

Viscusi, W.K. (1979). Employment Hazards: An Investigation of Market Performance. Cambridge, MA: Harvard University Press.

Viscusi, W.K. (1980). "Union, Labor Market Structure, and the Welfare Implications of the Quality of Work," Journal of Labor Research 1(1), 175-192.

Viscusi, W.K. (1981). "Occupational Safety and Health Regulation: Its Impact and Policy Alternatives." In J.P. Crecine (ed.), Research in Public Policy Analysis and Management. Greenwich, CT: JAI Press, vol. 2, 281-299.

Viscusi, W.K. (1983). Risk by Choice: Regulating Health and Safety in the Workplace. Cambridge, MA: Harvard University Press.

Viscusi, W.K. (1992a). Fatal Tradeoffs: Public and Private Responsibilities for Risk. New York: Oxford University Press.

Viscusi, W.K. (1992b). Wealth, Health Investments, and the Value of Life. Report prepared for the U.S. Office of Management and Budget, Washington, DC.

Viscusi, W.K. (1993). "The Value of Risks to Life and Health," Journal of Economic Literature 31, 1912-1946.

Viscusi, W.K. (1994a). "Mortality Effects of Regulatory Costs and Policy Evaluation Criteria," RAND Journal of Economics 25(1), 94-109. 
Viscusi, W.K. (1994b). "Risk-Risk Analysis," Journal of Risk and Uncertainty 8(1), 517.

Viscusi, W.K. (1998). Rational Risk Policy. New York: Oxford University Press.

Viscusi, W.K. (2000). "The Value of Life in Legal Contexts: Survey and Critique," American Law and Economics Review 2(1), 195-222.

Viscusi, W.K. and W. Evans. (1990). "Utility Functions that are Dependent on One's Health Status: Estimates and Economic Implications," American Economic Review 80, 353-374.

Viscusi, W.K., J.K. Hakes, and A. Carlin. (1997). "Measures of Mortality Risks," Journal of Risk and Uncertainty 14(3), 213-233.

Viscusi, W.K. and J. Hersch. (2001). "Cigarette Smokers as Job Risk Takers," Review of Economics and Statistics 83(2), 269-280.

Viscusi, W. K. and M.J. Moore. (1989). "Rates of Time Preference and Valuations of the Duration of Life," Journal of Public Economics 38, 297-317.

Viscusi, W.K. and C.J. O'Connor. (1984). "Adaptive Responses to Chemical Labeling: Are Workers Bayesian Decision Makers?” American Economic Review 74(5), 942-956.

Viscusi, W.K. and R.J. Zeckhauser. (1994). "The Fatality and Injury Costs of Expenditures," Journal of Risk and Uncertainty 8(1), 19-41.

Weiss, P., G. Maier, and S. Gerking. (1986). "The Economic Evaluation of Job Safety: A Methodological Survey and Some Estimates for Austria," Empirica 13(1), 53-67.

White, H. (1980). "A Heteroskedasticity-Consistent Covariance Matrix Estimator and a Direct Test for Heteroskedasticity," Econometrica 48(3), 817-830.

Wildavsky, A. (1980). "Richer is Safer," The Public Interest 60, 23-39.

Wildavsky, A. (1988). Searching for Safety. New Brunswick, NJ: Transaction Books. 
Figures and Tables 


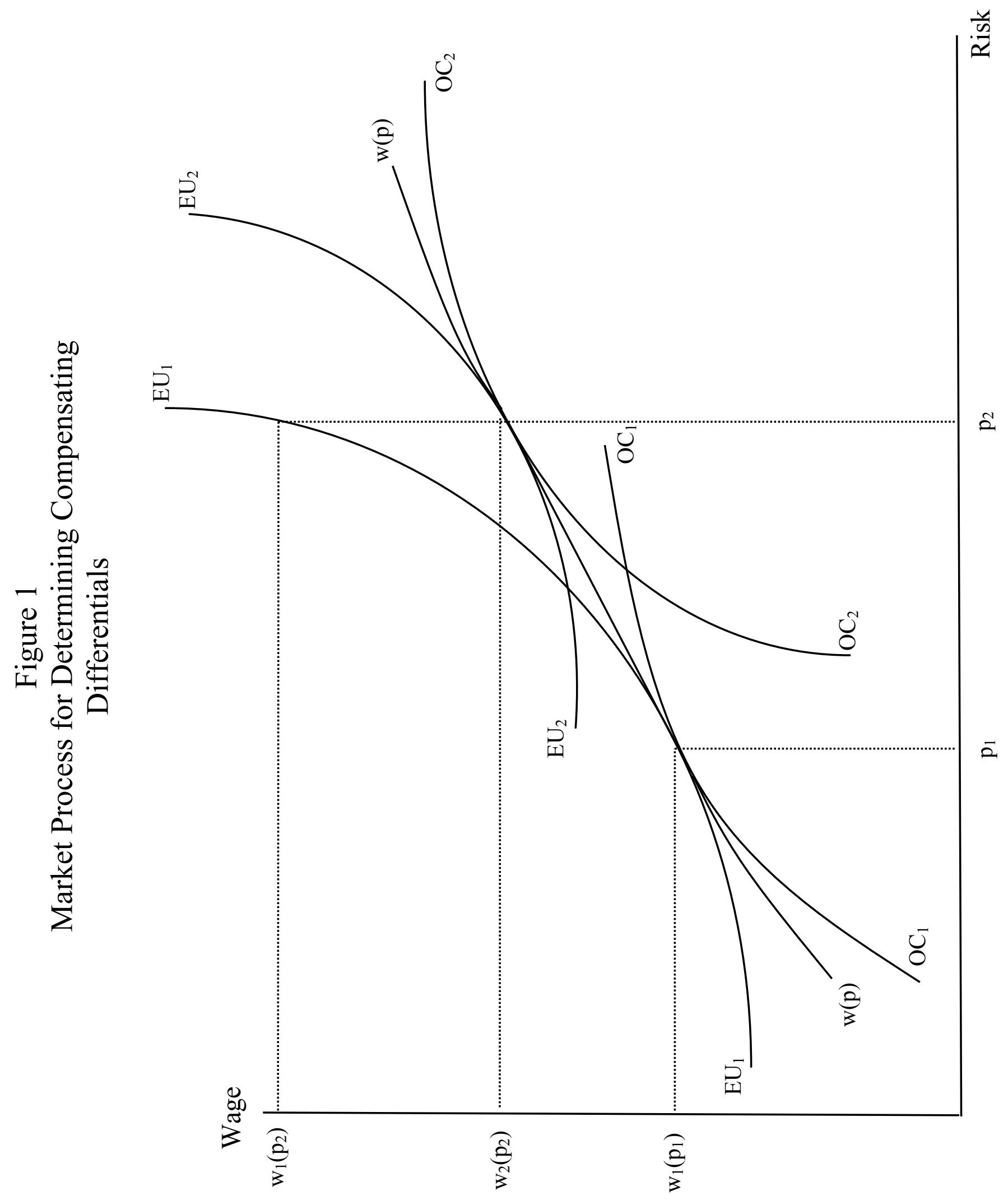




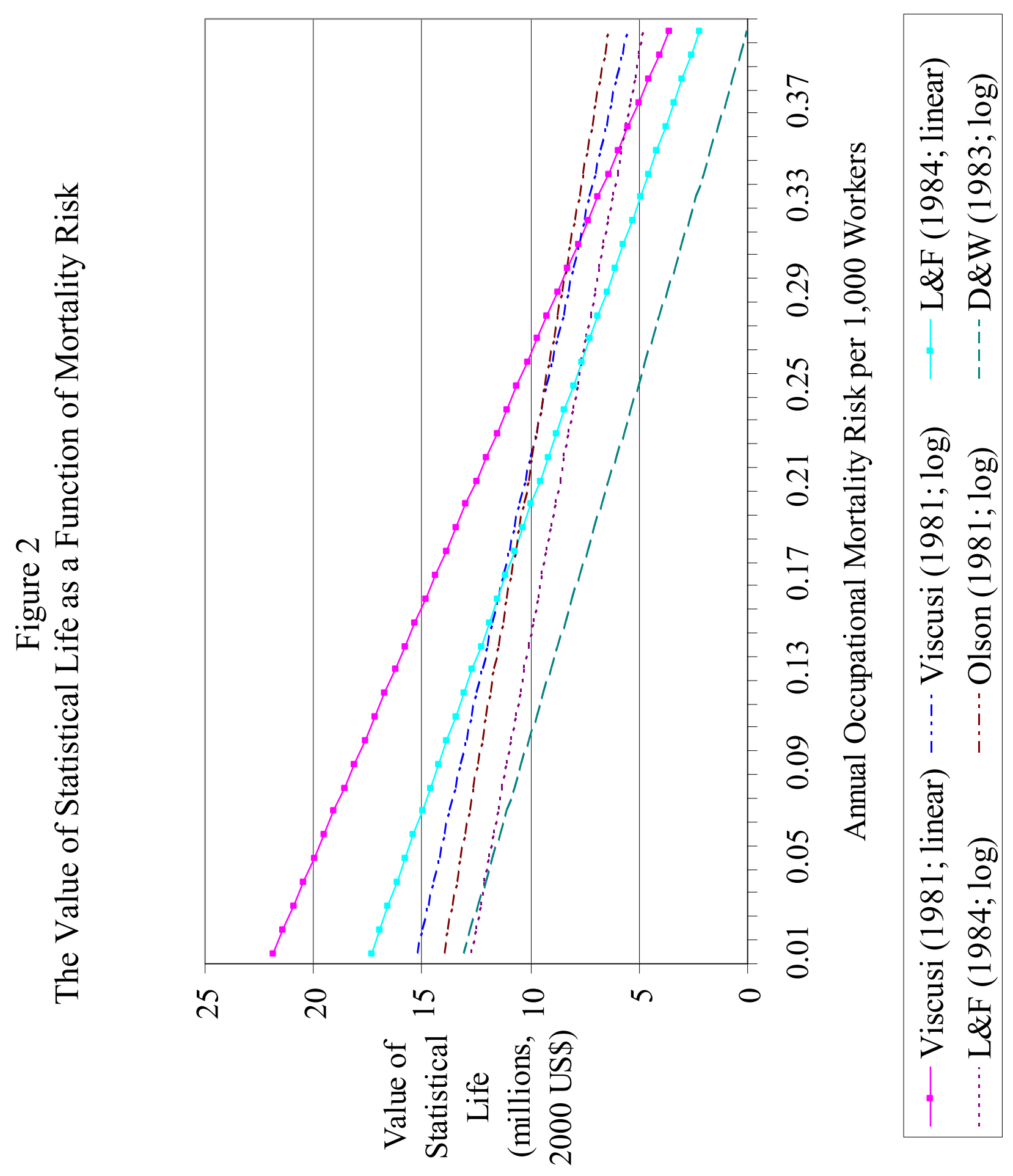




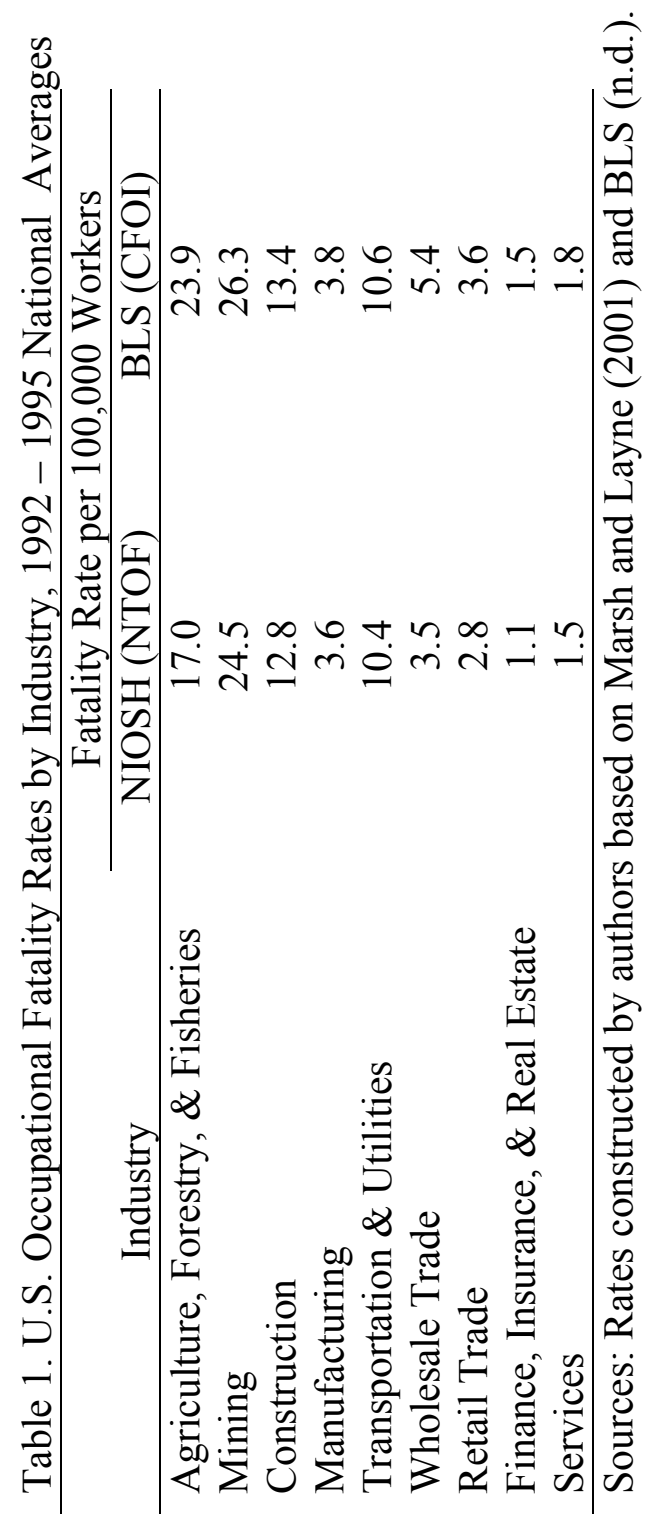




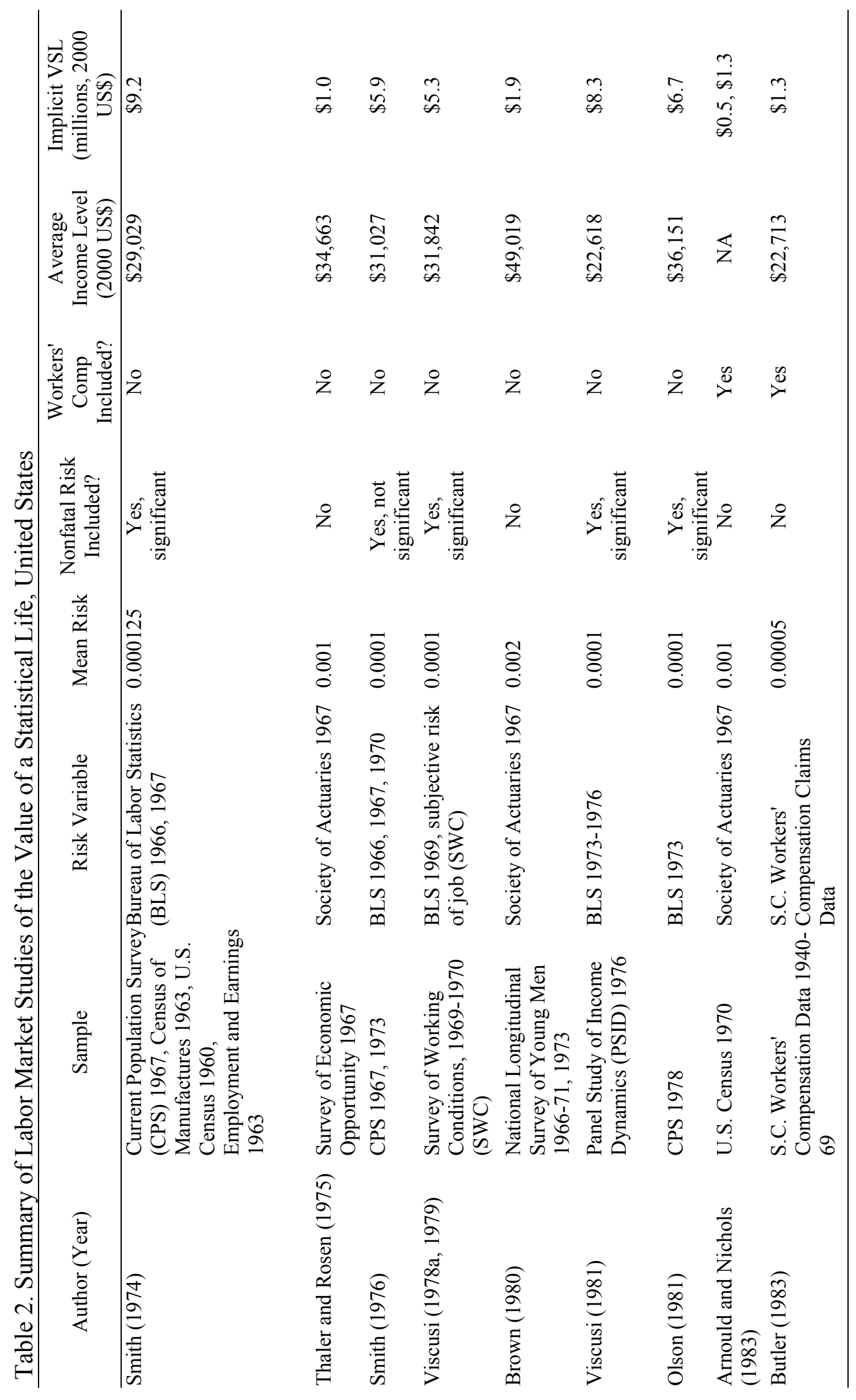




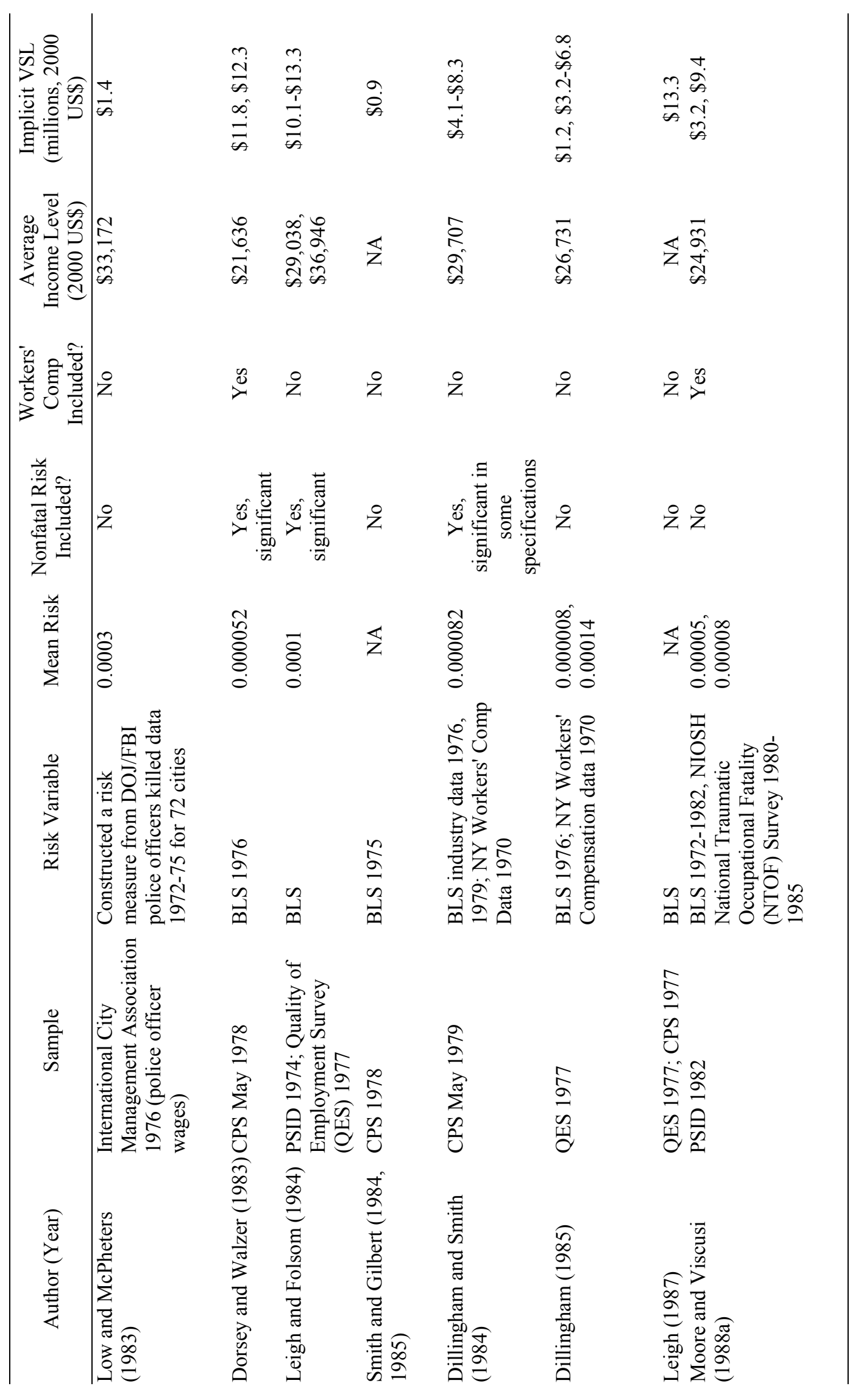




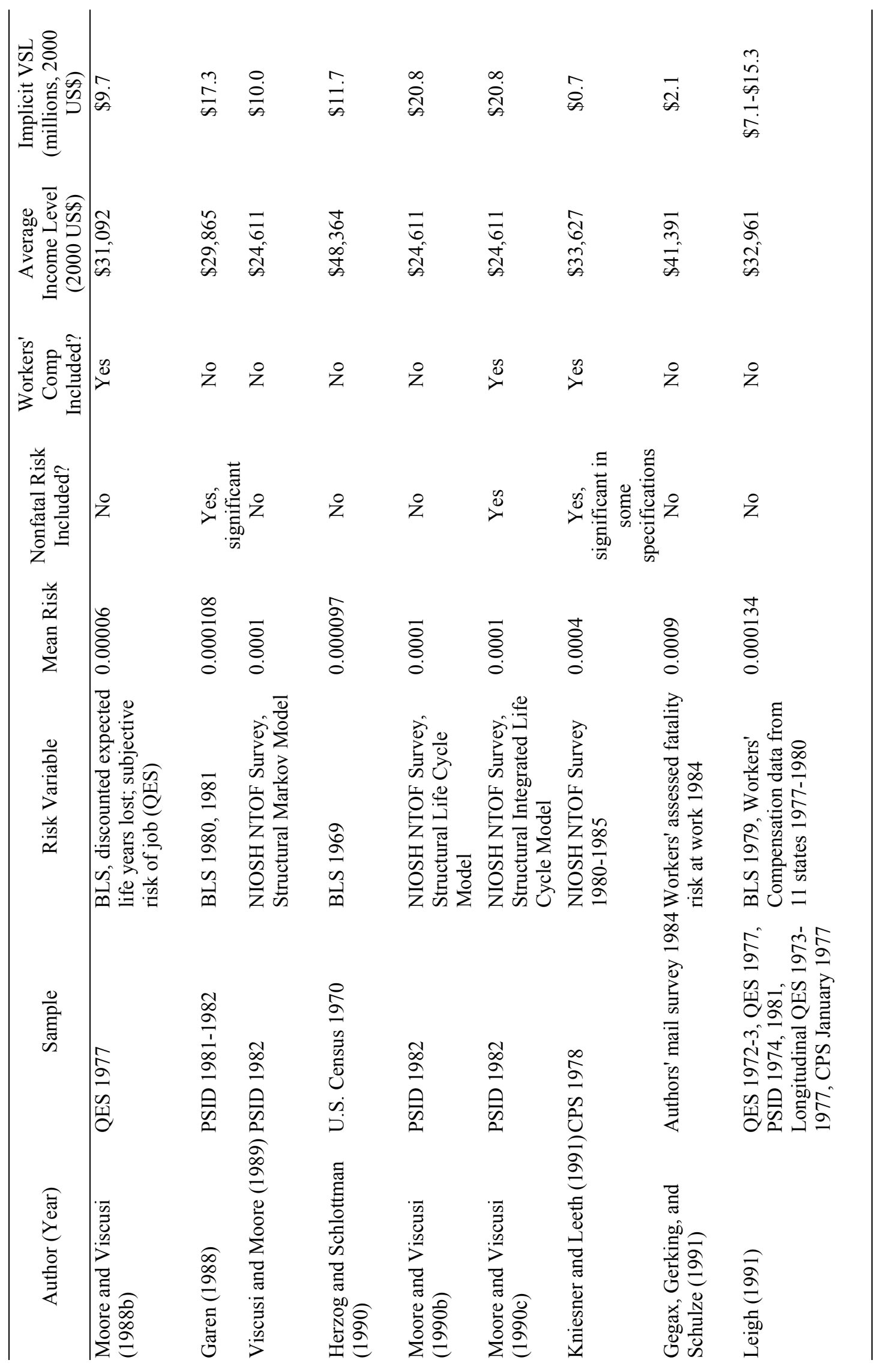




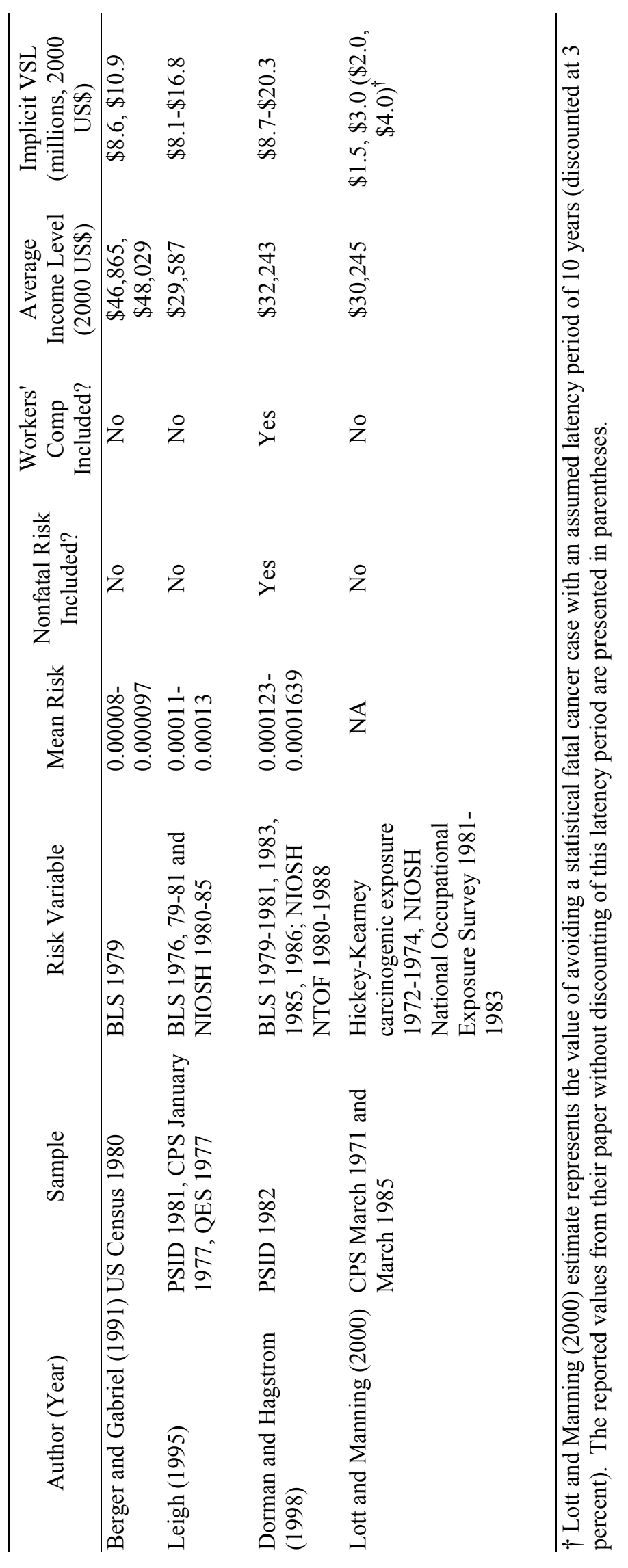




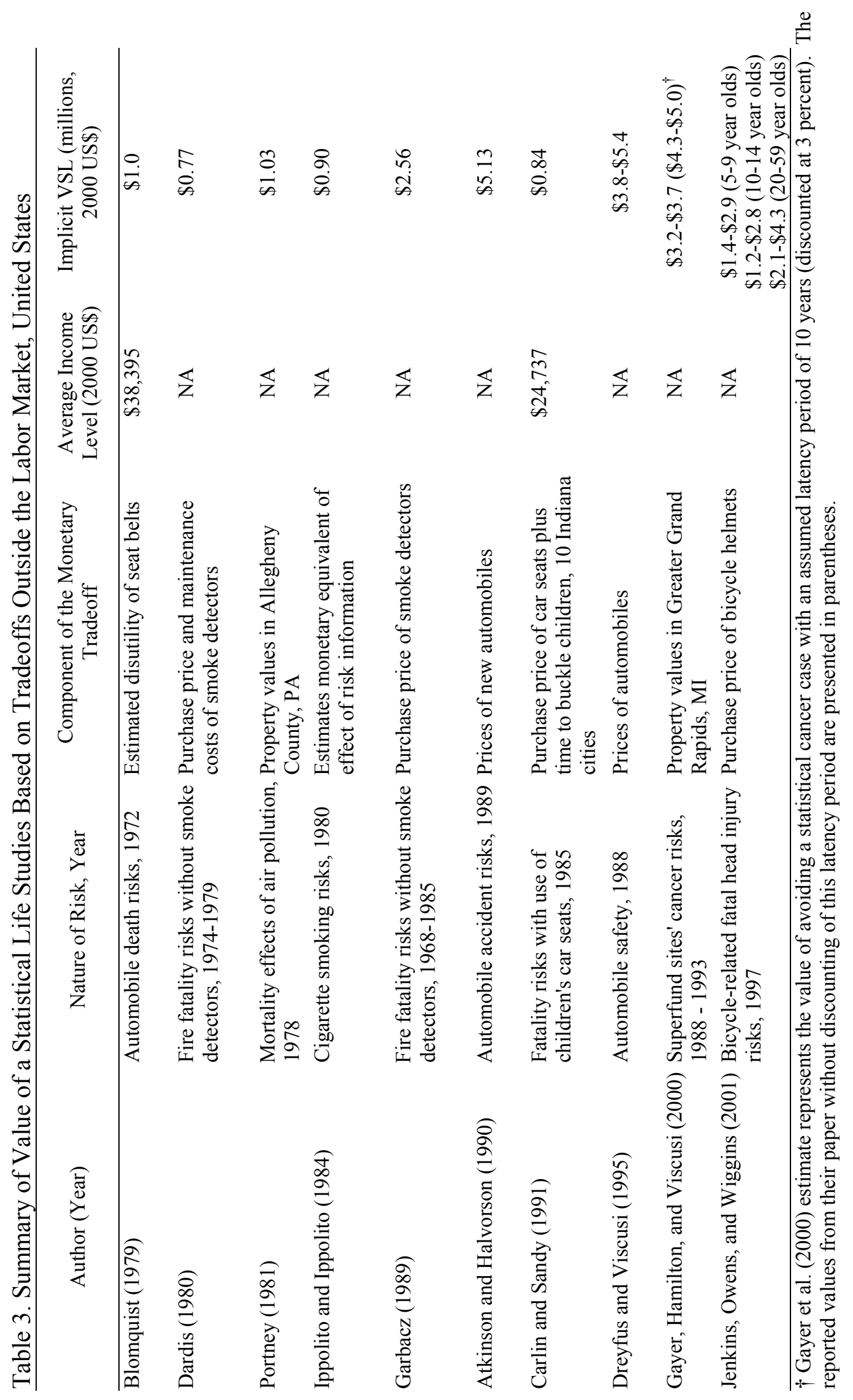




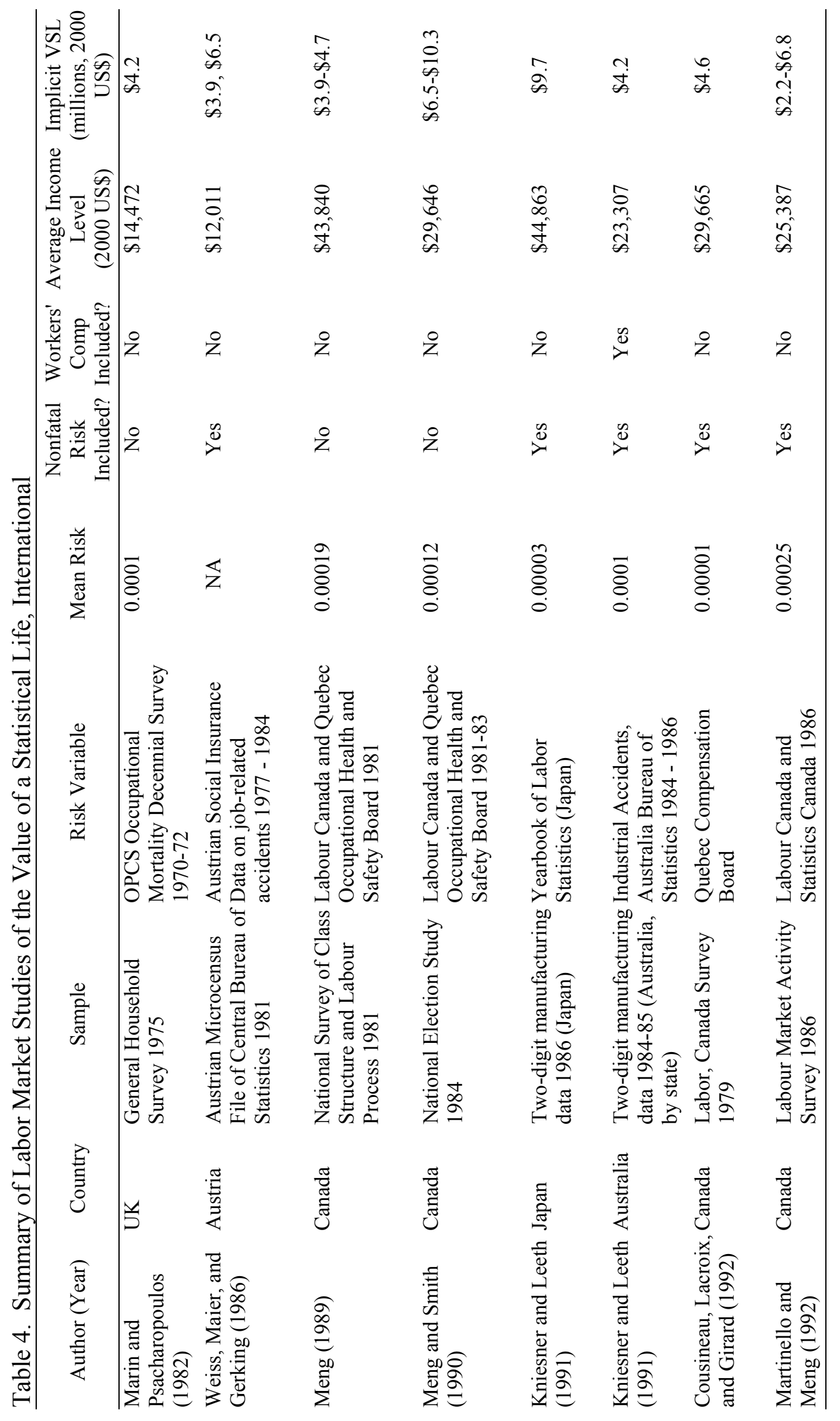




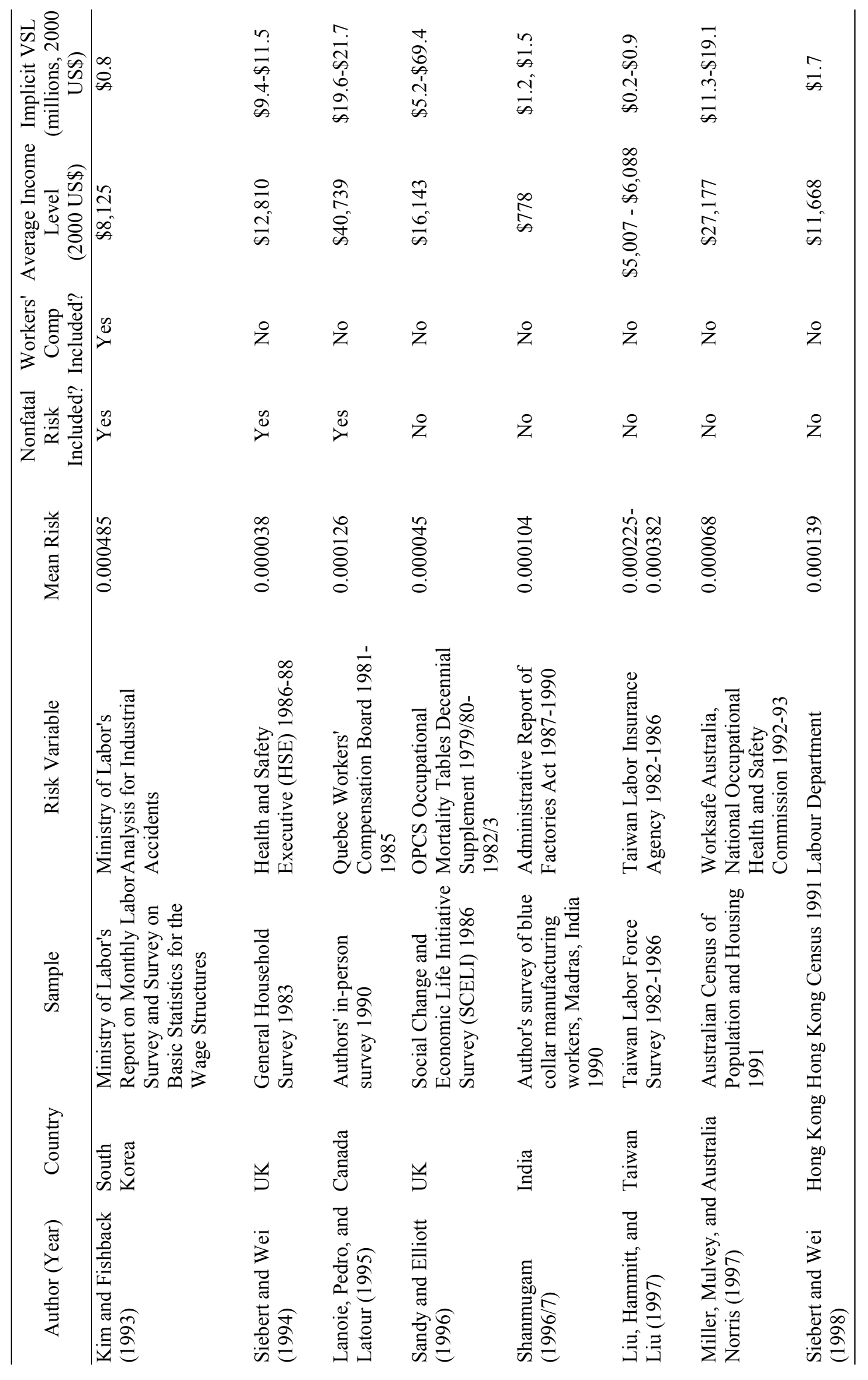




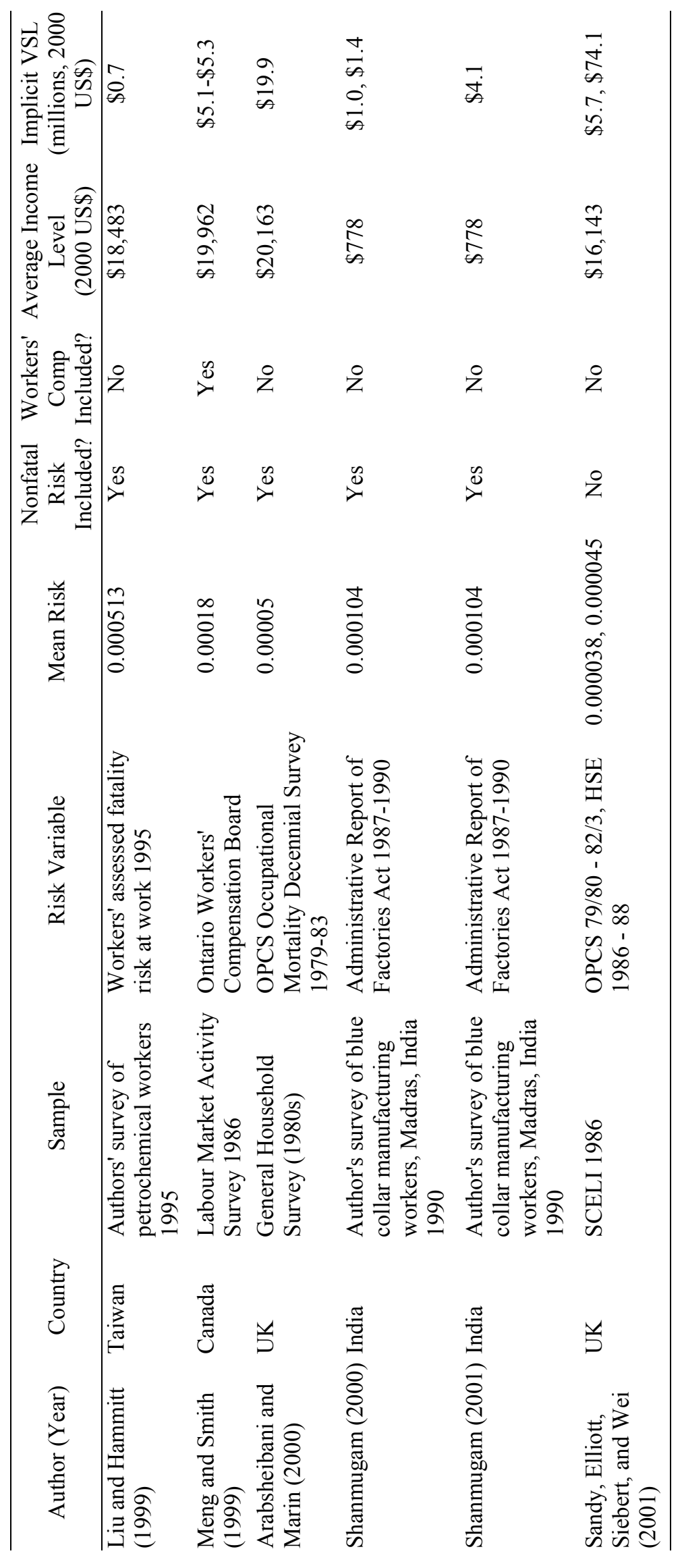




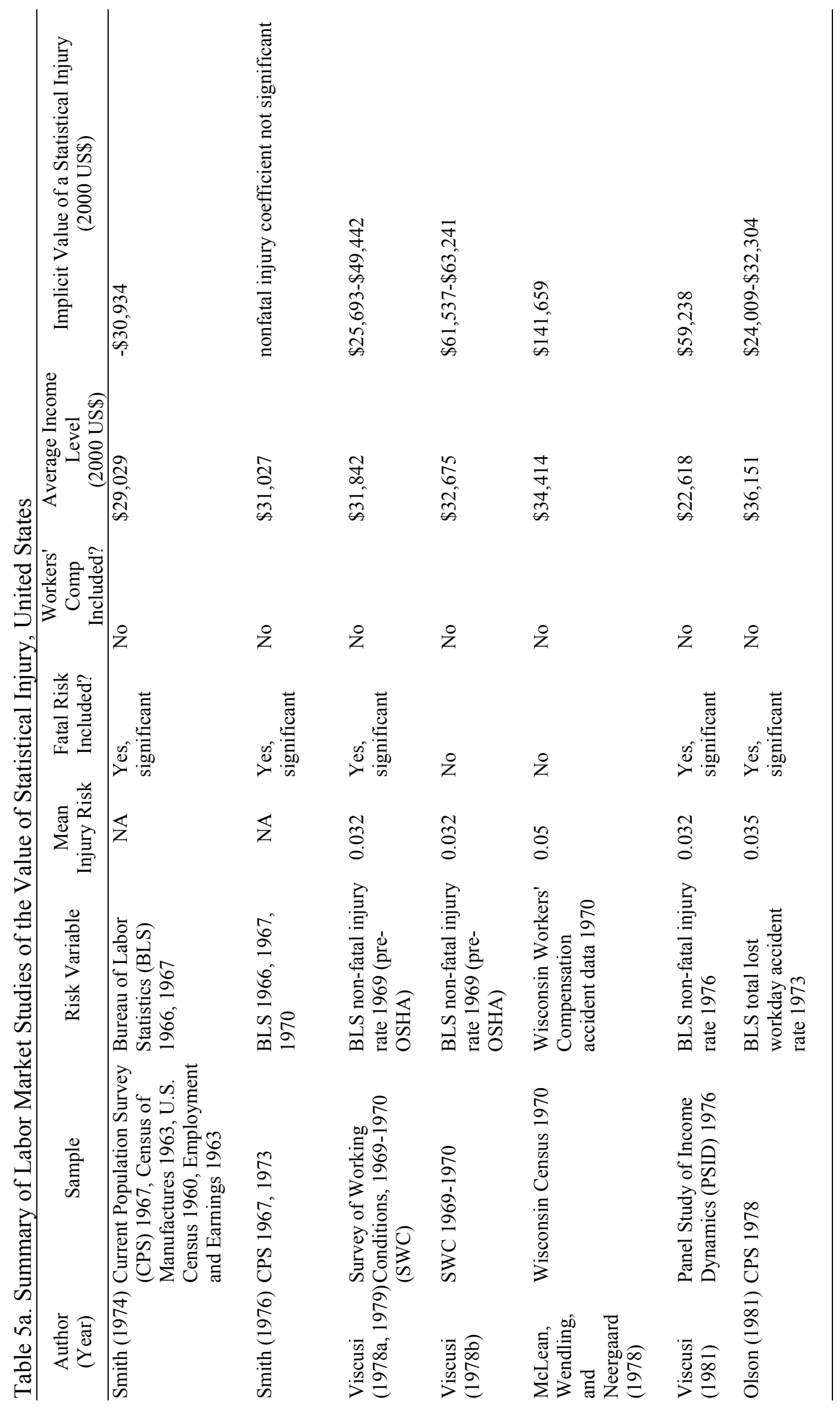




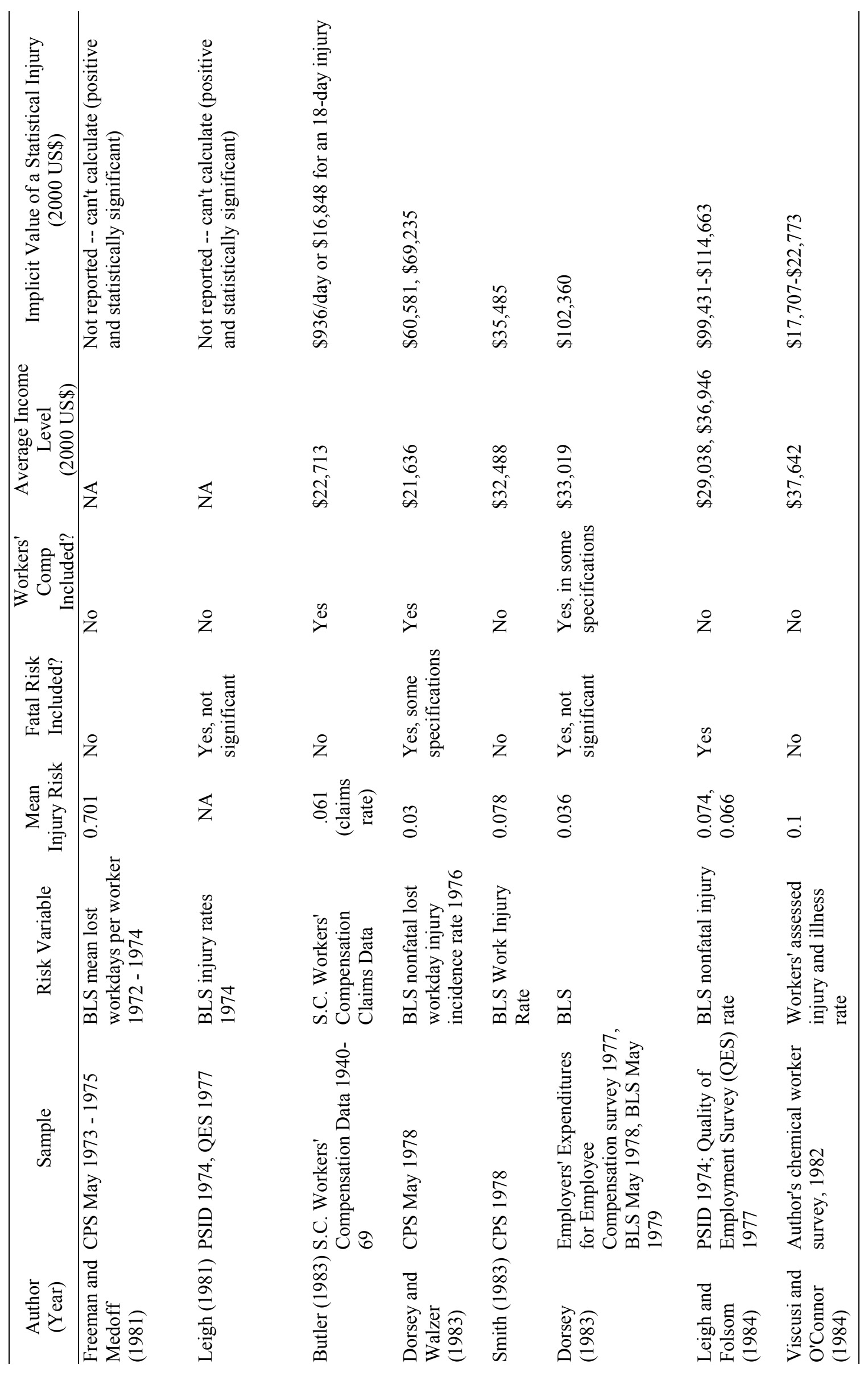




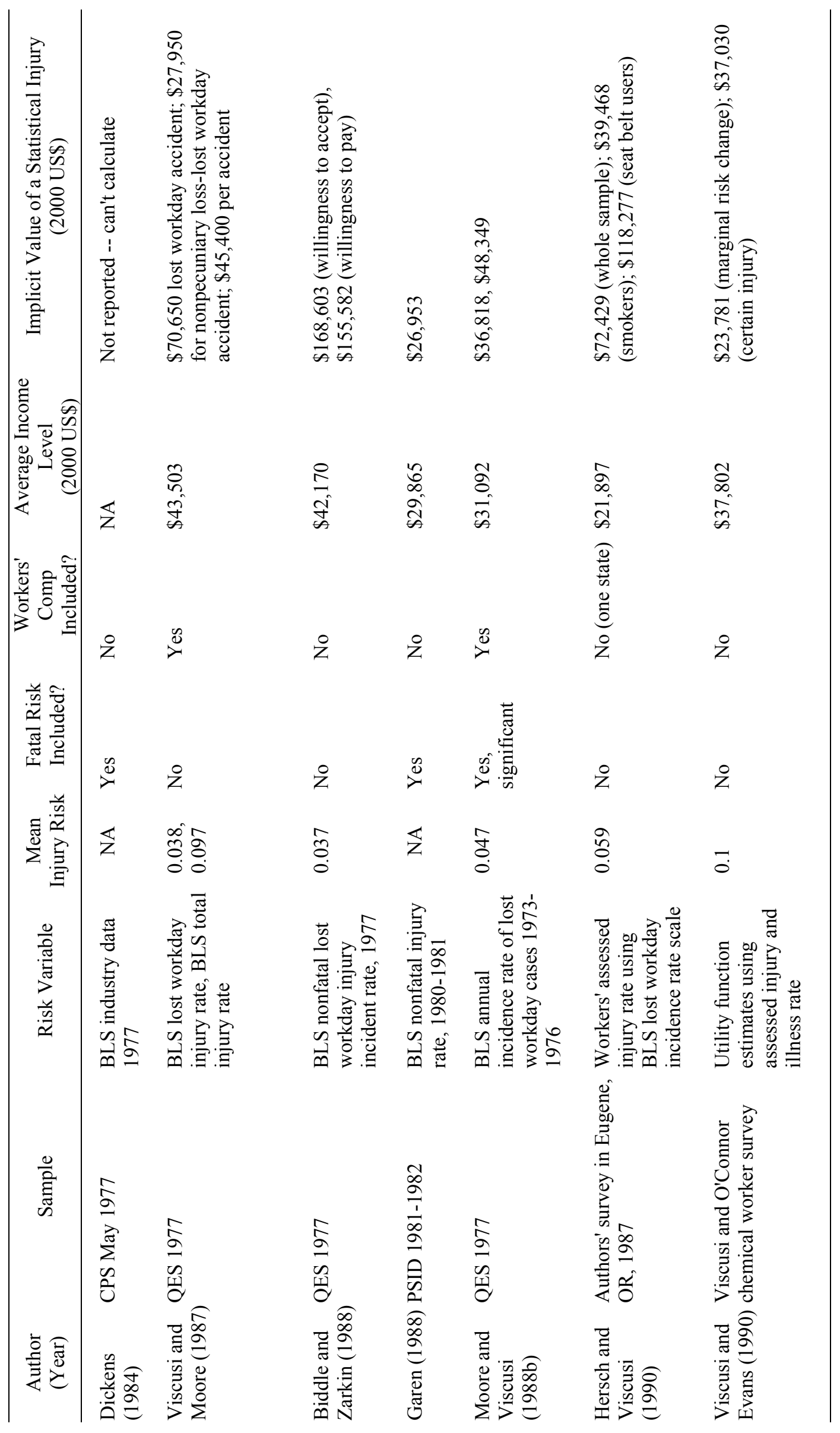




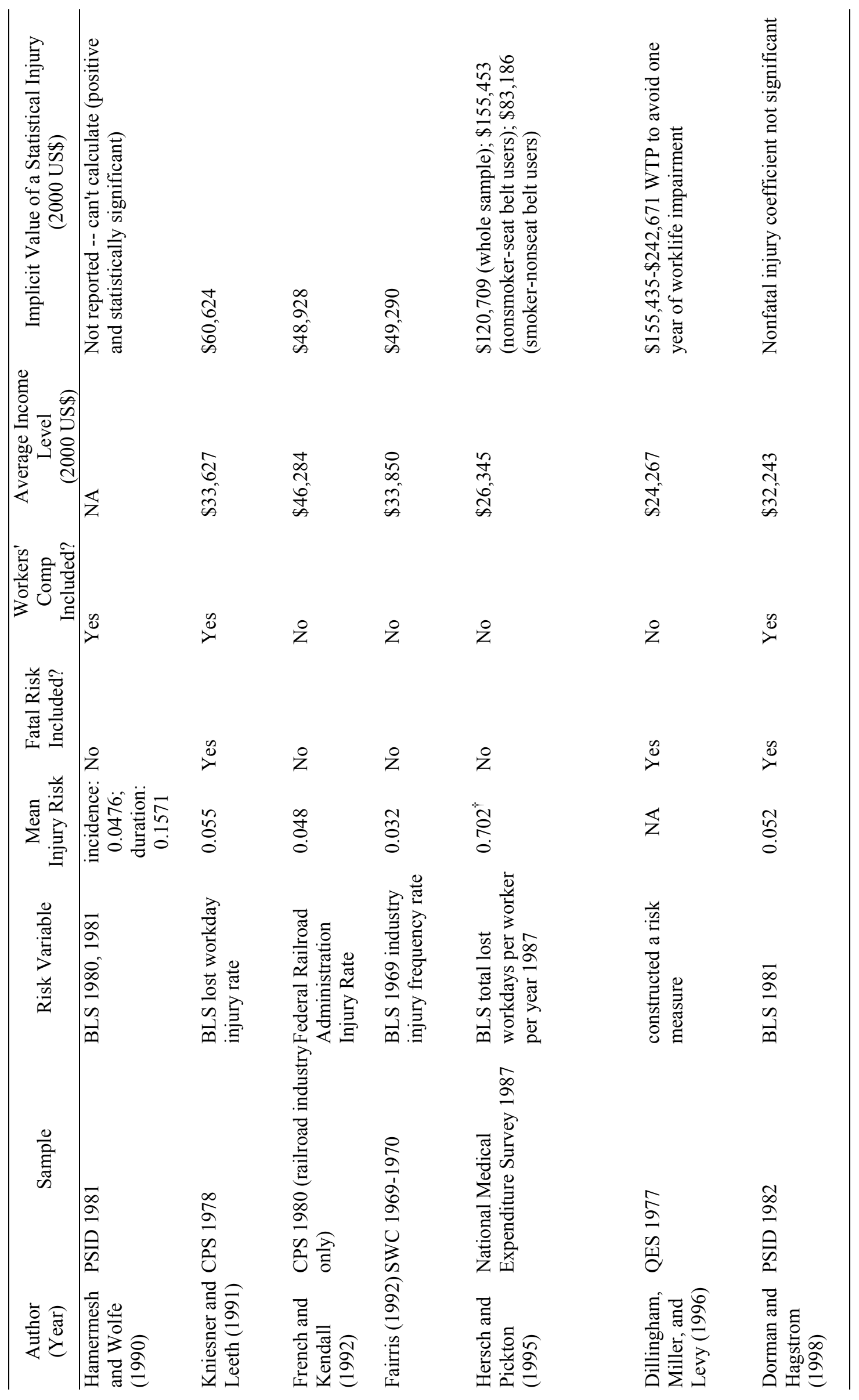

a 


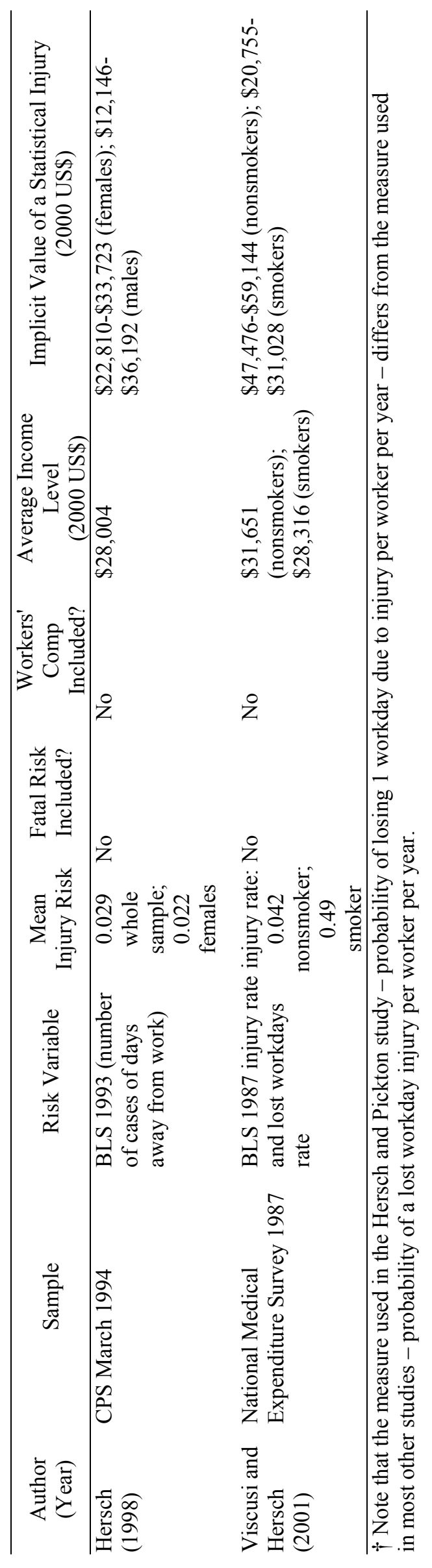




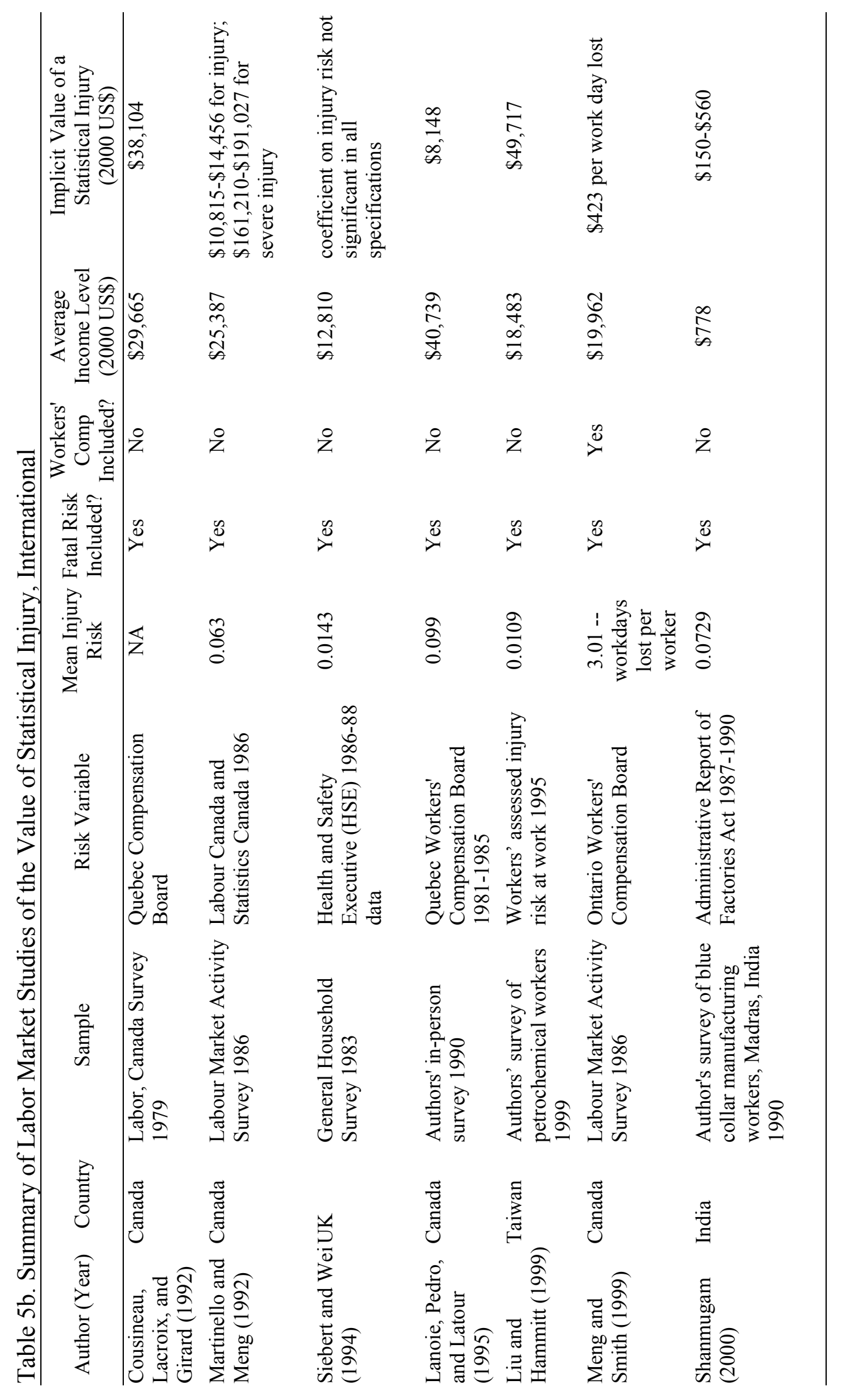




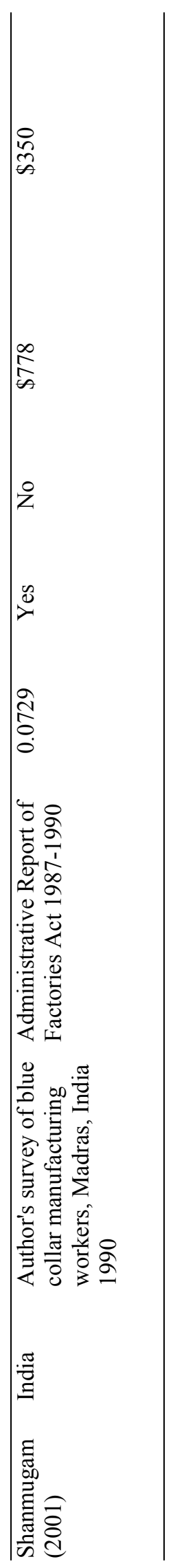

으 
Table 6. Replication of Published Meta-Analyses with Viscusi-Aldy Data

\begin{tabular}{|c|c|c|c|c|}
\hline Variable & $\begin{array}{l}\text { Viscusi-Aldy } \\
\text { Version of Liu } \\
\text { et al. (1997) } \\
\text { Equation } 2 \\
\text { (1) }\end{array}$ & $\begin{array}{c}\text { Viscusi-Aldy } \\
\text { Version of Miller } \\
\text { (2000) Model } 3 \\
\text { (2) } \\
\end{array}$ & $\begin{array}{c}\text { Viscusi-Aldy } \\
\text { Version of Bowland- } \\
\text { Beghin (2001) } \\
\text { Linear Model } \\
\text { (3) }\end{array}$ & $\begin{array}{c}\text { Viscusi-Aldy Version } \\
\text { of Mrozek-Taylor } \\
\text { (2002) Model } 2 \\
\text { (4) }\end{array}$ \\
\hline $\begin{array}{c}\text { Dependent } \\
\text { Variable }\end{array}$ & $\log (\mathrm{VSL})$ & $\log (\mathrm{VSL})$ & $\begin{array}{l}\text { VSL (Expressed in } \\
\text { Per Hour Terms) }\end{array}$ & $\log (\mathrm{VSL})$ \\
\hline $\log ($ Income $)$ & $\begin{array}{c}0.51^{*} \\
(0.15)\end{array}$ & $\begin{array}{c}0.53^{*} \\
(0.17)\end{array}$ & - & - \\
\hline Income & - & - & $\begin{array}{l}0.078^{* *} \\
(0.031)\end{array}$ & - \\
\hline Hourly Wage & - & - & - & $\begin{array}{c}0.040 \\
(0.026)\end{array}$ \\
\hline Mean Risk & $\begin{array}{l}-0.015^{*} \\
(0.0057)\end{array}$ & - & $\begin{array}{c}-19.34 * * \\
(8.56)\end{array}$ & $\begin{array}{l}-0.16^{* * *} \\
(0.075)\end{array}$ \\
\hline $\begin{array}{l}\text { Mean Risk } \\
\text { Squared }\end{array}$ & - & - & - & $\begin{array}{c}0.0019 \\
(0.0015)\end{array}$ \\
\hline $\begin{array}{l}\text { Union } \mathrm{x} \\
\text { Mean Risk }\end{array}$ & - & - & - & $\begin{array}{l}0.22 * * * \\
(0.11)\end{array}$ \\
\hline $\begin{array}{l}\text { Dillingham } \\
\text { Risk }\end{array}$ & - & - & - & $\begin{array}{l}-0.32 \\
(0.58)\end{array}$ \\
\hline $\begin{array}{l}\text { Society of } \\
\text { Actuaries Risk }\end{array}$ & - & $\begin{array}{l}-1.29 * \\
(0.28)\end{array}$ & - & - \\
\hline BLS Risk & - & - & $\begin{array}{l}1445.18^{* *} \\
(591.47)\end{array}$ & - \\
\hline NIOSH Risk & - & - & - & $\begin{array}{c}0.27 \\
(0.40)\end{array}$ \\
\hline $\begin{array}{l}\text { Education } \\
\text { Level }\end{array}$ & - & - & $\begin{array}{l}-157.14 \\
(192.32)\end{array}$ & - \\
\hline $\begin{array}{l}\text { Unemployment } \\
\text { Rate }\end{array}$ & - & - & - & $\begin{array}{c}0.045 \\
(0.048)\end{array}$ \\
\hline $\begin{array}{l}\text { U.S. National } \\
\text { Data }\end{array}$ & - & - & - & $\begin{array}{c}0.31 \\
(0.82)\end{array}$ \\
\hline $\begin{array}{l}\text { Non-U.S. } \\
\text { Study }\end{array}$ & - & - & - & $\begin{array}{l}-0.0048 \\
(0.81)\end{array}$ \\
\hline Union VSL & - & - & $\begin{array}{r}2995.05^{*} \\
(1086.09)\end{array}$ & $\begin{array}{l}-0.42 \\
(0.90)\end{array}$ \\
\hline $\begin{array}{l}\text { Union Dummy } \\
\text { Variable }\end{array}$ & - & - & $\begin{array}{l}1000.76 \\
(638.37)\end{array}$ & $\begin{array}{c}0.43 \\
(0.40)\end{array}$ \\
\hline
\end{tabular}




\begin{tabular}{|c|c|c|c|c|}
\hline Variable & $\begin{array}{l}\text { Viscusi-Aldy } \\
\text { Version of Liu } \\
\text { et al. (1997) } \\
\text { Equation } 2 \\
\text { (1) }\end{array}$ & $\begin{array}{c}\text { Viscusi-Aldy } \\
\text { Version of Miller } \\
\text { (2000) Model } 3 \\
\text { (2) } \\
\end{array}$ & $\begin{array}{c}\text { Viscusi-Aldy } \\
\text { Version of Bowland- } \\
\text { Beghin (2001) } \\
\text { Linear Model } \\
\text { (3) }\end{array}$ & $\begin{array}{l}\text { Viscusi-Aldy Version } \\
\text { of Mrozek-Taylor } \\
\text { (2002) Model } 2 \\
\text { (4) }\end{array}$ \\
\hline $\begin{array}{l}\text { Dependent } \\
\text { Variable }\end{array}$ & $\log (\mathrm{VSL})$ & $\log (\mathrm{VSL})$ & $\begin{array}{l}\text { VSL (Expressed in } \\
\text { Per Hour Terms) }\end{array}$ & $\log (\mathrm{VSL})$ \\
\hline $\begin{array}{l}\text { Male Only } \\
\text { Sample }\end{array}$ & - & - & $\begin{array}{l}-588.20 \\
(600.82)\end{array}$ & - \\
\hline $\begin{array}{l}\text { Blue Collar } \\
\text { Sample }\end{array}$ & - & - & $\begin{array}{l}-812.78 \\
(644.54)\end{array}$ & $\begin{array}{l}-0.68 \\
(0.49)\end{array}$ \\
\hline Quadratic Risk & - & - & - & $\begin{array}{c}0.54 \\
(0.33)\end{array}$ \\
\hline $\begin{array}{l}\text { Morbidity } \\
\text { Variable } \\
\text { Included }\end{array}$ & - & - & - & $\begin{array}{c}0.11 \\
(0.32)\end{array}$ \\
\hline $\begin{array}{l}\log (\text { Dependent } \\
\text { Variable })\end{array}$ & - & - & - & $\begin{array}{l}-0.24 \\
(0.36)\end{array}$ \\
\hline $\begin{array}{l}\text { Regional } \\
\text { Dummy } \\
\text { Variable }\end{array}$ & - & - & $\begin{array}{l}-757.70 \\
(601.16)\end{array}$ & $\begin{array}{c}0.16 \\
(0.35)\end{array}$ \\
\hline $\begin{array}{l}\text { Urban Dummy } \\
\text { Variable }\end{array}$ & - & - & $\begin{array}{c}-65.91 \\
(804.50)\end{array}$ & $\begin{array}{c}0.12 \\
(0.41)\end{array}$ \\
\hline $\begin{array}{l}\text { Workers' } \\
\text { Compensation }\end{array}$ & - & - & - & $\begin{array}{c}0.10 \\
(0.45)\end{array}$ \\
\hline $\begin{array}{l}\text { Wage in After } \\
\text { Tax Terms }\end{array}$ & - & - & - & $\begin{array}{l}-0.29 \\
(0.50)\end{array}$ \\
\hline $\begin{array}{l}\text { Industry } \\
\text { Dummy } \\
\text { Variable }\end{array}$ & - & - & - & $\begin{array}{r}0.081 \\
(0.27)\end{array}$ \\
\hline $\begin{array}{l}\text { Occupation } \\
\text { Dummy } \\
\text { Variable }\end{array}$ & - & - & - & $\begin{array}{l}0.0039 \\
(0.20)\end{array}$ \\
\hline $\begin{array}{l}\text { No Occupation } \\
\text { Dummy } \\
\text { Variable }\end{array}$ & - & $\begin{array}{c}0.48 \\
(0.33)\end{array}$ & - & - \\
\hline $\begin{array}{l}\text { Job } \\
\text { Characteristics } \\
\text { Dummy } \\
\text { Variable }\end{array}$ & - & - & - & $\begin{array}{l}-0.021 \\
(0.51)\end{array}$ \\
\hline Constant & $\begin{array}{l}10.56^{*} \\
(1.49)\end{array}$ & $\begin{array}{r}9.80 * \\
(1.78)\end{array}$ & $\begin{array}{c}1935.54 \\
(1506.92)\end{array}$ & $\begin{array}{l}15.68 * \\
(1.39)\end{array}$ \\
\hline
\end{tabular}




\begin{tabular}{ccccc}
\hline Variable & $\begin{array}{c}\text { Viscusi-Aldy } \\
\text { Version of Liu } \\
\text { et al. (1997) } \\
\text { Equation 2 } \\
(1)\end{array}$ & $\begin{array}{c}\text { Viscusi-Aldy } \\
\text { Version of Miller } \\
(2000) \text { Model 3 }\end{array}$ & $\begin{array}{c}\text { Viscusi-Aldy } \\
\text { Version of Bowland- } \\
\text { Beghin (2001) } \\
\text { Linear Model } \\
(3)\end{array}$ & $\begin{array}{c}\text { Viscusi-Aldy Version } \\
\text { of Mrozek-Taylor } \\
\text { (2002) Model 2 }\end{array}$ \\
\hline $\begin{array}{c}\text { Dependent } \\
\text { Variable }\end{array}$ & $\log (\mathrm{VSL})$ & $\log$ (VSL) & $\begin{array}{c}\text { VSL (Expressed in } \\
\text { Per Hour Terms) }\end{array}$ & $\begin{array}{c}\log (\mathrm{VSL}) \\
\mathrm{R}^{2}\end{array}$ \\
$\mathrm{n}$ & 0.37 & 0.27 & - & 0.83 \\
\hline $\mathrm{n}$ & 46 & 49 & 45 & 41 \\
\hline
\end{tabular}

Specifications (1), (2), and (4) estimated with ordinary least squares.

Specification (3) estimated with robust regression with Huber weights.

Robust (White) standard errors are presented in parentheses for specifications (1), (2), and (4).

Asymptotic standard errors presented in parentheses for specification (3).

* Indicates statistical significance at 1 percent level.

** Indicates statistical significance at 5 percent level.

*** Indicates statistical significance at 10 percent level. 
Table 7. Income Elasticity of Willingness-to-Pay to Reduce Mortality Risk

\begin{tabular}{lcc}
\hline \multicolumn{1}{c}{ Paper (Model) } & $\begin{array}{c}\text { Reported Elasticity in } \\
\text { Authors' Papers }\end{array}$ & Viscusi-Aldy Version \\
\hline $\begin{array}{l}\text { Liu et al. (1997) } \\
\text { (Equation 2) }\end{array}$ & 0.53 & $0.51^{*}$ \\
& & $(0.21-0.80)$ \\
$\begin{array}{l}\text { Miller (2000) } \\
\text { (Model 3) }\end{array}$ & $0.89^{*}$ & $0.53^{*}$ \\
$\begin{array}{l}\text { Mrozek and Taylor (2002) } \\
\text { (Model 2) }\end{array}$ & $0.46^{* *}$ & $(0.20-0.86)$ \\
Bowland and Beghin (2001) & & 0.52 \\
(Linear Model) & $1.66^{*}$ & $(-0.18-1.22)$ \\
\end{tabular}

* Indicates elasticity is based on coefficient that is statistically significant at 1 percent level.

** Indicates elasticity is based on coefficient that is statistically significant at 5 percent level.

Ranges in parentheses represent the 95 percent confidence interval around the point estimate for the income elasticity. 
Table 8. Regression Models for Viscusi-Aldy Meta-Analysis

\begin{tabular}{|c|c|c|c|c|c|c|}
\hline Variable & (1) & (2) & (3) & (4) & (5) & (6) \\
\hline $\begin{array}{c}\text { Regression } \\
\text { Technique }\end{array}$ & OLS & OLS & OLS & $\begin{array}{c}\text { Robust with } \\
\text { Huber weights }\end{array}$ & $\begin{array}{c}\text { Robust with } \\
\text { Huber weights }\end{array}$ & $\begin{array}{c}\text { Robust with } \\
\text { Huber weights }\end{array}$ \\
\hline $\log$ (Income) & $\begin{array}{c}0.51^{*} \\
(0.15)\end{array}$ & $\begin{array}{l}0.49^{*} \\
(0.13)\end{array}$ & $\begin{array}{c}0.60^{*} \\
(0.16)\end{array}$ & $\begin{array}{l}0.48^{*} \\
(0.12)\end{array}$ & $\begin{array}{c}0.46^{*} \\
(0.11)\end{array}$ & $\begin{array}{c}0.47^{*} \\
(0.15)\end{array}$ \\
\hline Mean Risk & $\begin{array}{l}-0.015 * * \\
(0.0057)\end{array}$ & $\begin{array}{l}-0.053^{*} \\
(0.011)\end{array}$ & $\begin{array}{l}-0.045^{*} \\
(0.015)\end{array}$ & $\begin{array}{l}-0.029 * \\
(0.0061)\end{array}$ & $\begin{array}{l}-0.090^{*} \\
(0.018)\end{array}$ & $\begin{array}{l}-0.11^{*} \\
(0.029)\end{array}$ \\
\hline Mean Risk Squared & - & $\begin{array}{c}0.00022^{*} \\
(0.000052)\end{array}$ & $\begin{array}{c}0.00016^{*} \\
(0.000055)\end{array}$ & - & $\begin{array}{r}0.00065^{*} \\
(0.00019)\end{array}$ & $\begin{array}{r}0.0010^{* *} \\
(0.00035)\end{array}$ \\
\hline $\begin{array}{l}\text { Society of Actuaries } \\
\text { Risk }\end{array}$ & - & - & $\begin{array}{c}0.50 \\
(0.87)\end{array}$ & - & - & dropped \\
\hline NIOSH Risk & - & - & $\begin{array}{c}0.50 \\
(0.41)\end{array}$ & - & - & $\begin{array}{c}0.56 \\
(0.41)\end{array}$ \\
\hline Subjective & - & - & $\begin{array}{l}-0.69 \\
(0.78)\end{array}$ & - & - & $\begin{array}{l}-0.16 \\
(0.98)\end{array}$ \\
\hline $\begin{array}{l}\text { Union Dummy } \\
\text { Variable }\end{array}$ & - & - & $\begin{array}{c}0.44 \\
(0.32)\end{array}$ & - & - & $\begin{array}{c}0.50 \\
(0.30)\end{array}$ \\
\hline Male Only Sample & - & - & $\begin{array}{c}0.24 \\
(0.36)\end{array}$ & - & - & $\begin{array}{c}0.36 \\
(0.34)\end{array}$ \\
\hline Blue Collar Sample & - & - & $\begin{array}{l}-0.016 \\
(0.31)\end{array}$ & - & - & $\begin{array}{l}-0.23 \\
(0.33)\end{array}$ \\
\hline Quadratic Risk & - & - & $\begin{array}{c}0.092 \\
(0.27)\end{array}$ & - & - & $\begin{array}{c}0.20 \\
(0.34)\end{array}$ \\
\hline $\begin{array}{l}\text { Morbidity Variable } \\
\text { Included }\end{array}$ & - & - & $\begin{array}{l}0.55^{* * * *} \\
(0.30)\end{array}$ & - & - & $\begin{array}{l}0.62 * * \\
(0.30)\end{array}$ \\
\hline $\begin{array}{l}\log (\text { Dependent } \\
\text { Variable })\end{array}$ & - & - & $\begin{array}{c}0.17 \\
(0.31)\end{array}$ & - & - & $\begin{array}{c}0.13 \\
(0.41)\end{array}$ \\
\hline $\begin{array}{l}\text { Regional Dummy } \\
\text { Variable }\end{array}$ & - & - & $\begin{array}{l}-0.16 \\
(0.25)\end{array}$ & - & - & $\begin{array}{c}0.16 \\
(0.31)\end{array}$ \\
\hline $\begin{array}{l}\text { Urban Dummy } \\
\text { Variable }\end{array}$ & - & - & $\begin{array}{c}0.38 \\
(0.29)\end{array}$ & - & - & $\begin{array}{r}0.087 \\
(0.39)\end{array}$ \\
\hline $\begin{array}{l}\text { Workers' } \\
\text { Compensation }\end{array}$ & - & - & $\begin{array}{l}-0.57 \\
(0.33)\end{array}$ & - & - & $\begin{array}{l}-0.28 \\
(0.38)\end{array}$ \\
\hline $\begin{array}{l}\text { Industry Dummy } \\
\text { Variable }\end{array}$ & - & - & $\begin{array}{l}-0.46 \\
(0.27)\end{array}$ & - & - & $\begin{array}{l}-0.37 \\
(0.28)\end{array}$ \\
\hline $\begin{array}{l}\text { Occupation Dummy } \\
\text { Variable }\end{array}$ & - & - & $\begin{array}{l}-0.45 \\
(0.31)\end{array}$ & - & - & $\begin{array}{l}-0.24 \\
(0.33)\end{array}$ \\
\hline Constant & $\begin{array}{l}10.56^{*} \\
(1.49)\end{array}$ & $\begin{array}{l}11.22 * \\
(1.30)\end{array}$ & $\begin{array}{r}9.58^{*} \\
(1.82)\end{array}$ & $\begin{array}{l}11.05^{*} \\
(1.23)\end{array}$ & $\begin{array}{l}11.83 * \\
(1.12)\end{array}$ & $\begin{array}{l}11.22 * \\
(1.68)\end{array}$ \\
\hline $\mathrm{R}^{2}$ & 0.37 & 0.55 & 0.72 & - & - & - \\
\hline $\mathrm{n}$ & 46 & 46 & 46 & 45 & 45 & 44 \\
\hline $\begin{array}{l}\text { Income Elasticity } \\
\text { (95\% Confidence } \\
\text { Interval) }\end{array}$ & $\begin{array}{c}0.51 \\
(0.21-0.80)\end{array}$ & $\begin{array}{c}0.49 \\
(0.23-0.75)\end{array}$ & $\begin{array}{c}0.60 \\
(0.27-0.94)\end{array}$ & $\begin{array}{c}0.48 \\
(0.23-0.73)\end{array}$ & $\begin{array}{c}0.46 \\
(0.24-0.69)\end{array}$ & $\begin{array}{c}0.47 \\
(0.15-0.78)\end{array}$ \\
\hline $\begin{array}{l}\text { Mean Predicted VSL, } \\
\text { Full Sample (millions } \\
2000 \text { US\$) (95\% } \\
\text { Confidence Interval) }\end{array}$ & $\begin{array}{c}5.0 \\
(3.4-7.4)\end{array}$ & $\begin{array}{c}5.4 \\
(3.7-7.8)\end{array}$ & $\begin{array}{c}5.9 \\
(2.7-13.9)\end{array}$ & $\begin{array}{c}5.5 \\
(4.1-7.5)\end{array}$ & $\begin{array}{c}5.9 \\
(4.4-8.1)\end{array}$ & $\begin{array}{c}6.2 \\
(2.5-15.7)\end{array}$ \\
\hline $\begin{array}{l}\text { Mean Predicted VSL, } \\
\text { U.S. Sample (millions } \\
2000 \text { US\$) (95\% }\end{array}$ & $\begin{array}{c}5.5 \\
(3.8-8.1)\end{array}$ & $\begin{array}{c}5.8 \\
(4.1-8.3)\end{array}$ & $\begin{array}{c}6.9 \\
(3.1-16.2)\end{array}$ & $\begin{array}{c}6.1 \\
(4.6-8.2)\end{array}$ & $\begin{array}{c}6.3 \\
(4.8-8.4)\end{array}$ & $\begin{array}{c}7.6 \\
(3.0-19.4)\end{array}$ \\
\hline
\end{tabular}




\begin{tabular}{ccccccc}
\hline Variable & (1) & (2) & (3) & (4) & (5) & (6) \\
\hline $\begin{array}{c}\text { Regression } \\
\text { Technique }\end{array}$ & OLS & OLS & OLS & Robust with & Robust with & Robust with \\
Confidence Interval) & & & & & & \\
\hline Huber weights & Huber weights & Huber weights \\
\hline
\end{tabular}

Dependent variable: $\log (\mathrm{VSL})$

Robust (White) standard errors presented in parentheses for specifications $1-3$.

Asymptotic standard errors presented in parentheses for specifications $4-6$.

* Indicates statistical significance at 1 percent level.

** Indicates statistical significance at 5 percent level.

*** Indicates statistical significance at 10 percent level.

Note: Estimation with robust standard errors clustered by wage data source yields same significance levels, with the exception of Mean Risk in (1) and (3) and Mean Risk Squared in (3), which are all significant at the 2 percent level, and the industry dummy variable in (3) which is significant at the 8 percent level. 


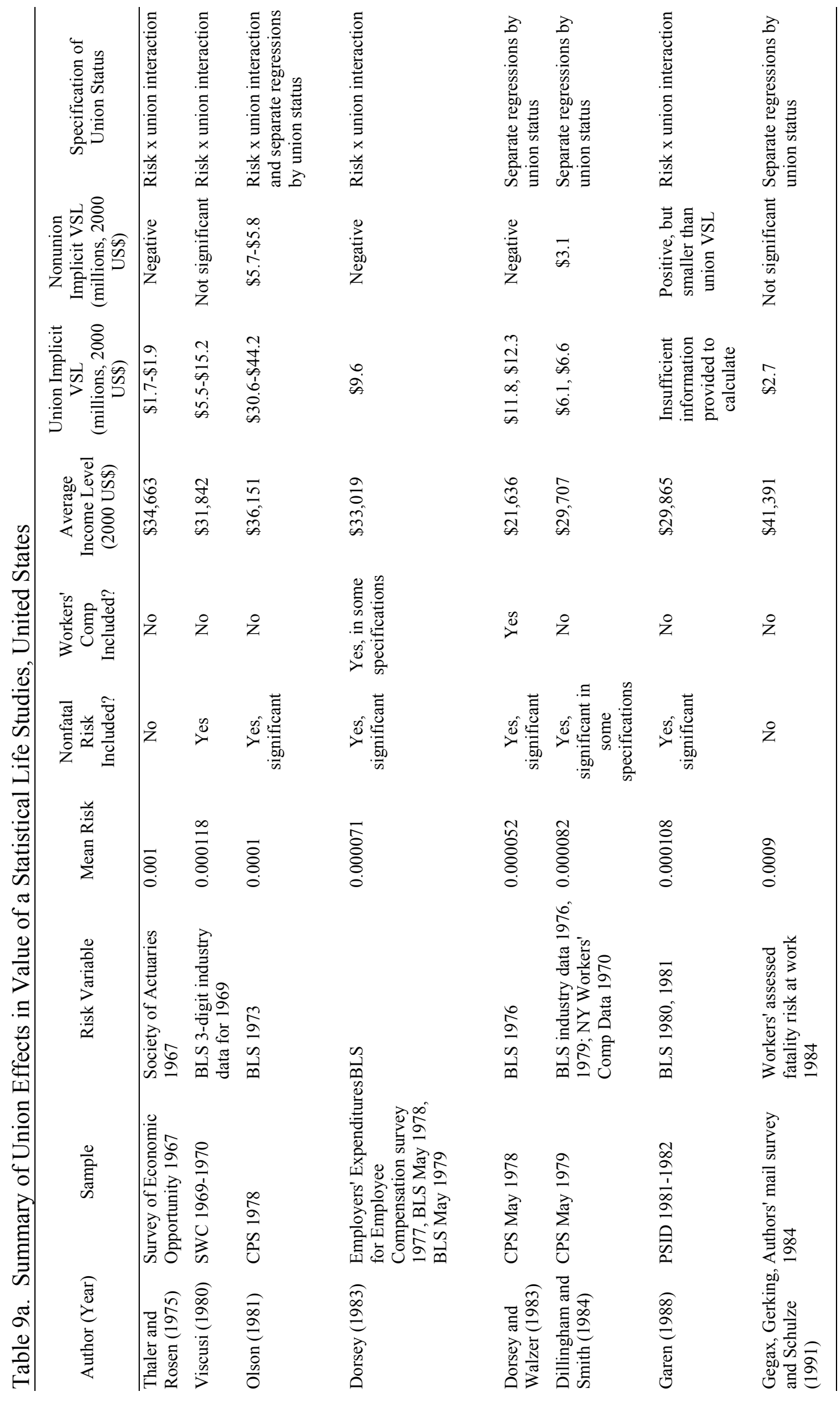




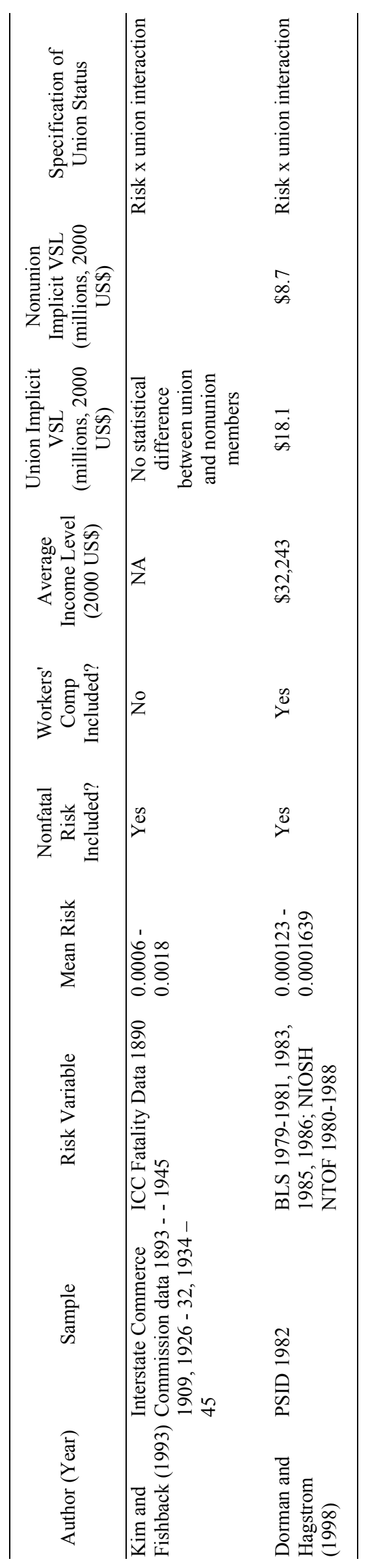

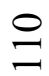 


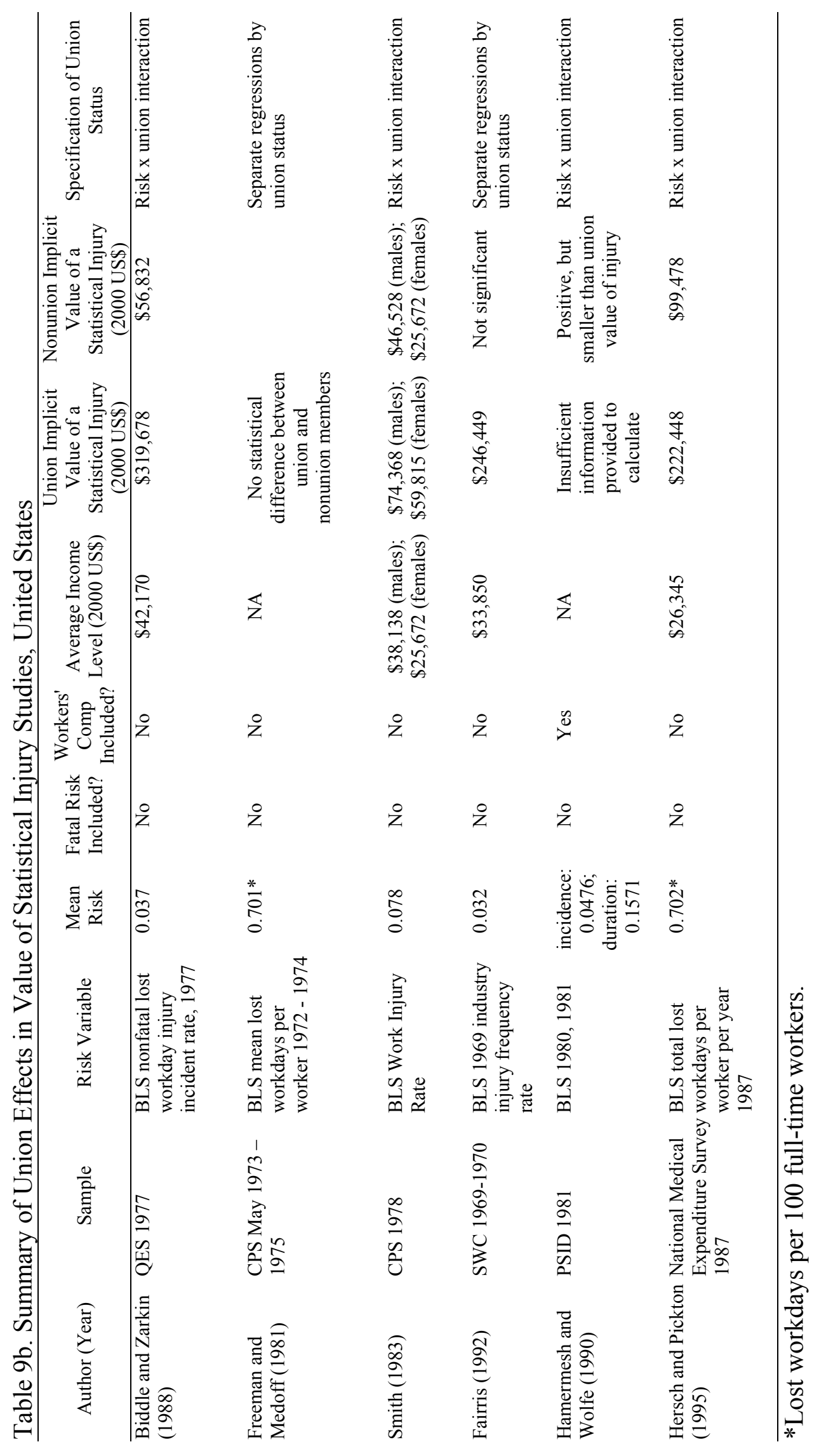




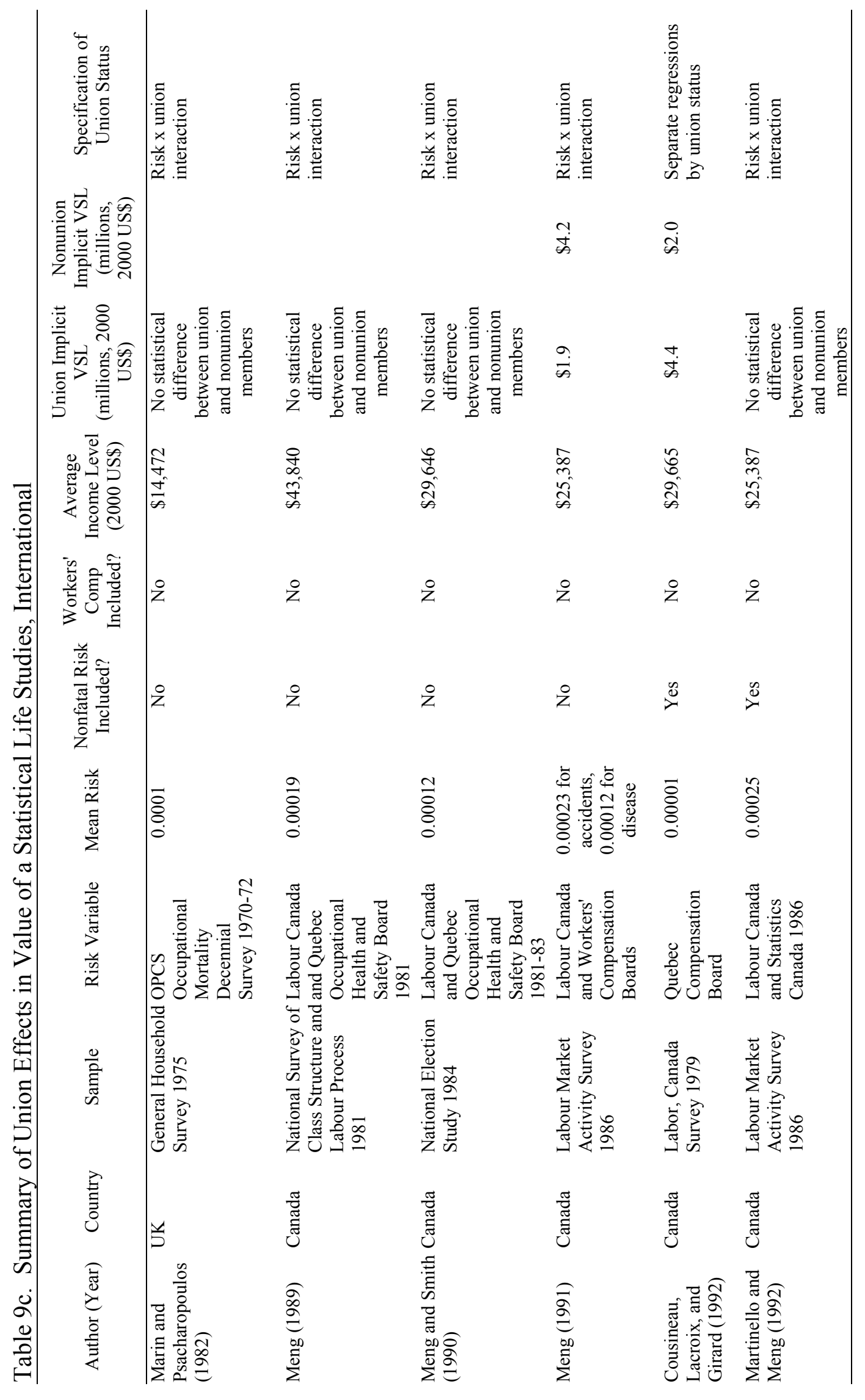




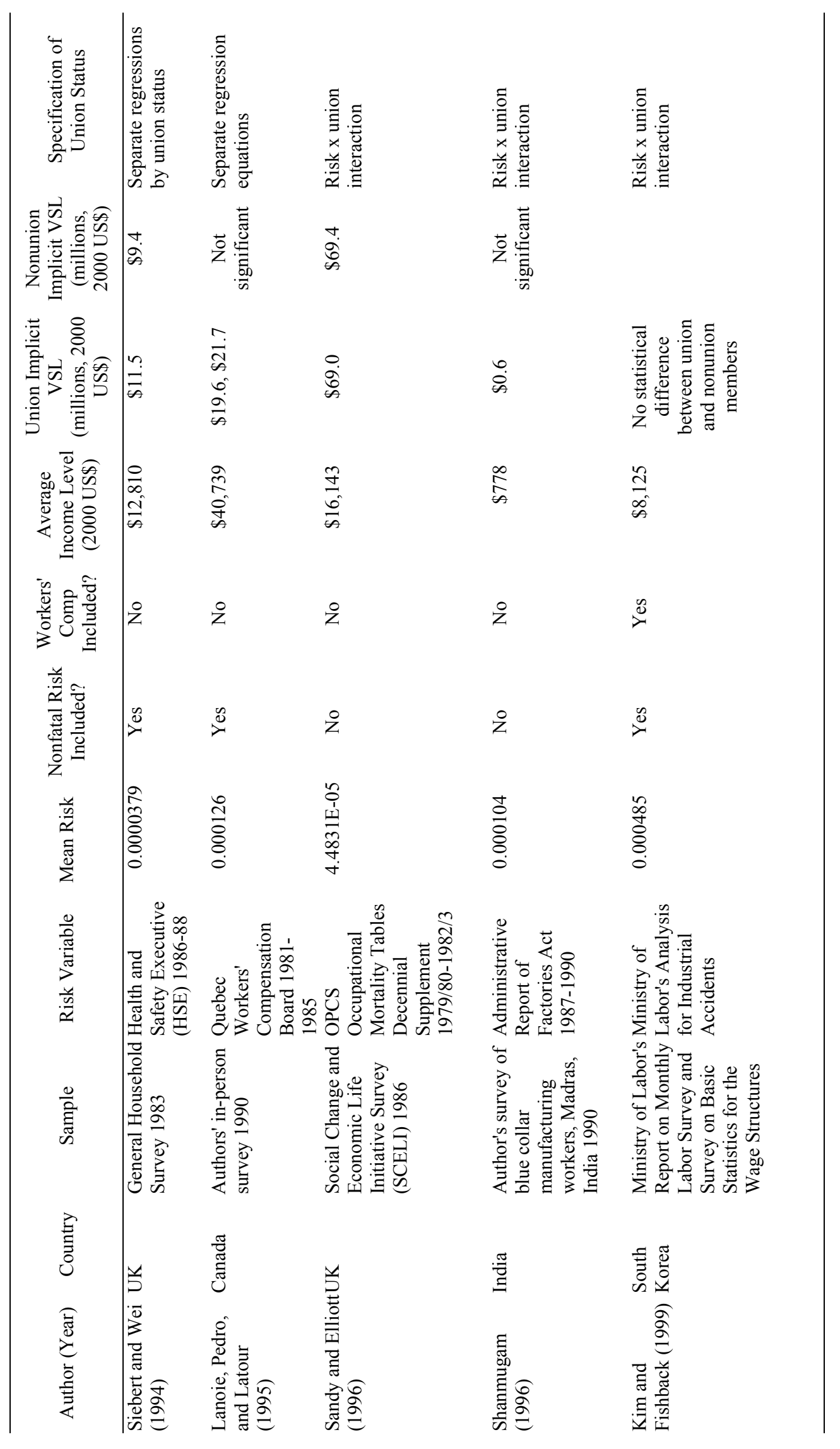




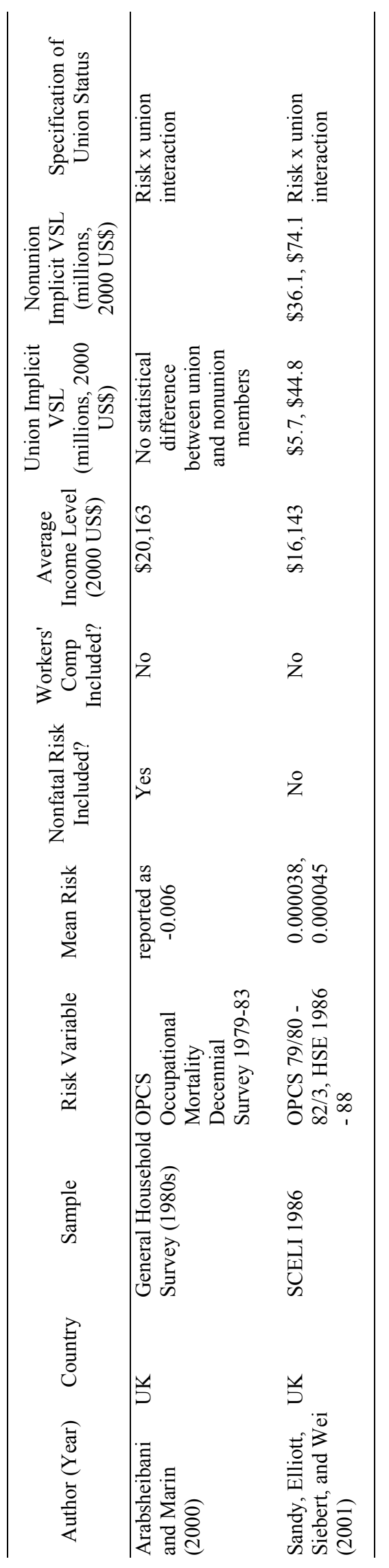




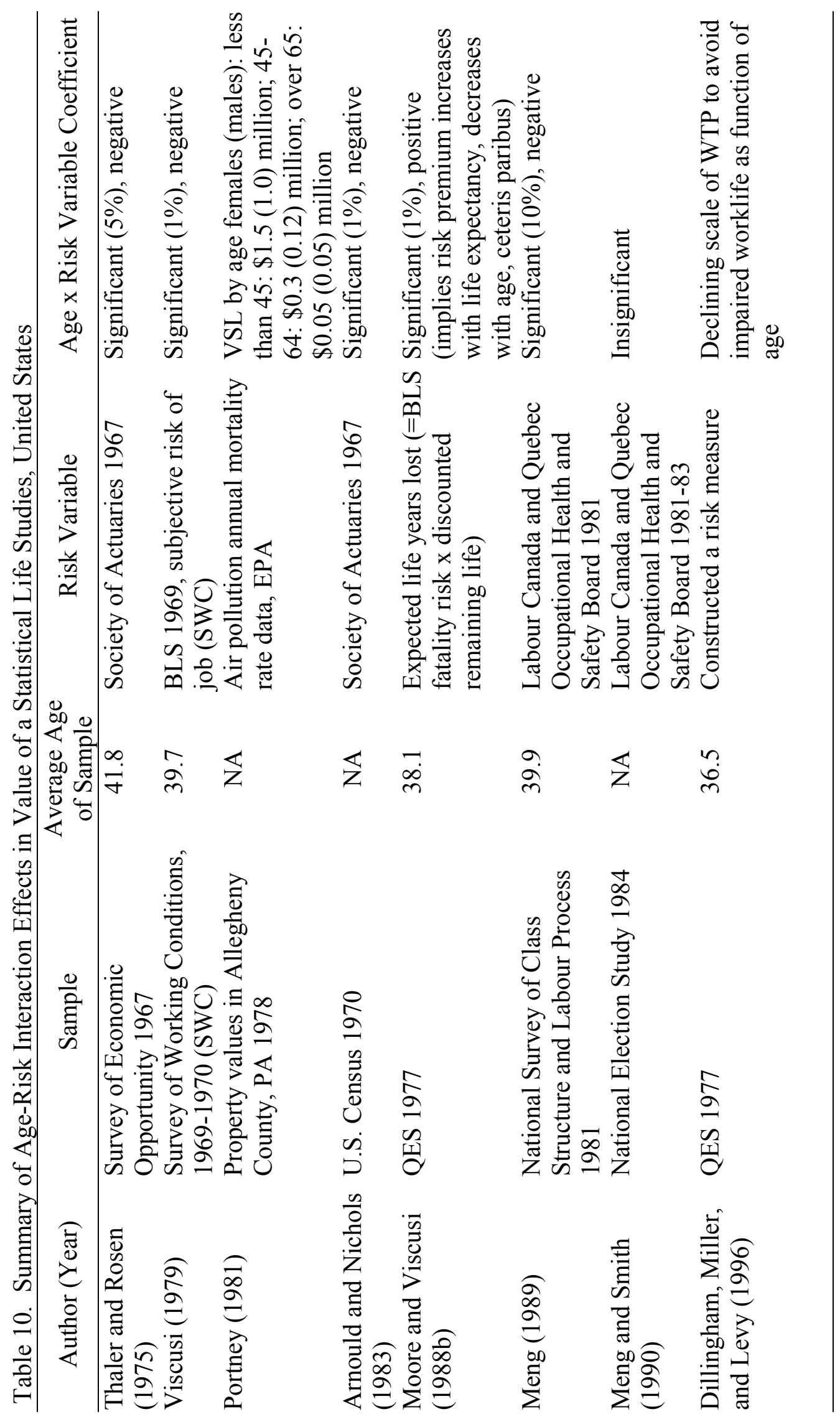




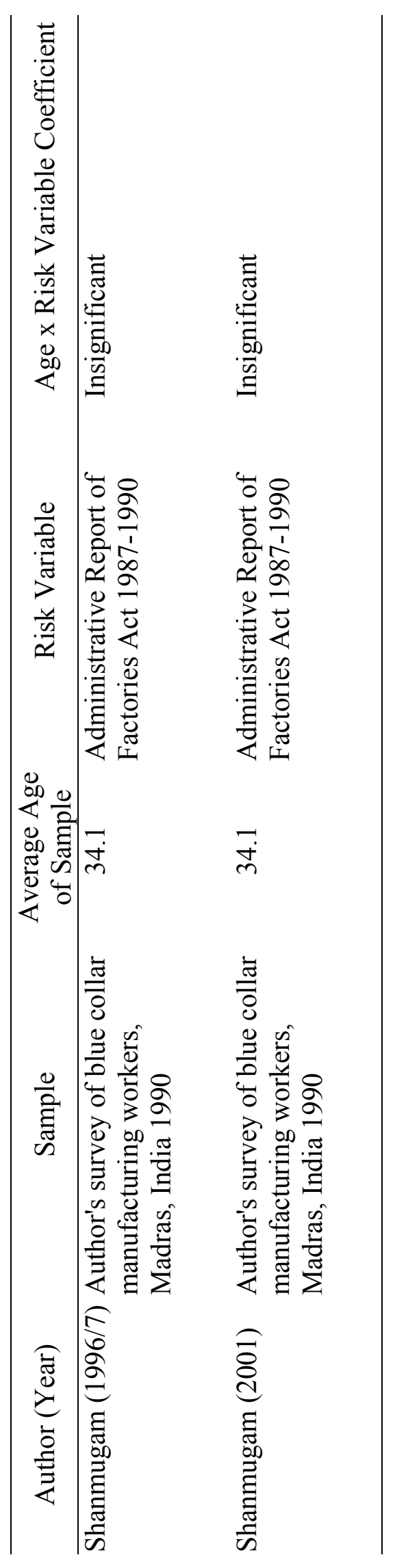

$\underline{=}$ 
Table 11. Summary of Imputed Discount Rate Studies, United States

\begin{tabular}{|c|c|c|c|c|}
\hline Year & Author (Year) & Type of Study & Sample & $\begin{array}{c}\text { Implicit } \\
\text { Discount Rate }\end{array}$ \\
\hline 1988 & $\begin{array}{l}\text { Moore and } \\
\text { Viscusi } \\
\text { (1988b) }\end{array}$ & $\begin{array}{l}\text { Labor Hedonic with } \\
\text { Reduced Form } \\
\text { Discounting Model }\end{array}$ & QES 1977 & $9.6 \%-12.2 \%$ \\
\hline 1989 & $\begin{array}{l}\text { Viscusi and } \\
\text { Moore (1989) }\end{array}$ & $\begin{array}{l}\text { Labor Hedonic with } \\
\text { Structural Markov } \\
\text { Model }\end{array}$ & PSID 1982 & $10.7 \%$ \\
\hline 1990 & $\begin{array}{l}\text { Moore and } \\
\text { Viscusi } \\
\text { (1990b) }\end{array}$ & $\begin{array}{l}\text { Labor Hedonic with } \\
\text { Structural Life Cycle } \\
\text { Model }\end{array}$ & PSID 1982 & $2 \%$ \\
\hline 1990 & $\begin{array}{l}\text { Moore and } \\
\text { Viscusi } \\
\text { (1990c) }\end{array}$ & $\begin{array}{l}\text { Labor Hedonic with } \\
\text { Structural Integrated } \\
\text { Life Cycle Model }\end{array}$ & PSID 1982 & $1.0 \%-14.2 \%$ \\
\hline 1995 & $\begin{array}{l}\text { Dreyfus and } \\
\text { Viscusi (1995) }\end{array}$ & Automobile Hedonic & $\begin{array}{l}1988 \text { Residential } \\
\text { Transportation Energy } \\
\text { Consumption Survey }\end{array}$ & $11 \%-17 \%$ \\
\hline
\end{tabular}


Table 12. Values of Statistical Life Used by U.S. Regulatory Agencies, $1985-2000^{*}$

\begin{tabular}{|c|c|c|c|}
\hline Year & Agency & Regulation & $\begin{array}{c}\text { Value of a } \\
\text { Statistical Life } \\
\text { (millions, 2000 \$) }\end{array}$ \\
\hline 1985 & $\begin{array}{l}\text { Federal Aviation } \\
\text { Administration }\end{array}$ & $\begin{array}{l}\text { Protective Breathing Equipment (50 Federal Register } \\
41452 \text { ) }\end{array}$ & $\$ 1.0 * *$ \\
\hline 1985 & $\begin{array}{l}\text { Environmental } \\
\text { Protection Agency }\end{array}$ & $\begin{array}{l}\text { Regulation of Fuels and Fuel Additives; Gasoline Lead } \\
\text { Content ( } 50 \text { FR 9400) }\end{array}$ & $\$ 1.7$ \\
\hline 1988 & $\begin{array}{l}\text { Federal Aviation } \\
\text { Administration }\end{array}$ & $\begin{array}{l}\text { Improved Survival Equipment for Inadvertent Water } \\
\text { Landings ( } 53 \text { FR 24890) }\end{array}$ & $\$ 1.5 * *$ \\
\hline 1988 & $\begin{array}{l}\text { Environmental } \\
\text { Protection Agency }\end{array}$ & Protection of Stratospheric Ozone (53 FR 30566) & $\$ 4.8$ \\
\hline 1990 & $\begin{array}{l}\text { Federal Aviation } \\
\text { Administration }\end{array}$ & $\begin{array}{l}\text { Proposed Establishment of the Harlingen Airport Radar } \\
\text { Service Area, TX ( } 55 \text { FR 32064) }\end{array}$ & $\$ 2.0 * *$ \\
\hline 1994 & $\begin{array}{l}\text { Food and Nutrition } \\
\text { Service (USDA) }\end{array}$ & $\begin{array}{l}\text { National School Lunch Program and School Breakfast } \\
\text { Program (59 FR 30218) }\end{array}$ & $\$ 1.7, \$ 3.5^{* *}$ \\
\hline 1995 & $\begin{array}{l}\text { Consumer Product } \\
\text { Safety Commission }\end{array}$ & $\begin{array}{l}\text { Multiple Tube Mine and Shell Fireworks Devices ( } 60 \\
\text { FR 34922) }\end{array}$ & $\$ 5.6 * *$ \\
\hline 1996 & $\begin{array}{l}\text { Food Safety } \\
\text { Inspection Service } \\
\text { (USDA) }\end{array}$ & $\begin{array}{l}\text { Pathogen Reduction; Hazard Analysis and Critical } \\
\text { Control Point Systems (61 FR 38806) }\end{array}$ & $\$ 1.9$ \\
\hline 1996 & $\begin{array}{l}\text { Food and Drug } \\
\text { Administration }\end{array}$ & $\begin{array}{l}\text { Regulations Restricting the Sale and Distribution of } \\
\text { Cigarettes and Smokeless Tobacco to Protect Children } \\
\text { and Adolescents (61 FR 44396) }\end{array}$ & $\$ 2.7 * *$ \\
\hline 1996 & $\begin{array}{l}\text { Federal Aviation } \\
\text { Administration }\end{array}$ & $\begin{array}{l}\text { Aircraft Flight Simulator Use in Pilot Training, } \\
\text { Testing, and Checking and at Training Centers ( } 61 \text { FR } \\
\text { 34508) }\end{array}$ & $\$ 3.0 * *$ \\
\hline 1996 & $\begin{array}{l}\text { Environmental } \\
\text { Protection Agency }\end{array}$ & $\begin{array}{l}\text { Requirements for Lead-Based Paint Activities in } \\
\text { Target Housing and Child-Occupied Facilities ( } 61 \text { FR } \\
\text { 45778) }\end{array}$ & $\$ 6.3$ \\
\hline 1996 & $\begin{array}{l}\text { Food and Drug } \\
\text { Administration }\end{array}$ & $\begin{array}{l}\text { Medical Devices; Current Good Manufacturing } \\
\text { Practice Final Rule; Quality System Regulation (61 FR } \\
\text { 52602) }\end{array}$ & $\$ 5.5 * *$ \\
\hline 1997 & $\begin{array}{l}\text { Environmental } \\
\text { Protection Agency }\end{array}$ & $\begin{array}{l}\text { National Ambient Air Quality Standards for Ozone ( } 62 \\
\text { FR 38856) }\end{array}$ & $\$ 6.3$ \\
\hline 1999 & $\begin{array}{l}\text { Environmental } \\
\text { Protection Agency }\end{array}$ & $\begin{array}{l}\text { Radon in Drinking Water Health Risk Reduction and } \\
\text { Cost Analysis (64 FR 9560) }\end{array}$ & $\$ 6.3$ \\
\hline 1999 & $\begin{array}{l}\text { Environmental } \\
\text { Protection Agency }\end{array}$ & $\begin{array}{l}\text { Control of Air Pollution from New Motor Vehicles: } \\
\text { Tier } 2 \text { Motor Vehicle Emissions Standards and } \\
\text { Gasoline Sulfur Control Requirements (65 FR 6698) }\end{array}$ & $\$ 3.9, \$ 6.3$ \\
\hline 2000 & $\begin{array}{l}\text { Consumer Product } \\
\text { Safety Commission }\end{array}$ & $\begin{array}{l}\text { Portable Bed Rails; Advance Notice of Proposed } \\
\text { Rulemaking ( } 65 \text { FR 58968) }\end{array}$ & $\$ 5.0 * *$ \\
\hline
\end{tabular}

* This table augments a similar presentation of values of a statistical life used in U.S. regulatory analyses in Adler and Posner (2000) by including more regulations and presenting VSLs in constant year dollars.

** The published summaries of the regulatory impact analyses for these rules do not specify the year in which the reported dollars are denominated. We have assumed that the dollar year corresponds to the date of rule publication for purposes of converting all values into 2000 dollars. Note that the CPSC reported a VSL of $\$ 5$ million in both its 1995 and 2000 regulations; the difference in values reflects our deflating to 2000 dollars. 
Table 13. Evaluation of Risk-Risk Tradeoff for 24 U.S. Regulations, 1986 - 1998

\begin{tabular}{|c|c|c|c|c|c|}
\hline Regulation & Year & Agency & $\begin{array}{c}\text { Discounted } \\
\text { Statistical Lives } \\
\text { Saved }\end{array}$ & $\begin{array}{c}\text { Fatalities } \\
\text { Induced by Cost } \\
\text { of Regulations }\end{array}$ & $\begin{array}{l}\text { Net Lives } \\
\text { Saved by } \\
\text { Regulations }\end{array}$ \\
\hline $\begin{array}{l}\text { Toxicity characteristics to determine } \\
\text { hazardous wastes }\end{array}$ & 1990 & EPA & 0.048 & -23 & 23 \\
\hline $\begin{array}{l}\text { Underground storage tanks: technical } \\
\text { requirements }\end{array}$ & 1988 & EPA & 1.1 & -22 & 24 \\
\hline $\begin{array}{l}\text { Manufactured home construction and } \\
\text { safety standards on wind standards }\end{array}$ & 1994 & HUD & 1.5 & -3.2 & 4.7 \\
\hline $\begin{array}{l}\text { Process safety management of highly } \\
\text { hazardous chemicals }\end{array}$ & 1992 & DOL & 220 & -42 & 260 \\
\hline $\begin{array}{l}\text { Regulations restricting the sale and } \\
\text { distribution of cigarettes and } \\
\text { smokeless tobacco to protect children } \\
\text { and adolescents }\end{array}$ & 1996 & HHS & 4,700 & -140 & 4,900 \\
\hline $\begin{array}{l}\text { Medicare and Medicaid programs: } \\
\text { hospital conditions of participation; } \\
\text { identification of potential organ, } \\
\text { tissue, and eye donors; and transplant } \\
\text { hospitals' provision of transplant- } \\
\text { related data }\end{array}$ & 1998 & HHS & 710 & 9.2 & 700 \\
\hline Quality mammography standards & 1997 & HHS & 75 & 1.4 & 74 \\
\hline Food labeling regulations & 1993 & HHS & 520 & 10 & 510 \\
\hline Childproof lighters & 1993 & CPSC & 95 & 2.9 & 92 \\
\hline $\begin{array}{l}\text { Standard for occupational exposure to } \\
\text { benzene }\end{array}$ & 1987 & DOL & 4.4 & 1.8 & 2.6 \\
\hline $\begin{array}{l}\text { Occupational exposure to methylene } \\
\text { chloride }\end{array}$ & 1997 & DOL & 12 & 5.9 & 6.2 \\
\hline $\begin{array}{l}\text { Occupational exposure to } 4,4^{\prime} \\
\text { methylenedianiline }\end{array}$ & 1992 & DOL & 0.7 & 0.71 & -0.01 \\
\hline $\begin{array}{l}\text { Asbestos: manufacture, importation, } \\
\text { processing, and distribution in } \\
\text { commerce -- prohibitions (total) }\end{array}$ & 1989 & EPA & 3.9 & 4.3 & -0.41 \\
\hline $\begin{array}{l}\text { National primary and secondary } \\
\text { water regulations -- phase II: } \\
\text { maximum contaminant levels for } 38 \\
\text { contaminants }\end{array}$ & 1991 & EPA & 44 & 63 & -19 \\
\hline Occupational exposure to asbestos & 1994 & DOL & 13 & 20 & -7.1 \\
\hline $\begin{array}{l}\text { Hazardous waste management system } \\
\text {-- wood preservatives }\end{array}$ & 1990 & EPA & 0.29 & 0.83 & -0.55 \\
\hline
\end{tabular}




\begin{tabular}{|c|c|c|c|c|c|}
\hline Regulation & Year & Agency & $\begin{array}{l}\text { Discounted } \\
\text { Statistical Lives } \\
\text { Saved }\end{array}$ & $\begin{array}{c}\text { Fatalities } \\
\text { Induced by Cost } \\
\text { of Regulations }\end{array}$ & $\begin{array}{l}\text { Net Lives } \\
\text { Saved by } \\
\text { Regulations }\end{array}$ \\
\hline $\begin{array}{l}\text { Sewage sludge use and disposal } \\
\text { regulations, } 40 \text { CFR pt. } 503\end{array}$ & 1993 & EPA & 0.24 & 2.6 & -2.3 \\
\hline $\begin{array}{l}\text { Land disposal restrictions for "third } \\
\text { third" scheduled wastes }\end{array}$ & 1990 & EPA & 2.8 & 30 & -27 \\
\hline $\begin{array}{l}\text { Hazardous waste management } \\
\text { system: final solvents and dioxins } \\
\text { land disposal restrictions rule }\end{array}$ & 1986 & EPA & 1 & 12 & -11 \\
\hline $\begin{array}{l}\text { Occupational exposure to } \\
\text { formaldehyde }\end{array}$ & 1987 & DOL & 0.21 & 4.8 & -4.5 \\
\hline $\begin{array}{l}\text { Prohibit the land disposal of the first } \\
\text { third of scheduled wastes ("second } \\
\text { sixth" proposal) }\end{array}$ & 1988 & EPA & 2.9 & 66 & -63 \\
\hline $\begin{array}{l}\text { Land disposal restrictions -- phase II: } \\
\text { universal treatment standards and } \\
\text { treatment standards for organic } \\
\text { toxicity, characteristic wastes, and } \\
\text { newly listed wastes }\end{array}$ & 1994 & EPA & 0.16 & 8.3 & -8.2 \\
\hline $\begin{array}{l}\text { Drinking water regulations, synthetic } \\
\text { organic chemicals -- phase V }\end{array}$ & 1992 & EPA & 0.0061 & 3.4 & -3.4 \\
\hline $\begin{array}{l}\text { Solid waste disposal facility criteria, } \\
40 \text { CFR pt. } 257 \text { and pt. } 258\end{array}$ & 1991 & EPA & 0.0049 & 10 & -10 \\
\hline
\end{tabular}

Source: Hahn, Lutter, and Viscusi (2000). 


\section{Appendix}

Table A. Description of Variables Used in Viscusi-Aldy Meta-Analyses

\begin{tabular}{|c|c|c|}
\hline Variable & Description & $\begin{array}{l}\text { Summary Statistic, } \\
\text { Viscusi-Aldy data }\end{array}$ \\
\hline VSL & Value of a statistical life (millions, 2000 US\$) & $\$ 6.7(\$ 5.6)$ \\
\hline Income & Annual labor income (2000 US\$) & $\$ 26,006(\$ 12,002)$ \\
\hline Mean Risk & Average mortality risk of sample & $0.0002(0.0003)$ \\
\hline Hourly Wage & $\begin{array}{l}\text { Hourly wage or hourly equivalent of weekly income ( } 2000 \\
\text { US\$) }\end{array}$ & $\$ 13.00(\$ 6.00)$ \\
\hline Union VSL & VSL for union members only (dummy variable) & $4 / 49$ \\
\hline Dillingham Risk & $\begin{array}{l}\text { VSL based on Dillingham (1985) constructed New York } \\
\text { workers compensation-based fatality risk measure (d.v.) }\end{array}$ & $1 / 49$ \\
\hline $\begin{array}{l}\text { Society of Actuaries } \\
\text { Risk }\end{array}$ & $\begin{array}{l}\text { VSL based on Society of Actuaries } 1967 \text { mortality risk data } \\
\text { (d.v.) }\end{array}$ & $2 / 49$ \\
\hline BLS Risk & VSL based on BLS mortality risk measure (d.v.) & $16 / 49$ \\
\hline NIOSH Risk & VSL based on NIOSH mortality risk measure (d.v.) & $5 / 49$ \\
\hline Subjective & VSL based on self-reported measure of mortality risk (d.v.) & $1 / 49$ \\
\hline Education Level & $\begin{array}{l}\text { Barro-Lee average educational attainment for population }> \\
25 \text { by country (in years) }\end{array}$ & $9.6(2.0)$ \\
\hline Unemployment Rate & Annual unemployment rate by year of wage data & $7.6(4.6)$ \\
\hline U.S. National Data & VSL based on national U.S. worker sample (d.v.) & $24 / 49$ \\
\hline Non-U.S. Study & VSL based on non-US wage-risk study (d.v.) & $22 / 49$ \\
\hline Male Only Sample & VSL based on male only sample (d.v.) & $21 / 49$ \\
\hline Blue Collar Sample & VSL based on blue collar only sample (d.v.) & $15 / 49$ \\
\hline Quadratic Risk & $\begin{array}{l}\text { VSL based on econometric specification quadratic in } \\
\text { mortality risk (d.v.) }\end{array}$ & $7 / 49$ \\
\hline $\begin{array}{l}\text { Morbidity Variable } \\
\text { Included }\end{array}$ & $\begin{array}{l}\text { VSL based on study that included an injury risk measure } \\
\text { (d.v.) }\end{array}$ & $25 / 49$ \\
\hline $\begin{array}{l}\log (\text { Dependent } \\
\text { Variable })\end{array}$ & $\begin{array}{l}\text { VSL derived from specification with natural logarithm of } \\
\text { dependent variable (d.v.) }\end{array}$ & $44 / 49$ \\
\hline Union D.V. & $\begin{array}{l}\text { VSL based on specification that included dummy variable } \\
\text { for union affiliation (d.v.) }\end{array}$ & $32 / 49$ \\
\hline Regional D.V. & $\begin{array}{l}\text { VSL based on specification with regional dummy variables } \\
\text { (d.v.) }\end{array}$ & $24 / 49$ \\
\hline Urban D.V. & $\begin{array}{l}\text { VSL based on specification with urban/MSA dummy } \\
\text { variable (d.v.) }\end{array}$ & $13 / 49$ \\
\hline $\begin{array}{l}\text { Workers' } \\
\text { Compensation }\end{array}$ & $\begin{array}{l}\text { VSL based on specification with workers' compensation } \\
\text { variable (d.v.) }\end{array}$ & $11 / 49$ \\
\hline $\begin{array}{l}\text { Wage in After Tax } \\
\text { Terms }\end{array}$ & $\begin{array}{l}\text { VSL based on specification with income expressed in after- } \\
\text { tax terms (d.v.) }\end{array}$ & $10 / 49$ \\
\hline Industry D.V. & $\begin{array}{l}\text { VSL based on specification with industry dummy variables } \\
\text { (d.v.) }\end{array}$ & $21 / 49$ \\
\hline Occupation D.V. & $\begin{array}{l}\text { VSL based on specification with occupational dummy } \\
\text { variables (d.v.) }\end{array}$ & $20 / 49$ \\
\hline No Occupation D.V. & $\begin{array}{l}\text { Study does not include occupational dummy variables } \\
\text { (dummy variable) }\end{array}$ & $29 / 49$ \\
\hline
\end{tabular}




\begin{tabular}{lcc}
\hline \multicolumn{1}{c}{ Variable } & Description & $\begin{array}{c}\text { Summary Statistic, } \\
\text { Viscusi-Aldy data }\end{array}$ \\
\hline Job Characteristics & $\begin{array}{l}\text { VSL based on specification with variables describing job } \\
\text { D.V. }\end{array}$ & $10 / 49$ \\
\hline $\begin{array}{l}\text { Means (standard deviations) reported for continuous variables. } \\
\text { Share of studies in which variable equals 1 reported for dummy variables. } \\
n=49\end{array}$ &
\end{tabular}




\section{Notes}

${ }^{1}$ Past reviews of this literature include Smith (1979), Miller (1990), and Viscusi (1992, 1993, 2000). Several researchers have conducted meta-analyses of this literature, including Liu, Hammitt, and Liu (1997), Miller (2000), Bowland and Beghin (2001), and Mrozek and Taylor (2002). See Hammitt (2002) and Krupnick (2002) for commentaries on the Mrozek and Taylor paper.

${ }^{2}$ For more extensive discussion of hedonic analysis, see Griliches (1971), Rosen (1974, 1986), Thaler and Rosen (1975), Smith (1979), and Viscusi (1979).

${ }^{3}$ For a discussion of irrational behavior in the presence of mortality risk inconsistent with expected utility theory, refer to Viscusi 1998.

${ }^{4}$ Individual risk neutrality or risk aversion, i.e., $\mathrm{U}^{\prime \prime}, \mathrm{V} " \leq 0$ is required to ensure a global maximum.

${ }^{5}$ Gaba and Viscusi (1998) compared qualitative and quantitative subjective measures of on-the-job accident risk. They find that for a given level of quantitative risk, a college-educated individual is more likely to report that risk as "dangerous" than an individual with less than college education. For example, for those workers who report their quantitative risk as comparable to an annual injury risk of less than 1 in 20 , half of the college-educated described their job risk as "dangerous" while only 19 percent of the lessthan-college educated reported their job risk as such. This differences in the "danger" cutoff biases estimates of risk premiums in wages, and this bias has implications distinct from typical measurement error. Gaba and Viscusi find that subjective quantitative measures of risk yielded wage premiums more consistent with estimates based on objective risk measures (BLS). Analysis of the qualitative risk measure (a dichotomous 0-1 "is the job dangerous?" variable) produced a much larger risk premium.

${ }^{6}$ Averaging over a period of 5 to 10 years would likely remove any potential distortions associated with catastrophic accidents in any particular year.

${ }^{7}$ Viscusi $(1979,1980)$ includes the danger variable in some regressions, although his research focused on compensating differentials based on BLS measures of injury and fatality risk discussed below.

${ }^{8}$ Leigh's (1991) analysis with risk data derived from workers' compensation records in 11 states appears to be the only U.S. study to aggregate such data from more than one state.

${ }^{9}$ Averaging fatality risk data over several years can reduce the distortion of a catastrophic event in one year in one industry on the measure of an industry's risk.

${ }^{10}$ Most hedonic wage-risk studies have not accounted for labor taxes in their construction of the wage variable or in their interpretation of the value of a statistical life. Exceptions include several papers that have focused on the effects of workers' compensation on the compensating differential for occupational risk (e.g., Moore and Viscusi 1990a). This reflects the more common use of pre-tax wages in the broader labor market analysis literature.

${ }^{11}$ In the product market context, Atkinson and Halvorsen (1990), Dreyfus and Viscusi (1995), and Gayer, Hamilton, and Viscusi (2000) employ Box-Cox transformations to evaluate their respective hedonic price models (the first two focused on automobile prices and the third on housing prices).

${ }^{12}$ Viscusi (1978a) excluded the dummy variables out of concern of inducing multicollinearity between an industry-level risk measure and industry dummy variables. Refer to the discussion below on

multicollinearity.

${ }^{13}$ We focus our discussion here on their NIOSH data-based results for several reasons. First, we believe that the NIOSH data are superior to the 1980s BLS fatality risk data as discussed above. Second, the regression models based on non-NIOSH data in Dorman and Hagstrom have insignificant risk coefficients for all specifications - without industry dummy variables, with industry dummy variables, and with other industry characteristics. While we are not certain why they did not find significant risk coefficients with the BLS risk data as previous researchers had, it seems moot to argue that a coefficient on a risk variable actually represents an industry effect if that coefficient is not significant.

${ }^{14} \mathrm{We}$ selected papers for inclusion in this literature review with a modest set of criteria. First, a study should be written in English. Second, a study should be published in either an academic journal or a book. Third, a study should provide enough information to calculate a value of a statistical life. In several cases, information provided in more recent papers (such as per capita incomes reported for some studies in Viscusi 1993 and Mrozek and Taylor 2002) has been used with reported coefficient estimates to calculate the value of a statistical life for a study. Our aim is to characterize as best as possible the universe of wagerisk studies in the literature, so we have not attempted to purge this assessment of so-called "low quality" studies or to modify the value of a statistical life estimates from such studies. For some studies, we have 
presented a range of the value of a statistical life estimates and for others we have presented an illustrative point estimate. In the case of the latter, we have focused on the reported results for the whole sample (as opposed to union-only, blue-collar only, managerial-only, etc. samples) based on the econometric specification preferred by the studies' authors.

${ }^{15}$ While these estimates have been adjusted to constant year dollars (2000 US\$), they have not been adjusted for differences in the samples' income levels. The per capita income data provided in Table 2 coupled with income elasticity estimates in Section 6 can be used to modify the values of a statistical life in Table 2 so that they reflect a common income level.

${ }^{16}$ In this paper, we present all VSLs in terms of 2000 US\$. All domestic values are converted using the CPI-U deflator series (Council of Economic Advisers 2002 Table B60). International conversions are made using purchasing power parity exchange rates from the Penn World Table 6.0 (see Summers and Heston 1991, Aten et al. 2001, and Internet: http://pwt.econ.upenn.edu) and then converted to year 2000 dollars with the CPI-U deflator series.

${ }^{17}$ Viscusi (1993) actually reports $\$ 3-\$ 7$ million in December 1990 US\$. This has served as a reference range in several subsequent value of a statistical life studies. Note that we have updated this range to 2000 US\$.

${ }^{18}$ Also refer to Fishback and Kantor (1992) for a historical evaluation of compensating differentials for occupational risk in the late 19th century.

${ }^{19}$ Smith (1983) also used the Hickey and Kearney carcinogen exposure index to complement his assessment of compensating differentials for injury risk in U.S. labor markets. He found that the index is significantly positively correlated with wages implying a risk premium for workers' operating in environments exposing them to more carcinogens. Further, Smith included a measure of total suspended particulates (TSP) based on the workers' locations and found a statistically significant and positive correlation between TSP and workers' wages. Since TSP has been linked with various respiratory diseases, this could illustrate another premium for workers' bearing long-term risks on the job.

${ }^{20}$ The values we report reflect an assumed latency period of 10 years and a real discount rate of 3 percent. Note that the VSL estimates in parentheses in Table 2 represent the values reported by Lott and Manning. Employing a real discount rate of 7 percent, consistent with U.S. Office of Management and Budget (1992) guidance, over a 10-year period effectively reduces the VSL reported by Lott and Manning in half.

${ }^{21}$ Meng (1991) attempted to account for occupational disease by including a variable that reflected the rate of heart attacks and industrial disease. However, very modest information about the basis for this variable is provided. It is difficult to discern whether the variable captures long-term work-related risks or simply a selection effect that contaminates the data like the Society of Actuaries data set.

${ }^{22}$ The authors also report estimates using the less reliable pre-1992 BLS risk data.

${ }^{23}$ Siebert and Wei (1998) found a concave wage-risk relationship with a risk and risk-squared specification for their analysis of the Hong Kong labor market. Meng and Smith $(1990,1999)$ also found the same relationship in their assessments of the Canadian labor market.

${ }^{24}$ All these studies evaluate risk-income tradeoffs in the United States. In our survey of the literature, we found only one study focusing on behavior outside of the United States. Ghosh, Lees, and Seal (1975) study the tradeoff between highway speeds and mortality risk in the United Kingdom. They derive a value of a statistical life estimate of $\$ 0.9$ million.

${ }^{25}$ We have discounted the reported VSLs assuming that homeowners perceive a 10 -year latency period and use a 3 percent discount rate in making their housing decisions.

${ }^{26}$ The difference between the mean subjective mortality risk and the objective mortality risk reported by the Taiwan Labor Insurance Agency is statistically significant at the 1 percent level.

${ }^{27}$ Studies for which we do not have an income measure were omitted.

${ }^{28} \mathrm{We}$ also estimated a regression with the Mrozek and Taylor set of control variables, with an important exception of replacing the hourly earnings variable with the natural logarithm of annual income. With an OLS specification, we estimated an income elasticity of 0.76 with a 95 percent confidence interval of 0.20 $-1.32(\mathrm{n}=41)$. In the robust regression with Huber weights specification, we estimated again a point estimate for the income elasticity of 0.76 , but with a much tighter 95 percent confidence interval of 0.73 $0.79(\mathrm{n}=38)$. The income variable was statistically significant at the 5 percent level in the OLS regression and significant at the 1 percent level in the robust regression. The iterative weighting process in robust regression with this much larger set of control variables effectively eliminated several low-VSL studies relative to specification 6 in Table 8, which may have resulted in the larger elasticity. 
${ }^{29}$ The Science Advisory Board (2000) has supported EPA's adjustment of the VSL for income growth.

${ }^{30} \mathrm{We}$ also calculated the median predicted VSL values for the full and U.S. samples. For the full sample, the median predicted VSL never exceeded the mean predicted VSL in any of the six regression models by more than 14 percent, and the mean predicted VSL never exceeded the median predicted VSL by more than 15 percent. For the U.S. sample, the median predicted VSL exceeded the mean predicted VSL in all six regressions, but never by more than 7 percent.

${ }^{31}$ For example, Dorsey (1983) estimated a statistically significant negative coefficient on the fatality risk variable and a statistically significant positive coefficient on the union $\mathrm{x}$ risk interaction variable. This combination (with the union $\mathrm{x}$ risk coefficient greater in magnitude than the fatality risk coefficient) results in a positive compensating differential for union workers and a negative differential for non-union workers. ${ }^{32}$ Rosen's research yields results similar to the Jones-Lee (1976), Jones-Lee et al. (1985), and Shepard and Zeckhauser $(1982,1984)$ finding that the value of a statistical life takes an inverted-U shape with respect to age. Also refer to Garber and Phelps (1997) for an assessment of quality-adjusted life-years (QALYs) in the cost-effectiveness literature. Jenkins et al. (2001) provide some evidence that the value of a statistical life is increasing over childhood through the pre-retirement years.

${ }^{33}$ Modifying utility functions in this way would be analogous to constructing QALY measures, common to valuations based on health status in the health economics literature. The QALYs are usually based on stated preference methods (see Cutler and Richardson 1997).

${ }^{34}$ Based on Rosen's life cycle model, one would expect that the marginal value of another year is greater for an elderly person than for a middle-aged person but that the value of all future years declines with age for a given individual. Accounting for health status may counter the effect of increasing marginal values for a one-year life extension for an elderly person. If health status is decreasing in age, then it may be ambiguous whether the marginal value of another year increases with age.

${ }^{35}$ For example, refer to the guidance to improve regulatory decision-making provided by the OECD (1995) to its member countries.

${ }^{36}$ For a review of the substance of this analysis, see Viscusi (1992a).

${ }^{37}$ Refer to Table E-1 at Internet: http://www.api.faa.gov/economic/EXECSUMM.PDF and http://www.api.faa.gov/economic/742SECT2.PDF.

${ }^{38}$ The low VSL used by the agency also reflects a political dimension as well. In the early 1990s when Viscusi prepared the report that was subsequently published as Viscusi (1993) for the Federal Aviation Administration, that branch of the agency favored a higher value of life than was later mandated for use throughout the department.

${ }^{39}$ Note that the Science Advisory Board to the U.S. Environmental Protection Agency considered the effects of latency and dread within the context of cancer-related mortality. The SAB (2000) concluded that the literature does not currently support a modification of the value of a statistical life to reflect dread. In contrast, the SAB did recommend that economic analyses account for latency by discounting future mortality to the present time consistent with the approach to other categories of benefits and costs.

${ }^{40}$ The conversion to U.S. dollars for the Hara Associates analysis was based on the annual market exchange rate reported by the Federal Reserve (refer to Internet:

http://www.federalreserve.gov/releases/g5a/current/) because the Penn World Table does not provide conversions for the most recent years.

${ }^{41}$ While Revesz suggests other adjustments to the value of a statistical life based on the qualitative characteristics of the risk, such as involuntariness of the risk, the Science Advisory Board (2000) noted that the existing literature does not justify adjustments for these effects.

${ }^{42}$ See Magat, Viscusi, and Huber (1996).

${ }^{43}$ This discussion implicitly acknowledges an important aspect of most occupational, safety, and environmental health risks: these risks are relatively small. In cases of certain, or near-certain death, the empirical economic evidence and this argument are not relevant (see our discussion in Section 1).

${ }^{44}$ For example, the 1997 final rule for the national ambient air quality standard for ozone introduced the section on the regulatory impact analysis with the following: "As discussed in Unit IV of this preamble, the Clean Air Act and judicial decisions make clear that the economic and technological feasibility of attaining ambient standards are not to be considered in setting NAAQS, although such factors may be considered in the development of State plans to implement the standards. Accordingly, although, as described below, a Regulatory Impact Analysis (RIA) has been prepared, neither the RIA nor the associated contractor reports have been considered in issuing this final rule" (62 FR 38856). 
${ }^{45}$ This relationship is also revealed within a cross-section of the U.S. population. Viscusi (1978b) found that work-related risk exposure decreases with worker wealth.

${ }^{46}$ Portney and Stavins (1994) question whether the income losses from regulations would reduce the population's health status. They claim that the nonlinear relationship between income and health and the modest impact of most regulations on the economy would not likely have a significant effect on health status. While individual regulations may involve small costs as a share of the economy, it is important to note that environmental regulations alone cost about $1-2$ percent of U.S. economic output (U.S. OMB 2001).

${ }^{47}$ We have updated the reported values in Keeney (1990) to 2000 U.S. dollars using the CPI-U deflator. ${ }^{48}$ The Keeney estimates are near the high end of 11 studies cited in Lutter and Morrall (1994) on the income gains necessary to avert one fatality. They are very similar to Lutter and Morrall's estimated range of $\$ 11.4$ million to $\$ 15.2$ million for the United States.

${ }^{49}$ Refer to UAW v. OSHA, United States Court of Appeals for the District of Columbia Circuit, 89-1559.

${ }^{50}$ A recent paper by Gerdtham and Johannesson (2002) attempts to address this problem by controlling for initial health status in regressions of mortality risk on income (with other relevant controls) for a study focusing on Sweden in the 1980s and 1990s. They find that an income loss ranging from $\$ 7.5-\$ 10.8$ million would induce an expected fatality in Sweden. The range reflects variation in the progressivity of the burden of the regulation.

${ }^{51}$ Viscusi (1994a, 1994b) selected a VSL estimate of \$5 million (in 1992 US\$) because it represented the midpoint of the basic range for VSLs of \$3 million - \$7 million in Viscusi 1993. In 2000 US\$, the midpoint would be $\$ 6.1$ million.

${ }^{52}$ Refer to Morrall (1986) and Tengs et al. (1995) for lists of regulations' cost-effectiveness for the United States. Tengs et al. found that for 124 environmental regulations (primarily toxin control), the median cost per life-year saved is $\$ 3.3$ million. About 15 percent of the environmental regulations exceeded $\$ 100$ million per life-year saved. Converting these life-year values to statistical life values would result in a significant number of regulations with incredibly exorbitant cost-effectiveness measures. Life-saving regulations in other sectors of the economy (e.g., health care, transportation) had much lower costs per lifeyear saved. Refer to Ramsberg and Sjoberg (1997) for an evaluation of the cost-effectiveness of lifesaving interventions in Sweden.

${ }^{53}$ Hahn, Lutter, and Viscusi only considered regulations with reduced mortality risk benefits comprising at least 90 percent of total monetized benefits.

${ }^{54}$ Note that the construction of discounted statistical lives saved reflects both an accounting for life-years saved and discounting for latency. 